\title{
Management of midtrimester prelabour rupture of membranes
}

Citation for published version (APA):

van Teeffelen, A. S. P. (2014). Management of midtrimester prelabour rupture of membranes. [Doctoral Thesis, Maastricht University]. Maastricht University. https://doi.org/10.26481/dis.20140327at

Document status and date:

Published: 01/01/2014

DOI:

10.26481/dis.20140327at

Document Version:

Publisher's PDF, also known as Version of record

\section{Please check the document version of this publication:}

- A submitted manuscript is the version of the article upon submission and before peer-review. There can be important differences between the submitted version and the official published version of record.

People interested in the research are advised to contact the author for the final version of the publication, or visit the DOI to the publisher's website.

- The final author version and the galley proof are versions of the publication after peer review.

- The final published version features the final layout of the paper including the volume, issue and page numbers.

Link to publication

\footnotetext{
General rights rights.

- You may freely distribute the URL identifying the publication in the public portal. please follow below link for the End User Agreement:

www.umlib.nl/taverne-license

Take down policy

If you believe that this document breaches copyright please contact us at:

repository@maastrichtuniversity.nl

providing details and we will investigate your claim.
}

Copyright and moral rights for the publications made accessible in the public portal are retained by the authors and/or other copyright owners and it is a condition of accessing publications that users recognise and abide by the legal requirements associated with these

- Users may download and print one copy of any publication from the public portal for the purpose of private study or research.

- You may not further distribute the material or use it for any profit-making activity or commercial gain

If the publication is distributed under the terms of Article $25 \mathrm{fa}$ of the Dutch Copyright Act, indicated by the "Taverne" license above, 
Management of midtrimester prelabour rupture of membranes 
(C) Copyright Augustinus S.P. van Teeffelen, Maastricht 2014

ISBN 9789461593221

Cover design: www.gertvriend.nl Layout: Tiny Wouters 


\title{
Management of midtrimester
}

\author{
prelabour rupture
}

\author{
of membranes
}

ter verkrijging van de graad van doctor

aan de Universiteit Maastricht, op gezag van de Rector Magnificus,

Prof.dr. L.L.G. Soete,

volgens het besluit van het College van Decanen,

in het openbaar te verdedigen

op donderdag 27 maart 2014 om 12:00 uur

door

Augustinus S.P. van Teeffelen

Geboren 5 april 1973 te Utrecht

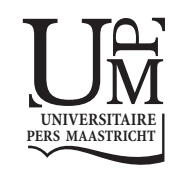




\section{Promotores}

Prof. Dr. J.G. Nijhuis

Prof. Dr. B.W.J. Mol, University of Adelaide, Australia

Co promotores

Dr. C. Willekes

Dr. E. Pajkrt, AMC Amsterdam

\section{Beoordelingscommissie}

Prof. A. zur Hausen (voorzitter)

Prof. dr. B. Kramer

Dr. A.M.L. Oude Lashof

Prof. dr. S.G. Oei, TU Eindhoven

Prof. dr. P.H.M. Savelkoul 


\section{Contents}

$\begin{array}{lll}\text { Chapter } 1 & \text { General introduction. } & 7\end{array}$

Chapter 2 The relation between duration of ruptured membranes and 21 perinatal outcome in patients with midtrimester preterm prelabor rupture of membranes.

Chapter 3 Prelabour rupture of membranes: overview of diagnostic methods.

Chapter 4 Is it useful to measure C-reactive protein and leukocytes in patients with prelabor rupture of membranes?

Chapter 5 The accuracy of clinical parameters in the prediction of perinatal pulmonary hypoplasia secondary to midtrimester prelabour rupture of fetal membranes: a meta-analysis.

Chapter 6 The accuracy of imaging parameters in the prediction of lethal pulmonary hypoplasia secondary to midtrimester prelabour rupture of fetal membranes: a systematic review.

Chapter 7 Transabdominal amnioinfusion for improving fetal outcomes after oligohydramnios secondary to preterm prelabour rupture of membranes before 26 weeks (Review).

Chapter 8 Midtrimester preterm prelabour rupture of membranes (PPROM). Expectant management or Amnioinfusion for improving perinatal outcomes (PPROMEXIL - III trial)

Chapter 9 Concluding remarks and future perspectives

Conclusies en toekomstperspectieven

Dankwoord

Curriculum vitae

List of publications 



\section{Chapter 1}

General introduction 
Chapter 1

8 


\section{Definitions and incidence}

Fetal membranes surround the fetus and the amniotic fluid to form the amniotic cavity. 'Rupture of the membranes' is the medical term for 'the breaking of a woman's water'. When this occurs before labour starts, this is called prelabour rupture of the membranes (PROM). PROM happening before a gestational age of 37 weeks is called preterm prelabour rupture of membranes (PPROM). PPROM is a common obstetrical problem, since it is associated with adverse outcome for both the mother and the fetus. PPROM occurs in approximately $3 \%$ of all pregnancies, with reported incidences of 1,5\%, $1 \%$ and 0,5\% for PPROM between 34 and 37 weeks, 26 and 34 weeks, and 16 and 26 weeks gestational age, respectively ${ }^{1}$. The interval between 16 and 26 weeks is often referred to as the 'midtrimester'. Another term frequently used is periviable PROM, this is defined by rupture of membranes before 24 weeks. It can be estimated that midtrimester PROM occurs around 900 times per year in The Netherlands based on a total of around 180.000 deliveries.

\section{Outcome after midtrimester PROM}

Midtrimester PROM is associated with high perinatal mortality and morbidity. A metaanalysis of six studies showed a survival rate of almost 50\% (122/275) in babies born after midtrimester PROM ${ }^{2}$. Unpublished data from a retrospective analysis by Van der Heijden et al. showed that in 164 singleton pregnancies with periviable PROM in three tertiary centres in The Netherlands, perinatal mortality was $71 \%$. Since not all pregnancies with previable PROM will be referred from second line hospitals, this might be an underestimation ${ }^{3}$. The main causes of adverse outcome are prematurity, pulmonary hypoplasia and infection.

\section{Prematurity}

Since midtrimester PROM occurs near the limit of viability, outcome is greatly determined by the consequences of extreme prematurity. Muris and Girard reported that $38 \%$ of women delivered within one week, and $69 \%$ delivered within 5 weeks after PROM before 25 weeks $^{4}$. Perinatal mortality rates per gestational age at delivery from the Dutch perinatal registry (PRN) between 2000 and 2006 in the Netherlands are shown in Figure $1.1^{5}$.

Preterm birth causes acute problems as IRDS (infant respiratory distress syndrome), intraventricular haemorraghe (IVH), necrotizing enterocolitis (NEC), sepsis, whilst bronchopulmonary dysplasia (BPD), cerebral palsy (CP) and other disabilities complicate long term outcome ${ }^{2,6}$. Long term data on outcome after very preterm birth in Europe have recently been reviewed by Milligan ${ }^{7}$. 


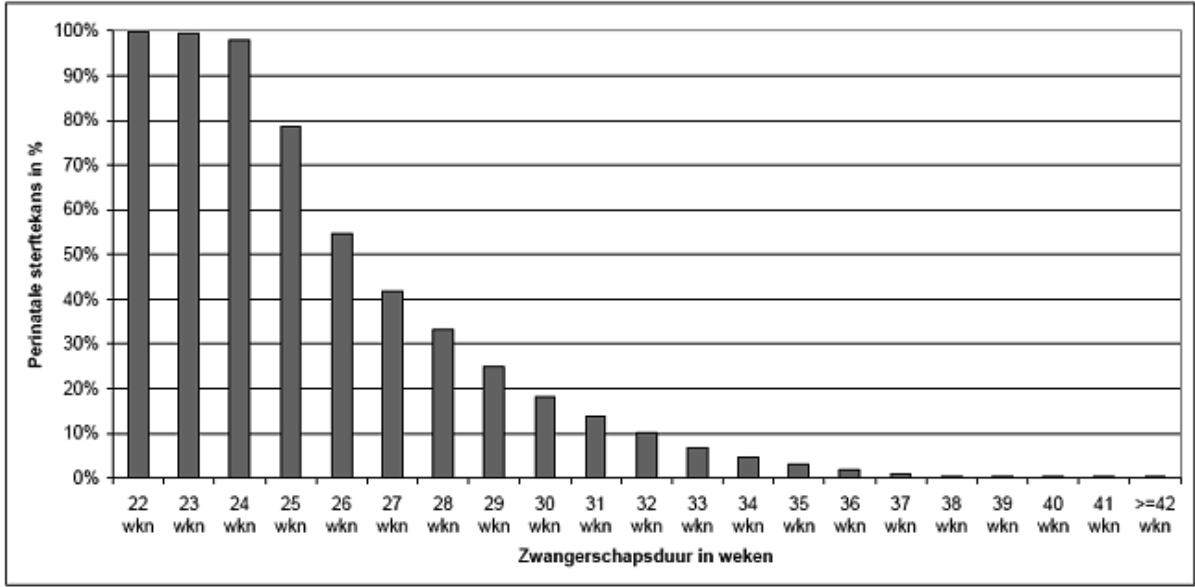

Figure 1.1 Perinatal mortality per gestational age at delivery. Dutch perinatal registry (PRN) between 2000 and 2006, $n=1257026$.

\section{Pulmonary hypoplasia}

Midtrimester PROM is associated with an increased risk of altered pulmonary development leading to pulmonary hypoplasia. Pulmonary hypoplasia is a term to describe pulmonary underdevelopment. It is characterised by an inadequate formation of the respiratory tree resulting in a reduced amount of functional lung tissue, with reduced capacity for gas exchange ${ }^{8}$.

It is thought that the formation of lung tissue is dependent on an adequate amount of amniotic fluid, especially during the interval between 16 and 26 weeks. A reduced amount of amniotic fluid (oligohydramnios) after PROM in this interval might cause pulmonary hypoplasia ${ }^{9}$.

Pulmonary hypoplasia can present as severe breathing problems resulting in early neonatal death or as milder and even transient breathing problems. It can be accompanied by bleeding in the lung. It can also result in chronic breathing problems due to scarring of lung tissue ${ }^{8}$.

In a review of 11 studies on midtrimester PROM, the reported incidence of pulmonary hypoplasia secondary to midtrimester PROM ranged widely from 1 to $48 \%{ }^{10}$. In another review the reported incidence also varied widely from 0 to $24 \%{ }^{9}$. Since IRDS, BPD and pneumonia can occur simultaneously, a clinical diagnosis without autopsy is difficult.

\section{Infection}

It is estimated that $40-70 \%$ of cases of preterm births with PROM or spontaneous labour are complicated by chorioamnionitis ${ }^{11}$. The association of infection with 
spontaneous preterm birth is stronger, the earlier preterm delivery occurs. Infection can be either the cause or the result of PPROM. It is becoming more and more clear that chorioamnionitis in fact is a major risk factor for preterm birth, rather than a consequence $^{12-14}$.

Ascending infection from the lower genital tract can cause a maternal and fetal inflammatory response with activation of matrix metallopproteinases (MMP's) and cytokines and apoptosis, after which PPROM can occur. Histological studies suggest that rupture occurs near the site of inflammation ${ }^{14}$.

Infection may manifest itself as a clinical chorioamnionitis (with or without labour and PPROM), once a maternal inflammatory response can be clinically noticed. Clinical chorioamnionitis is diagnosed by fever, uterine tenderness, maternal and or fetal tachycardia, and purulent or foul amniotic fluid. Maternal complications are endomtetritis, wound infection, pelvic abcess, sepsis and haemorrage. Severe maternal morbidity or even fatal outcome is rare ${ }^{11}$.

Only a minority of cases with chorioamnionitis will present with clinical symptoms. Subclinical infection is thought to influence neonatal outcome, however the exact magnitude of this influence remains unclear ${ }^{15}$.

Subclinical or clinical chorioamnionitis may initiate a fetal inflammatory respons (FIRS). In cases where chorioamnionitis is present, FIRS is thought to be an important determinant of severe adverse neonatal outcome ${ }^{16}$.

Presence of subclinical infection can be diagnosed by pathological examination of the placenta postnatally (histological chorioamnionitis), or by microbiological examination of placental tissue or amniotic fluid. FIRS can be diagnosed postnatally by biochemical test (cytokine response) or histologically by vasculitis in the chorion or umbilical cord (funisitus). Clinical usefulness is limited since it may take several days before the results of such examination become available. Furthermore, with current conventional culturing techniques intrauterine infection is difficult to detect ${ }^{17}$. It is important to note that there is only a limited overlap between histological, microbiological or biochemical and clinical chorioamnionitis ${ }^{18}$.

Thus a substantial part of midtrimester PROM is associated with subclinical infection, and FIRS can be subclinically present, causing long term morbidity.

\section{Factors associated with adverse outcome}

Oligohydramnios, gestational age at rupture, latency, gestational age at delivery are factors that have been studied to predict adverse outcome in cases amenable for expectant management.

Oligohydramnios in cases of PPROM is associated with increased mortality and morbidity. Perinatal mortality in a group of 178 prospectively followed pregnancies with PPROM between 20-25 weeks, and delivery after 26 weeks gestational age was 
$2,1 \%$ in cases with adequate amniotic fluid, versus $69 \%$ in cases with inadequate amniotic fluid. Oligohydramnios is associated with shorter intervals from gestational age at PPROM to delivery ${ }^{19}$. Pulmonary development is impaired by oligohydramnios, and risk of chorioamnionitis and contractures is increased ${ }^{20,21}$.

It has been observed that earlier gestational age at rupture increases risk of pulmonary hypoplasia ${ }^{22}$. Earlier gestational age at rupture is associated with increased risk of infection. Furthermore, obviously an earlier gestational age at rupture predisposes to a periviable delivery, with increased risks due to immaturity or prematurity.

Regarding latency, i.e. the time interval between PROM and the actual delivery, controversy exists. The effect of gestational age on latency is not clear, some authors observed that earlier gestational ages at ROM is followed by relatively shorter latencies $^{23}$, whereas others observe longer latencies after earlier gestational age at rupture $^{24,25}$. The key question regarding to latency is however, if, a longer stay in a possibly unfavourable environment is hazardous, and should be considered apart from the gestational age of delivery.

It has been observed that cases with shorter latencies are more frequently associated with chorioamnionitis. The highest frequency has been observed in the first week after rupture. This is not a surprise since subclinical infection is a known cause of preterm labour. For those fetuses that remain undelivered, the question is how the risk of chorioamnionitis will evolve with increasing length of latency.

A study that stratified for gestational age at delivery showed that longer latencies after PPROM between 28 and 34 weeks were associated with in increased risk for adverse outcome. Apparently the benefit of increased maturity outweighed the risks associated by prolonged latency ${ }^{26}$.

To date no such studies have been published for midtrimester PROM. However it can be hypothesized that the same principle applies, that is, an overall beneficial effect of longer latency.

Not surprisingly, gestational age at delivery is most predictive of favourable outcome in infants born at the threshold of viability for various indications ${ }^{27}$.

\section{Impact}

Pregnancies complicated by midtrimester PROM are associated with high immediate and long-term costs. These are caused by extended maternal hospital admissions, increased incidence of premature delivery, and frequent neonatal complications hereafter requiring NICU-admission. At the long term, disabilities in survivors can have a life-long impact.

For early preterm delivery (<32 weeks' gestation) occurring in only $1-2 \%$ of total births, it is estimated that it accounts for nearly $50 \%$ of all longterm neurological morbidity ${ }^{28}$. For midtrimester PROM, having a higher perinatal mortality, this might be different. 
Studies with long term follow up are scarce. In a study by Pristauz on neonatal outcome after 2 years, from a group of 71 fetuses that were expectantly managed after spontaneous PROM <25 weeks, 12 infants could be discharged alive. Of these 12,6 had normal neonatal outcome at 2 years ${ }^{29}$.

\section{Diagnosis of ROM}

In approximately $90 \%$ of cases the diagnosis of ROM can be based on a history of fluid loss, combined with ultrasound and or speculum examination. Digital examination is to be avoided, since it increases the risk of infection. Speculum examination allows for visualisation of fluid passing from the cervix and for examination of this fluid using a nitrazine test or a microscope to visualize ferning ${ }^{30}$. These tests together are called 'conventional testing'.

It has been claimed that this clinical approach has a significant false-negative rate of $12 \%{ }^{31}$. Furthermore, false positive tests are common, due to vaginal contamination with blood, urine, or semen ${ }^{32-35}$.

The inaccuracy of the conventional test and the intrusive nature of a speculum examination have prompted many investigators to develop new tests to diagnose rupture of membranes.

\section{Management of midtrimester PROM}

\section{General principles}

Midtrimester PROM is a worrisome clinical situation. Until the 1990's, termination of pregnancy was usually offered to patients, obstetricians fearing maternal infectious morbidity, and estimating the probability of favourable outcome as minimal. Since the 1990 's, expectant management of very early PROM became more acceptable, with the advantages brought by improvement of neonatal care, outweighing the maternal risks ${ }^{36}$.

Expectant management of PPROM can be considered in cases where complications (labour, chorioamnionitis or abruption) are not manifest. This management varies internationally, but usually consists of hospitalization at the border of viability and administration of intramuscular corticosteroids and antibiotics to prolong latency. When expectant management can be considered as an option, counselling should take place. Parents should be informed about the risks of extreme prematurity, and on the risks of a prolonged stay in utero. Surveillance during expectant management is aimed at preterm birth, (sequels of) infection, and pulmonary hypoplasia, being the main 
causes of perinatal mortality. Abruptio placentae, prolapse and or compression of the umbilical cord are other complications that can occur during expectant management.

\section{Current management and surveillance of PPROM}

\section{Corticosteroids, tocolytics and antibiotics}

Although corticosteroids in women at risk for preterm birth (including those with PPROM) have proven beneficial from 26 weeks gestational onwards, there is no evidence from randomised controlled trials that prove corticosteroids to be beneficial before 26 weeks. However, there also is no proven harm ${ }^{37}$. In a review by Waters and Mercer four non-randomised studies were found that reported on survival according to steroid exposure. Although subject to bias, a significant benefit seemed apparent ${ }^{2}$.

The American Congress of Obstetrics and Gynaecology recommends a single course of corticosteroids for PPROM, after 24 weeks $^{38}$. The long term effects of corticosteroids in cases with chorioamnionitis specifically remains to be elucidated ${ }^{39}$.

The use of profylactic tocolyics is controversial ${ }^{2}$. Regarding antibiotics the same applies. Extrapolation from short term benefit observed in randomized studies such as the Oracle study, has led to the recommendation to administer broad spectrum antibiotics from 24 weeks onwards. In the Oracle study approximately $10 \%$ of included women had PROM before 26 weeks, however there was no subgroup analysis ${ }^{40}$. The Dutch guideline as well as the guideline from the United Kingdom do not specify a lower border of gestational age at which corticosteroids and antibiotics are recommended ${ }^{1,41}$. For antibiotic treatment in case of a Group B positive culture, the same applies.

One RCT reported on weekly progesteron in cases of PPROM between 20 and 30 weeks and found no benefit ${ }^{42}$.

\section{Non-traditional therapies}

Several therapies have been evaluated with the goal of normalizing the fluid volume in the amniotic cavity. Sealing of the membrane defect to prevent further leaking was attempted by several investigators. However, series were small and control groups were absent ${ }^{2}$.

Another way to relieve oligohydramnios after PPROM is amnioinfusion, a more extensively studied strategy. Amnioninfusion might improve fetal outcome by preventing pulmonary hypoplasia, by preventing neurological complications, increasing time to delivery interval, and improving fetal biophysical profile through prevention of umbilical cord compression. It also might prevent fetal deformity ${ }^{43}$.

A recent meta-analysis concluded that there might be benefit in amnioinfusion for oligohydramnios secondary to early PPROM. However, this meta-analysis found only 2 RCT's and 1 quasi RCT as well as 4 observational studies. The 2 RCT's were on patients 
with PPROM after 24 weeks, the quasi randomised study was on midtrimester PPROM $^{44}$.

\section{Predicting preterm delivery}

Cervical length in PPROM is currently not used to direct management of PPROM. International guidelines vary. Berghella et. al. investigated if knowledge of cervical length improved management of PPROM but found no results ${ }^{45}$.

Recently, Cobo et. al. measured 24 inflammatory biomarkers in 60 women with PPROM between 22 and 34 weeks and found no predictive value for preterm delivery within 1 week $^{46}$. Similarly Mercer et al did not find useful predictive value of maternal plasma markers ${ }^{47}$.

\section{Prediction of chorioamnionitis}

As specified before, there is limited overlap of clinical, histological, and microbiological chorioamnionitis. Ultimately prediction of FIRS and or neonatal sepsis is of key importance for clinical management. Maternal complications of chorioamnionitis are not considered here.

During expectant management, inflammatory markers indicative of intra amniotic infection can give rise to systemic effects, or local effects. Clinical parameters as well as laboratory tests (blood, amniotic fluid, cervicovaginal secrtetions) are available instruments to investigate this.

Clinical parameters needed to establish the diagnosis of clinical chorioamnionitis used in clinical research are antepartum temperature at least $100.4^{\circ} \mathrm{F}$, in addition to two other signs (uterine tenderness, maternal or fetal tachycardia and foul/purulent amniotic fluid), although these criteria are not uniformely used ${ }^{11,47}$.

These individual parameters generally have low specificity, and limited sensitivity. When clinical signs are not conclusive or absent, and chorioamnionitis is suspected, for example in case of PPROM or preterm labour, serum and amniotic fluid can be tested.

Determination of white blood cell count (leucocytes) and C-reactive protein (CRP) is being used to assess evidence of infection. However, one might question this since an elevated CRP and or leucocytosis in case of PPROM is a non-specific finding in absence of other clinical signs.

\section{Prediction of pulmonary hypoplasia}

An assessment of the probability of pulmonary hypoplasia is important both for clinical decision making and counselling of patients. It has been attempted to predict pulmonary hypoplasia using clinical parameters - gestational age at PPROM, latency period and degree of oligohydramnios - as well as biometric parameters assessed by 
ultrasound (two- or three dimensional, Doppler) or MRI. If presence of lethal pulmonary hypoplasia seems very likely, expectant management may be reconsidered.

\section{Aims of this thesis}

This thesis deals with the following questions:

- What is the true prognosis of midtrimester PPROM, and what is the role of longer latency? (chapter 2).

- What is the value of several diagnostic tests used to diagnose PROM? (chapter 3).

- Does determination of C-reactive protein and leucoytes make sense in surveillance of expectant management during PPROM, in order to predict neonatal infectious disease? (chapter 4).

- What is the predictive value of clinical- and imaging parameters in women at risk of pulmonary hypoplasia after midtrimester PPROM? (chapters 5 and 6).

- Does serial transabdominal amnioinfusion improve outcome after midtrimester PPROM? (chapters 7 and 8). 


\section{References}

1. NVOG, Breken van de vliezen voor het begin van de baring.pdf>. NVOG richtlijn (Guideline of the Dutch society of obstetrics and gynaecology), 2002.

2. Waters TP, Mercer BM. The management of preterm premature rupture of the membranes near the limit of fetal viability. Am J Obstet Gynecol 2009;201:230-40.

3. van der Heyden JL, van der Ham DP, van Kuijk S, Notten KJ, Janssen T, Nijhuis JG, Willekes C, Porath M, van der Post JA, Halbertsma F, Mol BW, Pajkrt E. Outcome of pregnancies with preterm prelabor rupture of membranes before 27 weeks' gestation: a retrospective cohort study. Eur J Obstet Gynecol Reprod Biol 2013;170:125-30.

4. Muris C, Girard B, Creveuil C, Durin L, Herlicoviez M, Dreyfus M. Management of premature rupture of membranes before 25 weeks. Eur J Obstet Gynecol Reprod Biol 2007;131:163-8.

5. NVOG, Richtlijn dreigende vroeggeboorte (Guideline on imminent pretem delivery). NVOG richtlijn (Guideline of the Dutch society of obstetrics and gynaecology), 2011.

6. Schucker JL, Mercer BM. Midtrimester premature rupture of the membranes. Semin Perinatol 1996;20:389-400.

7. Milligan DW. Outcomes of children born very preterm in Europe. Arch Dis Child Fetal Neonatal Ed 2010;95:F234-40.

8. Sherer DM, Davis JM, Woods JR Jr. Pulmonary hypoplasia: a review. Obstet Gynecol Surv 1990;45:792803.

9. Kilbride HW, Thibeault DW. Neonatal complications of preterm premature rupture of membranes. Pathophysiology and management. Clin Perinatol 2001;28:761-85.

10. Grisaru-Granovsky S, Eitan R, Kaplan M, Samueloff A. Expectant management of midtrimester premature rupture of membranes: a plea for limits. J Perinatol 2003;23:235-9.

11. Tita AT, Andrews WW. Diagnosis and management of clinical chorioamnionitis. Clin Perinatol 2010;37: 339-54.

12. Goldenberg RL, Hauth JC, Andrews WW. Intrauterine infection and preterm delivery. N Engl J Med 2000;342:1500-7.

13. Lahra MM, Beeby PJ, Jeffery HE. Intrauterine inflammation, neonatal sepsis, and chronic lung disease: a 13-year hospital cohort study. Pediatrics 2009;123:1314-9.

14. Menon R, Fortunato SJ. Infection and the role of inflammation in preterm premature rupture of the membranes. Best Pract Res Clin Obstet Gynaecol 2007;21:467-78.

15. Thomas W, Speer CP. Chorioamnionitis: important risk factor or innocent bystander for neonatal outcome? Neonatology 2011;99:177-87.

16. Gantert M, Been JV, Gavilanes AW, Garnier Y, Zimmermann L, Kramer BW. Chorioamnionitis: a multiorgan disease of the fetus? J Perinatol 2010;30 Suppl:S21-30.

17. Goldenberg RL, Culhane JF, lams JD, Romero R. Epidemiology and causes of preterm birth. Lancet 2008;371:75-84.

18. Smulian JC, Shen-Schwarz S, Vintzileos AM, Lake MF, Ananth CV. Clinical chorioamnionitis and histologic placental inflammation. Obstet Gynecol 1999;94:1000-5.

19. Melamed N, Hadar E, Ben-Haroush A, Kaplan B, Yogev Y. Factors affecting the duration of the latency period in preterm premature rupture of membranes. J Matern Fetal Neonatal Med 2009;22:1051-6.

20. Williams O, Hutchings G, Hubinont C, Debauche C, Greenough A. Pulmonary effects of prolonged oligohydramnios following mid-trimester rupture of the membranes--antenatal and postnatal management. Neonatology 2012;101:83-90.

21. Hadi HA, Hodson CA, Strickland D. Premature rupture of the membranes between 20 and 25 weeks' gestation: role of amniotic fluid volume in perinatal outcome. Am J Obstet Gynecol 1994;170:1139-44.

22. Falk SJ, Campbell LJ, Lee-Parritz A, Cohen AP, Ecker J, Wilkins-Haug L, Lieberman E. Expectant management in spontaneous preterm premature rupture of membranes between 14 and 24 weeks' gestation. J Perinatol 2004;24:611-6.

23. Verma U, Goharkhay N, Beydoun S. Conservative management of preterm premature rupture of membranes between 18 and 23 weeks of gestation--maternal and neonatal outcome. Eur J Obstet Gynecol Reprod Biol 2006;128:119-24. 
24. Deutsch A, Deutsch E, Totten C, Downes K, Haubner L, Belogolovkin V. Maternal and neonatal outcomes based on the gestational age of midtrimester preterm premature rupture of membranes. J Matern Fetal Neonatal Med 2010;23:1429-34.

25. Aziz N, Cheng YW, Caughey AB. Factors and outcomes associated with longer latency in preterm premature rupture of membranes. J Matern Fetal Neonatal Med 2008;21:821-5.

26. Melamed N, Ben-Haroush A, Pardo J, Chen R, Hadar E, Hod M, Yogev Y. Expectant management of preterm premature rupture of membranes: is it all about gestational age? Am J Obstet Gynecol 2011;204:48 e1-8.

27. Manuck TA, Maclean CC, Silver RM, Varner MW. Preterm premature rupture of membranes: does the duration of latency influence perinatal outcomes? Am J Obstet Gynecol 2009;201:414 e1-6.

28. Goldenberg RL. The management of preterm labor. Obstet Gynecol 2002;100:1020-37.

29. Pristauz G, Bauer M, Maurer-Fellbaum U, Rotky-Fast C, Bader AA, Haas J, Lang U. Neonatal outcome and two-year follow-up after expectant management of second trimester rupture of membranes. Int J Gynaecol Obstet 2008;101:264-8.

30. Mercer BM. Preterm premature rupture of the membranes. Obstet Gynecol 2003;101:178-93.

31. Ladfors L, Mattsson LA, Eriksson M, Fall O. Is a speculum examination sufficient for excluding the diagnosis of ruptured fetal membranes? Acta Obstet Gynecol Scand 1997; 76:739-42.

32. Gorodeski IG, Haimovitz L, Bahari $\mathrm{CM}$. Reevaluation of the $\mathrm{pH}$, ferning and nile blue sulphate staining methods in pregnant women with premature rupture of the fetal membranes. J Perinat Med 1982;10: 286-92.

33. Friedman ML, McElin TW. Diagnosis of ruptured fetal membranes. Clinical study and review of the literature. Am J Obstet Gynecol 1969;104:544-50.

34. Erdemoglu E, Mungan T. Significance of detecting insulin-like growth factor binding protein-1 in cervicovaginal secretions: comparison with nitrazine test and amniotic fluid volume assessment. Acta Obstet Gynecol Scand 2004;83:622-6.

35. de Haan HH, Offermans PM, Smits F, Schouten HJ, Peeters LL. Value of the fern test to confirm or reject the diagnosis of ruptured membranes is modest in nonlaboring women presenting with nonspecific vaginal fluid loss. Am J Perinatol 1994;11:46-50.

36. Major CA, Kitzmiller JL. Perinatal survival with expectant management of midtrimester rupture of membranes. Am J Obstet Gynecol 1990;163:838-44.

37. Roberts D, Dalziel S. Antenatal corticosteroids for accelerating fetal lung maturation for women at risk of preterm birth. Cochrane Database Syst Rev 2006:CD004454.

38. ACOG, Practice bulletins no. 139: premature rupture of membranes. Obstet Gynecol 2013;122:918-30.

39. Been JV, Rours IG, Kornelisse RF, Lima Passos V, Kramer BW, Schneider TA, de Krijger RR, Zimmermann $\amalg$. Histologic chorioamnionitis, fetal involvement, and antenatal steroids: effects on neonatal outcome in preterm infants. Am J Obstet Gynecol 2009;201:587 e1-8.

40. Kenyon SL, Taylor DJ, Tarnow-Mordi W. Broad-spectrum antibiotics for preterm, prelabour rupture of fetal membranes: the ORACLE I randomised trial. Lancet 2001;357:979-988.

41. RCOG, Preterm Prelabour Rupture of Membranes. Green-top Guideline Royal College of Obstetricians and Gynaecologists, 2010. November2006 (MinoramendmentOctober2010)(No. 44).

42. Briery CM, Veillon EW, Klauser CK, Martin RW, Magann EF, Chauhan SP, Morrison JC. Women with preterm premature rupture of the membranes do not benefit from weekly progesterone. Am J Obstet Gynecol 2011;204:54 e1-5.

43. Gramellini D, Fieni S, Kaihura C, Piantelli G, Verrotti C. Antepartum amnioinfusion: a review. J Matern Fetal Neonatal Med 2003;14:291-6.

44. Porat S, Amsalem H, Shah PS, Murphy KE. Transabdominal amnioinfusion for preterm premature rupture of membranes: a systematic review and metaanalysis of randomized and observational studies. Am J Obstet Gynecol 2012;207:393 e1-11.

45. Berghella V, Baxter JK, Hendrix NW. Cervical assessment by ultrasound for preventing preterm delivery. Cochrane Database Syst Rev 2013;1:CD007235.

46. Cobo T, Kacerovsky M, Holst RM, Hougaard DM, Skogstrand K, Wennerholm UB, Hagberg H, Jacobsson B. Intra-amniotic inflammation predicts microbial invasion of the amniotic cavity but not spontaneous preterm delivery in preterm prelabor membrane rupture. Acta Obstet Gynecol Scand 2012;91:930-5. 
47. Mercer BM, Crouse DT, Goldenberg RL, Miodovnik M, Mapp DC, Meis PJ, Dombrowski MP; Eunice Kennedy Shriver National Institute of Child Health and Human Development Maternal-Fetal Medicine Units Network. The antibiotic treatment of PPROM study: systemic maternal and fetal markers and perinatal outcomes. Am J Obstet Gynecol 2012;206:145 e1-9. 



\section{Chapter}

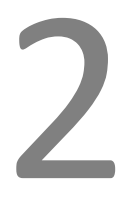

The relation between duration of ruptured

membranes and perinatal outcome in patients with midtrimester prelabour rupture of membranes

van Teeffelen ASP, van der Heyden JL, van der Ham DP, Schaaf JM, Ravelli A, Pajkrt E, Willekes C, Nijhuis JG, Mol BW

Submitted 


\section{Abstract}

\section{Objective}

To assess impact of gestational age at rupture and latency on perinatal outcome after midtrimester PROM.

\section{Study design}

We obtained data on singleton pregnancies from 22 weeks onwards from the Dutch Perinatal Registry from 1999 to 2007, congenital abnormalities were excluded. In women with PPROM before 26 weeks, we studied impact of gestational age at rupture and latency on perinatal mortality and severe morbidity.

\section{Results}

From 1,445,305 pregnancies, 1,233 suffered midtrimester PROM. Higher gestational age at delivery increased the probability of survival without morbidity, but the moment at which PPROM had occurred did not. For babies born between 24-26, 26-28, 28-30, 30-34 and after 34 weeks, perinatal mortality rates were $70 \%, 26 \%, 14 \%, 6 \%$ and $2 \%$, respectively. The perinatal mortality rate for babies born after PPROM between $16-18$ weeks was $26 \%$, for babies born after PPROM between 18-20, 20-22, 22-24 and $24-26$ this was respectively $29 \%, 52 \%, 66 \%$ and $33 \%$.

Morbidity free survival rates were $5 \%, 13 \%, 25 \%, 36 \%$ and $95 \%$ for babies born between $24-26$, 26-28, 28-30, 30-34 and after 34 weeks. For babies born after PPROM between 16-18, 18-20, $20-22,22-24$ and $24-26$ these rates were $68 \%, 60 \%, 31 \%, 21 \%$ and $27 \%$ respectively. Sepsis occurred in $45 \%$ of children born between 24 and 32 weeks, but occurred in $2 \%$ born after 34 weeks.

\section{Conclusion}

Midtrimester PROM is associated with increased mortality and morbidity, but longer latency and early gestational age at PPROM have limited impact in patients delivering after 22 weeks. 


\section{Introduction}

Midtrimester PPROM occurs in approximately 0,5 to $1 \%$ of all pregnancies and is associated with poor perinatal outcome ${ }^{1}$. If after midtrimester PPROM imminent delivery does not occur, discussion of the possible outcome is part of patient counselling. Based on the information provided, parents will have to decide between expectant management and, if they want to avoid the risk of perinatal morbidity and mortality, immediate delivery by means of termination of pregnancy. However, data that could be used in counselling are mainly from small heterogeneous studies and difficult to interpret.

A meta-analysis of six of those studies showed a survival rate of almost $50 \%(122 / 275)$ in babies born after midtrimester PPROM [2]. Among surviving infants, morbidity is high and includes (sequels of) premature delivery, pulmonary hypoplasia, infection, growth retardation and restriction deformities ${ }^{2,3}$. Gestational age at delivery has a profound effect on outcome if one considers the periviable period ${ }^{4}$, longer latency (i.e., the interval between rupture of membranes and delivery) thereby having a favourable effect .

Obviously, at the moment of counselling, latency is unknown. Reports on median latency after midtrimester PPROM vary, with contradictory relationships between the moment at which PPROM occurs, and latency ${ }^{5-7}$.

The relationship between latency after very early PPROM and outcome is complex. A longer latency after very early midtrimester PPROM theoretically decreases the risk associated with prematurity. However, it is also debated that longer latency carries a higher risk of pulmonary hypoplasia, a condition associated with high mortality, especially if oligohydramnios is also present ${ }^{8-10}$. Pulmonary hypoplasia has been described after a latency of only 6 days ${ }^{11}$. Furthermore, prolonged exposure to subclinical chorioamnionitis might worsen the outcome ${ }^{12}$.

Thus, counselling of patients with midtrimester PPROM remains challenging. The aim of this study was to provide data on perinatal outcome after midtrimester PPROM in patients who delivered after 22 weeks by extracting data from the Dutch Perinatal Registry (PRN). Furthermore we assessed the effect of latency and gestational age at PPROM on outcome by stratification of gestational age at delivery and gestational age at PPROM.

\section{Materials and methods}

We studied data collected by the PRN between 1999 and 2007. These data contain detailed population-based information, collected by prenatal caregivers, on pregnancies, deliveries, and (re)admissions until 28 days after delivery. Source data are available from three independent registries: the midwifery registry (LVR1), the obstetric 
registry (LVR2) and the neonatology/pediatric registry (LNR).The midwifery and obstetric registries start at the booking visit and contain complete perinatal data from $22^{+0}$ gestational weeks onwards. The neonatology registry contains only data on hospital admissions of newborns. These databases are then combined into one nationwide perinatal database via a validated linkage method ${ }^{13}$. The PRN registry covers $96 \%$ of all births in the Netherlands ${ }^{14}$.

We included all singleton pregnancies with a gestational age at delivery starting from $22^{+0}$ gestational weeks onwards. Women with pregnancies with congenital abnormalities $(2.4 \%)$ were excluded as well as women with a multiple pregnancy (3.9\%). We selected all cases with a rupture of membranes before $26^{+0}$ weeks, with a minimum latency of 24 hours. Rupture of membranes was diagnosed based on history and clinical findings such as gross vaginal fluid loss, in combination with other available diagnostic test methods when necessary. The final decision on whether a patient had rupture of membranes or not was made by the attending staff.

As outcome measurements we studied both perinatal mortality during the first 4 weeks after birth as well as severe neonatal morbidity. Perinatal mortality was defined as the number of fetal deaths (stillbirths) and neonatal deaths in the first four weeks of life per 1000 total births. Severe morbidity was defined as a composite of IVH (intraventricular haemorrhage), BPD (bronchopulmonary dysplasia) or IRDS (infant respiratory distress syndrome), neonatal sepsis or Apgar score after 5 minutes $<7$. A part of these composite morbidity outcome measurements were defined at the hospital admission of the child by the neonatologist, and occurred in the same admission after birth or during a re-admission within the first four weeks of life. Perinatal survival was defined as the absence of perinatal mortality. The PRN does not record long term neonatal outcome. First the baseline characteristics, as far as these were available from the PRN database, were described. Subgroup analysis: Since not all hospitals with neonatal care register in the LNR, we repeated the analysis limited to the hospitals who registered during at least 2 or more years during the study period.

\section{Results}

From a population of 1,445,305 pregnancies registered, from 1999 to 2007, 1,233 patients with singleton pregnancies complicated by midtrimester rupture of membranes, delivered after 22 weeks (Figure 2.1). 


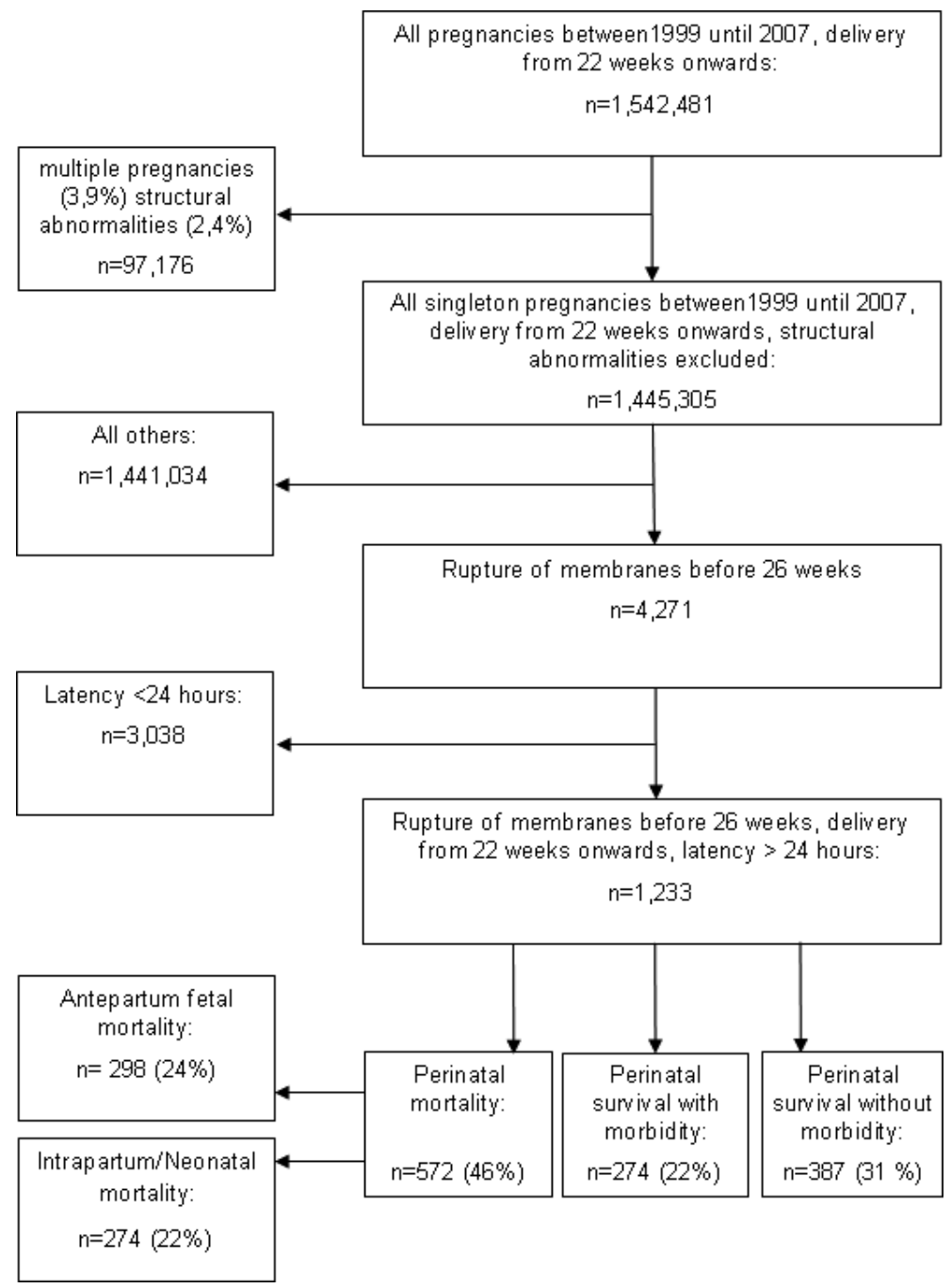

Figure 2.1 Patient enrollment.

Maternal demographics and characteristics are listed in Table 2.1. Factors possibly affecting outcome like ante partum bleeding, amniocentesis and history of preterm birth were non-obligatory variables in the PRN database, and were therefore not included in this table.

The overall perinatal mortality was 572 from $1233(46,4 \%)$. There were 298 cases of stillbirth $(24,2 \%)$, while 274 babies died intrapartum or postpartum $(22,2 \%)$. Perinatal 
survival with morbidity occurred in $274(22,2 \%)$ children, while 387/1233 (31,4\%) survived without severe morbidity (Figure 2.1).

Table 2.1 Maternal and fetal demographics and characteristics.

\begin{tabular}{lccc}
\hline & $\begin{array}{c}\text { Patients experiencing } \\
\text { perinatal death or } \\
\text { neonatal morbidity } \\
(\mathrm{n}=846)\end{array}$ & $\begin{array}{c}\text { Perinatal survival } \\
\text { without morbidity } \\
(\mathrm{n}=387)\end{array}$ & P value \\
\hline Maternal characteristics & 30.6 & 30.5 & 0.8 \\
Maternal Age (yrs) & $623(74 \%)$ & $292(75 \%)$ & 0.52 \\
Caucasian (n) & $373(44 \%)$ & $154(40 \%)$ & 0.17 \\
Nulliparous (n) & & & $<0.0001$ \\
Fetal characteristics & 805 & 2905 & 0.46 \\
Fetal Birthweight (grams) & 455 & 199 & \\
Fetal gender male $(\mathrm{n})$ & & & \\
\hline
\end{tabular}

One or more items of the composite morbidity were present in 759 of 1233 patients. In 485 of cases of mortality on or more items of morbidity were present. 278 suffered from sepsis, in 550 infants there was an apgar score after 5 minutes $<7.223$ suffered from IRDS, 106 from BPD, in 58 cases IVH was present.

More advanced gestational age at delivery increased the probability of survival, but a more advanced moment at which PPROM occurred did not.(Table 2.2). For babies born between 24-26, 26-28, 28-30,30-32 and 32-34 weeks the survival rates were $30 \%, 74 \%$, $86 \%, 93 \%$ and $95 \%$ respectively. Above 34 weeks, survival was above $98 \%$. For all babies delivered after 22 weeks, if PPROM occurred at $16-18$ weeks survival was $74 \%$, in the groups with PPROM at 18-20, 20-22, 22-24 and 24-26 weeks this was $71 \%, 48 \%$, $34 \%$ and $67 \%$, respectively.

Table 2.2 Patients surviving by gestational age of delivery and PROM.

\begin{tabular}{lcccccc}
\hline $\begin{array}{l}\text { GA at delivery } \\
\text { in weeks }\end{array}$ & $16^{+0}-17^{+6}$ & $18^{+0}-19^{+6}$ & $20^{+0}-21^{+6}$ & $22^{+0}-23^{+6}$ & $24^{+0}-25^{+6}$ & All \\
\hline $22^{+0}-23^{+6}$ & $0 \%(0 / 9)$ & $0 \%(0 / 18)$ & $1 \%(1 / 93)$ & $1 \%(2 / 194)$ & NA & $\mathbf{0 \% ( 3 / 3 1 4 )}$ \\
$24^{+0}-25^{+6}$ & $0 \%(0 / 4)$ & $25 \%(3 / 12)$ & $22 \%(2 / 9)$ & $17 \%(15 / 90)$ & $37 \%(63 / 166)$ & $\mathbf{3 0 \% ( 8 3 / 2 8 1 )}$ \\
$26^{+0}-27^{+6}$ & $0 \%(0 / 4)$ & $33 \%(1 / 3)$ & $80 \%(12 / 15)$ & $85 \%(18 / 20)$ & $74 \%(93 / 125)$ & $\mathbf{7 4 \% ( 1 2 3 / 1 6 7 )}$ \\
$28^{+0}-29^{+6}$ & $100 \%(2 / 2)$ & $66 \%(2 / 3)$ & $85 \%(11 / 13)$ & $93 \%(14 / 15)$ & $84 \%(27 / 32)$ & $\mathbf{8 6 \% ( 5 6 / 6 5 )}$ \\
$30^{+0}-31^{+6}$ & $100 \%(2 / 2)$ & $100 \%(4 / 4)$ & $89 \%(8 / 9)$ & $100 \%(10 / 10)$ & $88 \%(15 / 17)$ & $\mathbf{9 3 \% ( 3 9 / 4 2 )}$ \\
$32^{+0}-33^{+6}$ & $100 \%(3 / 3)$ & $80 \%(4 / 5)$ & $100 \%(12 / 12)$ & $83 \%(5 / 6)$ & $100 \%(18 / 18)$ & $\mathbf{9 5 \% ( 4 2 / 4 4 )}$ \\
$34^{+0}-35^{+6}$ & $100 \%(1 / 1)$ & NA (0/0) & $100 \%(5 / 5)$ & $100 \%(4 / 4)$ & $100 \%(16 / 16)$ & $\mathbf{1 0 0 \% ( 2 6 / 2 6 )}$ \\
$\geq 36^{+0}$ & $94 \%(50 / 53)$ & $98 \%(66 / 67)$ & $98 \%(46 / 47)$ & $100 \%(71 / 71)$ & $100 \%(56 / 56)$ & $\mathbf{9 8 \% ( 2 8 9 / 2 9 4 )}$ \\
All & $\mathbf{7 4 \% ( 5 8 / 7 8 )}$ & $\mathbf{7 1 \% ( 8 0 / 1 1 2 )}$ & $\mathbf{4 8 \% ( 9 7 / 2 0 3 )}$ & $\mathbf{3 4 \% ( 1 3 8 / 4 1 0 )}$ & $\mathbf{6 7 \% ( 2 8 8 / 4 3 0 )}$ & $\mathbf{5 4 \% ( 6 6 1 / 1 2 3 3 )}$ \\
\hline
\end{tabular}

GA: Gestational age. ROM: rupture of membranes. NA: not applicable.

Similarly, a more advanced gestational age at delivery increased the probability of survival without severe morbidity (Table 2.3). For babies born between 24-26, 26-28, $28-3030-32,32-34$ and after 34 weeks, the morbidity free survival rates were $5 \%, 13 \%$, 
$25 \%, 31 \%, 41 \%$ and $98 \%$, respectively. For all babies born after 22 weeks, morbidity free survival was $48 \%$ when PPROM had occurred at 16-18 weeks. In the groups with PPROM at $18-20,20-22,22-24$ and $24-26$ weeks this was $60 \%, 31 \%, 21 \%$ and $27 \%$, respectively. There was no sign that earlier gestational age at PPROM was related to adverse outcome. Morbidity free survival as a percentage of all survivors is shown as well. For the groups with PPROM at 16-20, 18-20, 20-22, 22-24 and 24-26 weeks this was $65 \%, 84 \%, 65 \%, 62 \%$ and $41 \%$ respectively. In all survivors $58 \%$ were without severe morbidity.

Table 2.3 Patients surviving without severe morbidity, as a percentage of all, and as a percentage of all survival

\begin{tabular}{|c|c|c|c|c|c|c|}
\hline GA at delivery & & & $\mathrm{GA}$ at $\mathrm{RC}$ & $M$ in weeks & & \\
\hline in weeks & $16^{+0}-17^{+6}$ & $18^{+0}-19^{+6}$ & $20^{+0}-21^{+6}$ & $22^{+0}-23^{+6}$ & $24^{+0}-25^{+6}$ & All \\
\hline $22^{+0}-23^{+6}$ & $0 \%(0 / 9)$ & $0 \%(0 / 18)$ & $0 \%(0 / 93)$ & $0 \%(0 / 194)$ & NA & $0 \%(0 / 314)$ \\
\hline $24^{+0}-25^{+6}$ & $0 \%(0 / 4)$ & $0 \%(0 / 12)$ & $0 \%(0 / 9)$ & $1 \%(1 / 90)$ & $7 \%(12 / 166)$ & $5 \%(13 / 281)$ \\
\hline $26^{+0}-27^{+6}$ & $0 \%(0 / 4)$ & $0 \%(0 / 3)$ & $20 \%(3 / 15)$ & $20 \%(4 / 20)$ & $12 \%(15 / 125)$ & $13 \%(22 / 167)$ \\
\hline $28^{+0}-29^{+6}$ & $100 \%(2 / 2)$ & $0 \%(0 / 3)$ & $15 \%(2 / 13)$ & $27 \%(4 / 15)$ & $25 \%(8 / 32)$ & $25 \%(16 / 65)$ \\
\hline $30^{+0}-31^{+6}$ & $50 \%(1 / 2)$ & $25 \%(1 / 4)$ & $44 \%(4 / 9)$ & $30 \%(3 / 10)$ & $24 \%(4 / 17)$ & $31 \%(13 / 42)$ \\
\hline $32^{+0}-33^{+6}$ & $0 \%(0 / 3)$ & $20 \%(1 / 5)$ & $42 \%(5 / 12)$ & $17 \%(1 / 6)$ & $61 \%(11 / 18)$ & $41 \%(18 / 44)$ \\
\hline $34^{+0}-35^{+6}$ & $100 \%(1 / 1)$ & $N A(0 / 0)$ & $80 \%(4 / 5)$ & $75 \%(3 / 4)$ & $75 \%(12 / 16)$ & $77 \%(20 / 26)$ \\
\hline$\geq 36^{+0}$ & $92 \%(49 / 53)$ & $97 \%(65 / 67)$ & $96 \%(45 / 47)$ & $99 \%(70 / 71)$ & $100 \%(56 / 56)$ & $97 \%(285 / 294)$ \\
\hline $\begin{array}{l}\text { All (severe } \\
\text { morbidity } \\
\text { free survival) }\end{array}$ & $68 \%(53 / 78)$ & $60 \%(67 / 112)$ & $31 \%(63 / 203)$ & $21 \%(86 / 410)$ & $27 \%(118 / 430)$ & $31 \%(387 / 1233)$ \\
\hline $\begin{array}{l}\text { All (severe } \\
\text { morbidity } \\
\text { free survival } \\
\text { as a \% of } \\
\text { survival) }\end{array}$ & $91 \%(53 / 58)$ & $84 \%(67 / 80)$ & $65 \%(63 / 97)$ & $62 \%(86 / 138)$ & $41 \%(118 / 288)$ & $58 \%(387 / 661)$ \\
\hline
\end{tabular}

GA: Gestational age. ROM: rupture of membranes. NA: not applicable.

From all 78 women who suffered PPROM between 16 and 18 weeks and reached $22^{+0}$ weeks, 54 patients delivered after 34 weeks (69\%). For the women suffering PPROM at $18-20,20-22,22-24$ and $24-26$ weeks this was $60 \%, 26 \%, 18 \%$ and $17 \%$, respectively. Sepsis occurred in $45 \%$ of children born between 24 and 32 weeks, but occurred in five of 320 infants born after 34 weeks (2\%). (Table 2.4). Analysis of the neonatal outcomes limited to the hospitals who registered during at least 2 or more years during the study period yielded similar results (data not shown). 
Table 2.4 Prevalence of sepsis by gestational age of delivery and gestational age of PROM.

\begin{tabular}{lcccccc}
\hline $\begin{array}{l}\text { GA at delivery } \\
\text { in weeks }\end{array}$ & $16^{+0}-17^{+6}$ & $18^{+0}-19^{+6}$ & $20^{+0}-21^{+6}$ & $22^{+0}-23^{+6}$ & $24^{+0}-25^{+6}$ & All \\
\hline $22^{+0}-23^{+6}$ & $0 \%(0 / 9)$ & $0 \%(0 / 18)$ & $1 \%(1 / 93)$ & $1 \%(2 / 194)$ & NA & $\mathbf{1 \% ( 3 / 3 1 4 )}$ \\
$24^{+0}-25^{+6}$ & $0 \%(0 / 4)$ & $17 \%(2 / 12)$ & $22(2 / 9)$ & $19 \%(17 / 90)$ & $34 \%(56 / 166)$ & $\mathbf{2 7 \% ( 7 7 / 2 8 1 )}$ \\
$26^{+0}-27^{+6}$ & $50 \%(2 / 4)$ & $33 \%(1 / 3)$ & $53 \%(8 / 15)$ & $50 \%(10 / 20)$ & $70 \%(88 / 125)$ & $\mathbf{6 5 \% ( 1 0 9 / 1 6 7 )}$ \\
$28^{+0}-29^{+6}$ & $0 \%(0 / 2)$ & $66 \%(2 / 3)$ & $77 \%(10 / 13)$ & $67 \%(10 / 15)$ & $63 \%(20 / 32)$ & $\mathbf{6 5 \% ( 4 2 / 6 5 )}$ \\
$30^{+0}-31^{+6}$ & $50 \%(1 / 2)$ & $75 \%(3 / 4)$ & $33 \%(3 / 9)$ & $50 \%(5 / 10)$ & $65 \%(11 / 17)$ & $\mathbf{5 5 \% ( 2 3 / 4 2 )}$ \\
$32^{+0}-33^{+6}$ & $100 \%(3 / 3)$ & $20 \%(1 / 5)$ & $50 \%(6 / 12)$ & $33 \%(2 / 6)$ & $39 \%(7 / 18)$ & $\mathbf{4 3 \% ( 1 9 / 4 4 )}$ \\
$34^{+0}-35^{+6}$ & $0 \%(0 / 1)$ & NA (0/0) & $20 \%(1 / 5)$ & $25 \%(1 / 4)$ & $13 \%(2 / 16)$ & $\mathbf{1 5 \% ( 4 / 2 6 )}$ \\
$\geq 36^{+0}$ & $0 \%(0 / 53)$ & $1 \%(1 / 67)$ & $0 \%(0 / 47)$ & $0 \%(0 / 71)$ & $0 \%(0 / 56)$ & $\mathbf{0 \% ( 1 / 2 9 4 )}$ \\
All & $\mathbf{8 \% ( 6 / 7 8 )}$ & $\mathbf{9 \% ( 1 0 / 1 1 2 )}$ & $\mathbf{1 5 \% ( 3 1 / 2 0 3 )}$ & $\mathbf{1 1 \% ( 4 7 / 4 1 0 )}$ & $\mathbf{4 3 \% ( 1 8 4 / 4 3 0 )}$ & $\mathbf{2 3 \% ( 2 8 7 / \mathbf { 1 2 3 3 } )}$ \\
\hline
\end{tabular}

GA: Gestational age. ROM: rupture of membranes. NA: not applicable.

\section{Discussion}

In this study, we found increased mortality and morbidity rates in patients with PPROM delivering after 22 weeks. In these patients, longer latency and early gestational age at PPROM have limited impact.

To our knowledge, this is the largest study on outcome after midtrimester PPROM. Similarly to Manuck et al, we stratified outcome on the basis of both gestational age at rupture of membranes, and gestational age at delivery ${ }^{4,15}$. This approach allows counseling of women that have reached a certain gestational age following very early PPROM, and a more straightforward comparison of different latencies and their influence on outcome.

The use of the PRN data however has limitations. Outcome on patients with midtrimester PPROM who deliver prior to 22 weeks is not registered. Counseling women with PPROM at 20 weeks gestational age remains therefore difficult, as data on median latency after PPROM at for example 16 weeks cannot be given.

A second important limitation is the absence of data on oligohydramnios, a known predictor of adverse outcome. In a study by Hadi et al. ${ }^{16}, 98 \%$ survival was seen in 91 patients admitted with PPROM between 20 and 25 weeks of gestational age, when there was a fluid pocket larger than $2 \mathrm{~cm}$, versus $31 \%$ of 13 patients with a pocket less than $2 \mathrm{~cm}$, in a group delivering at similar gestational age. Overall, reports on the actual incidence of oligohydramnios after midtrimester PPROM and its exact influence on outcome are scarce ${ }^{17}$.

The definition of severe morbidity that we used might also be subject of debate. Figures on pulmonary hypoplasia, restriction deformities, necrotizing enterocolitis and periventricular leukomalacia could not be included for example. Moreover, to our knowledge long term follow up on patients registered in the PRN during our study interval so far is absent. 
Borgida et al. found a $1 \%$ rate of PPROM after amniocentesis, with significantly longer latencies and better perinatal outcomes compared with outcomes after spontaneous PPROM at a similar gestational age ${ }^{18}$. It is not clear how this phenomenon has affected outcome in our study, nor are data available on amniocentesis prior to PPROM.

Information about the incidence of termination of pregnancy is missing as well, as this is a non-obligatory variable in the PRN. It is possible that due to pregnancy terminations bad outcome is being underestimated, since in patients with risk factors such as anhydramnion or vaginal bleeding termination of pregnancy might seem more appropriate.

Midtrimester PPROM is a worrisome clinical situation. Termination of pregnancy is offered to patients if the perinatologist estimates that the probability of favorable outcome is minimal. If expectant management is an option, counselling parents on chances of survival without severe morbidity is important, but difficult due to limitations in quality and quantity of available data.

An overview of studies on perinatal survival published from 2000 onwards after very early PPROM is shown in Table 2.4. The available data are likely to be biased by the fact that patients not amenable to continued expectant management are often excluded (i.e. bleeding, labour, stillbirths, pregnancy terminations in patients with structural abnormalities), and therefore survival is likely to be overestimated ${ }^{2}$.

The studies shown in this overview present mostly small series and differ in minimal latency included as well as in other inclusion criteria, such as multiple pregnancies. Median gestational age at time of rupture of membranes varies, and management schemes are not uniform.

Adverse outcome after midtrimester PPROM is mainly determined by prematurity, pulmonary hypoplasia, infectious disease and deformities ${ }^{3}$. Persistent oligohydramnios during the midtrimester has extensively been described as a poor prognostic sign ${ }^{3,8}$. Gestational age at PPROM, oligohydramnios and latency are known factors predicting pulmonary hypoplasia, though doubt remains whether latency is a predictor independent of gestational age at PPROM ${ }^{17}$.

Furthermore it has been hypothesized that expectant management increases the risk of development of chorioamnionitis and sepsis, with subclinical intrauterine infection contributing to this risk as well as to other neonatal morbidities such as periventricular leuko-malacia, intraventricular hemorrhage, cerebral palsy pulmonary hypoplasia and bronchopulmonary dysplasia ${ }^{12,19}$. In our data, early PPROM and thus longer latency did not increase chances of adverse outcome for any gestational age at delivery once $22^{+0}$ weeks of gestation has been reached.

Regarding sepsis our findings are in line with existing literature. Chorioamnionitis is strongly associated with shorter latencies, with highest incidences reported between two and five days after rupture of membranes ${ }^{20}$. Consequently, neonatal sepsis - as a 
sequel of chorioamnionitis - could be expected to occur more frequently in pregnancies with shorter latencies (Table 2.4).

Careful interpretation of solid data should replace subjective factors. Our study provides figures on outcome after midtrimester PPROM for patients with a certain gestational age of at least 22 weeks. Our study suggests that there does not seem to be a detrimental effect of longer latency nor early gestational age on perinatal outcome in patients once they reach 22 weeks. Therefore, after 22 weeks, these factors should not be used as an argument to terminate the pregnancy. Even before 22 weeks, where imminent delivery in a supposedly large group will lead to an almost certain perinatal mortality, expectant management is a reasonable course given the high percentage of morbidity free survival in the ones who do survive. There is a need for similar data on outcome before 22 weeks gestational age. 


\section{References}

1. Taylor J, Garite TJ. Premature rupture of membranes before fetal viability. Obstet Gynecol 1984;64: 615-20.

2. Waters TP, Mercer BM. The management of preterm premature rupture of the membranes near the limit of fetal viability. Am J Obstet Gynecol 2009;201:230-40.

3. Schucker JL, Mercer BM. Midtrimester premature rupture of the membranes. Semin Perinatol 1996;20: 389-400.

4. Manuck TA, Eller AG, Esplin MS, Stoddard GJ, Varner MW, Silver RM. Outcomes of expectantly managed preterm premature rupture of membranes occurring before 24 weeks of gestation. Obstet Gynecol 2009;114:29-37.

5. Deutsch A, Deutsch E, Totten C, Downes K, Haubner L, Belogolovkin V. Maternal and neonatal outcomes based on the gestational age of midtrimester preterm premature rupture of membranes. J Matern Fetal Neonatal Med 2010;23:1429-34.

6. Verma U, Goharkhay N, Beydoun S. Conservative management of preterm premature rupture of membranes between 18 and 23 weeks of gestation--maternal and neonatal outcome. Eur J Obstet Gynecol Reprod Biol 2006;128:119-24.

7. Falk SJ, Campbell LJ, Lee-Parritz A, Cohen AP, Ecker J, Wilkins-Haug L, Lieberman E. Expectant management in spontaneous preterm premature rupture of membranes between 14 and 24 weeks' gestation. J Perinatol 2004;24:611-6.

8. Winn HN, Chen M, Amon E, Leet TL, Shumway JB, Mostello D. Neonatal pulmonary hypoplasia and perinatal mortality in patients with midtrimester rupture of amniotic membranes--a critical analysis. Am J Obstet Gynecol 2000;182:1638-44.

9. Kurkinen-Raty M, Koivisto M, Jouppila P. Perinatal and neonatal outcome and late pulmonary sequelae in infants born after preterm premature rupture of membranes. Obstet Gynecol 1998;92:408-15.

10. Kilbride HW, Yeast J, Thibeault DW. Defining limits of survival: lethal pulmonary hypoplasia after midtrimester premature rupture of membranes. Am J Obstet Gynecol 1996;175:675-81.

11. Thibeault DW, Beatty EC Jr, Hall RT, Bowen SK, O'Neill DH. Neonatal pulmonary hypoplasia with premature rupture of fetal membranes and oligohydramnios. J Pediatr 1985;107:273-7.

12. Ramsey PS, Lieman JM, Brumfield CG, Carlo W. Chorioamnionitis increases neonatal morbidity in pregnancies complicated by preterm premature rupture of membranes. Am J Obstet Gynecol 2005;192:1162-6.

13. Méray N, Reitsma JB, Ravelli AC, Bonsel GJ. Probabilistic record linkage is a valid and transparent tool to combine databases without a patient identification number. J Clin Epidemiol 2007;60:883-91.

14. Ravelli AC, Tromp M, van Huis M, Steegers EA, Tamminga P, Eskes M, Bonsel GJ. Decreasing perinatal mortality in The Netherlands, 2000-2006: a record linkage study. J Epidemiol Community Health 2009;63:761-5.

15. Manuck TA, Maclean CC, Silver RM, Varner MW. Preterm premature rupture of membranes: does the duration of latency influence perinatal outcomes? Am J Obstet Gynecol 2009;201:414 e1-6.

16. Hadi HA, Hodson CA, Strickland D. Premature rupture of the membranes between 20 and 25 weeks' gestation: role of amniotic fluid volume in perinatal outcome. Am J Obstet Gynecol 1994;170:1139-44.

17. van Teeffelen AS, van der Ham DP, Oei SG, Porath MM, Willekes C, Mol BW. The accuracy of clinical parameters in the prediction of perinatal pulmonary hypoplasia secondary to midtrimester prelabour rupture of fetal membranes: a meta-analysis. Eur J Obstet Gynecol Reprod Biol 2010;148:3-12.

18. Borgida AF, Mills AA, Feldman DM, Rodis JF, Egan JF. Outcome of pregnancies complicated by ruptured membranes after genetic amniocentesis. Am J Obstet Gynecol 2000;183:937-9.

19. Everest NJ, Jacobs SE, Davis PG, Begg L, Rogerson S. Outcomes following prolonged preterm premature rupture of the membranes. Arch Dis Child Fetal Neonatal Ed 2008;93:F207-11.

20. McElrath TF, Allred EN, Leviton A. Prolonged latency after preterm premature rupture of membranes: an evaluation of histologic condition and intracranial ultrasonic abnormality in the neonate born at $<28$ weeks of gestation. Am J Obstet Gynecol 2003;189:794-8. 
21. Azria E, Anselem O, Schmitz T, Tsatsaris V, Senat MV, Goffinet F. Comparison of perinatal outcome after pre-viable preterm prelabour rupture of membranes in two centres with different rates of termination of pregnancy. BJOG 2012;119:449-57.

22. Dinsmoor MJ, Bachman R, Haney El, Goldstein M, Mackendrick W. Outcomes after expectant management of extremely preterm premature rupture of the membranes. Am J Obstet Gynecol 2004;190:183-7.

23. Grisaru-Granovsky S, Eitan R, Kaplan M, Samueloff A. Expectant management of midtrimester premature rupture of membranes: a plea for limits. J Perinatol 2003;23:235-9.

24. Homer L, Bernard C, Collet M. Management and outcomes of pregnancies complicated by preterm premature rupture of membranes before 26 weeks of gestation. Gynecol Obstet Fertil 2012.

25. Margato MF, Martins GL, Passini Júnior R, Nomura ML. Previable preterm rupture of membranes: gestational and neonatal outcomes. Arch Gynecol Obstet 2012;285:1529-34.

26. Muris C, Girard B, Creveuil C, Durin L, Herlicoviez M, Dreyfus M. Management of premature rupture of membranes before 25 weeks. Eur J Obstet Gynecol Reprod Biol 2007;131:163-8.

27. Pristauz G, Bauer M, Maurer-Fellbaum U, Rotky-Fast C, Bader AA, Haas J, Lang U. Neonatal outcome and two-year follow-up after expectant management of second trimester rupture of membranes. Int J Gynaecol Obstet 2008;101:264-8.

28. Yang LC, Taylor DR, Kaufman HH, Hume R, Calhoun B. Maternal and fetal outcomes of spontaneous preterm premature rupture of membranes. J Am Osteopath Assoc 2004;104:537-42. 


\section{Chapter}

\section{Prelabour rupture of membranes:}

overview of diagnostic methods

van der Ham DP, van Teeffelen ASP, Mol BW

Curr Opin Obstet Gynecol 2012;24:408-412 


\section{Abstract}

\section{Purpose of review}

To evaluate diagnostic accuracy studies for rupture of the fetal membranes (ROM)

\section{Recent findings}

Sample sizes of recent studies are small and studies used different "silver standard" definitions for ROM. Therefore, reported results should be interpreted with caution. Over the review period the focus of diagnostic studies has been on two bedside test strips: insulin-like growth factorbinding protein-1 (IGFBP-1) and placental alpha microglobulin-1 (PAMG-1). Bedside tests improve the confidence of the clinician about their diagnosis. Compared to nitrazine or ferning test alone, IGFBP-1 and PAMG-1 are more accurate. However, compared to the conventional testing (combination of history, ferning, nitrazine, speculum and ultrasound) no statistical difference in accuracy was found. In vitro PAMG-1 is shown to be superior to IGFPB-1. Furthermore, soluble intercellular adhesion molecule-1 (SICAM-1) and Axl receptor tyrosine kinase (Axl) seem to be promising new specific biomarkers for diagnosing ROM.

\section{Summary}

IGFBP-1 and PAMG-1 are the most commonly used bedside test for diagnosing ROM. Both tests seem to be sensitive and specific, however evidence is lacking especially in equivocal cases and comparative studies against the real golden standard (amnio-dye) have still not been published. Further effectiveness research is needed before tests can be applied in practice. 


\section{Introduction}

Prelabour rupture of the fetal membranes (PROM) complicates 5 to $10 \%$ of all pregnancies $^{1,2}$ and it is associated with an increased incidence of chorioamnionitis, prematurity and with increased perinatal and maternal morbidity and mortality ${ }^{3}$. In the majority of women, the diagnosis of ruptured fetal membranes can be based on a history of PROM with speculum examination. This clinical approach has, however, a

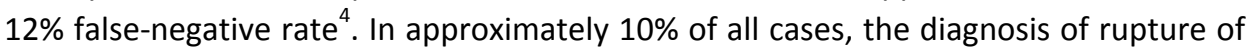
membranes is difficult to establish ${ }^{5,6}$.

In order to improve the accuracy to diagnose PROM a wide variety of tests have been introduced, the first one to be alkaline testing introduced in the $1930 \mathrm{~s}^{7}$. For decades, a combination of visual pooling of amniotic fluid during speculum examination, alkaline $\mathrm{pH}$ determination and microscopic evidence of ferning and decreased amniotic fluid by ultrasound has been widely used to determine rupture of membranes. This combination has been referred to as "conventional testing". These tests, however, are prone to false positive results secondary to vaginal contamination with blood, urine, or semen $^{5,8-10}$.

Besides the inaccuracy of the conventional test, many women find the use of a speculum examination intrusive ${ }^{11}$. In order to improve the accuracy of diagnostic test and simplify test procedures without the use of a speculum, dozens of tests have been developed over the last decades. In this review, we highlight and report the diagnostic accuracy studies on diagnostic test for PROM that have been published since a systematic review on diagnostic methods for rupture of the fetal membranes in equivocal cases $^{12^{*}}$.

\section{Systematic review}

We performed a systematic review to assess the accuracy of several tests for the diagnosis of ROM in equivocal cases ${ }^{12^{*}}$. Over a review period from 1960 to September 2010 we identified and obtained 146 full manuscripts, 133 were excluded due to multiple reasons. The remaining 13 studies were scored by an expert panel. Only three studies ${ }^{13-15}$ with a total of 155 patients fulfilled all criteria for a diagnostic test accuracy studies $^{16-19}$. These articles tested three different methods, $\mathrm{pH}$ measurement (64 patients) ${ }^{13}$, insulin-like growth factor binding protein-1 (ILGBP-1, 83 patients) ${ }^{14}$ and alpha fetoprotein (AFP, 8 patients) ${ }^{15}$. Sensitivity varied from $88 \%(\mathrm{pH})$ to $100 \%$ (AFP), specificity varied from $56 \%$ (ILGPP-1) to $100 \%$ (AFP). Based on the limited evidence on the accuracy of tests to diagnose ruptured membranes, we concluded that the use of a particular test cannot be recommended ${ }^{12^{*}}$.

For the present review, we repeated our search strategy for the period September 2010 until May 2012 and found 7 new articles, which will be described in more detail. 


\section{The lack of a gold standard}

Amniocentesis with infusion of a dye is widely considered as the gold standard for the diagnosis of rupture of membranes. However, this procedure is invasive, costly and may itself cause rupture of membranes and other complications, such as infections ${ }^{13,20-22}$. Because of this, many researchers and medical ethical committees find it unethical to expose women to amnio-dye infusion. However over the last decades due to better ultrasound technology, success rate of amniocentesis improved and complication rate seems nowadays to be low ${ }^{23}$. Studies reporting adverse outcome were published between 1976 and $1983^{20-22}$. The last published study which used amnion infusion with a dye as a gold standard was performed more than 15 years ago. In that study, it took researchers 12 year to include 64 women $^{13}$. Recently, preliminary results have been published in which placental alpha-microglobulin 1 (PAMG-1) was compared to amniodye test ${ }^{24}$. The final results have, however, not been published yet.

Meanwhile the lack of a noninvasive gold standard test for PROM is a severe limitation to study (new) diagnostic tests ${ }^{25}$. The recently published studies which are discussed in this review all lack the use of a gold standard and still do not meet all the criteria for the methodological assessment and reporting of diagnostic accuracy studies as suggested in previously reported guidelines ${ }^{16-19}$.

\section{Rationale of current diagnostic tests}

Because of a lack of a gold standard for the majority of the clinical studies and the limitations and inaccuracy of "conventional testing" as well as the need for a less invasive, less intrusive method, researches have been searching for the identification biochemical markers which are present in high quantities in case of ROM, and absent in cervicovaginal discharge when membranes are intact. Many of these markers have shown to be less valuable because they are also present in other physiological fluid such as blood, vaginal secretion of seminal fluid ${ }^{25}$. Other markers such as fetal fibronectin (fFN) seem to indicate the mechanical or inflammatory-mediated detachment of the membranes from the decidua and are nowadays merely used as a predictor for pre-term delivery and are no longer considered to indicate ruptured membrane ${ }^{26-28}$. Insulin-like growth factor binding protein-1 (IGFBP-1) and placental alpha macroglobulin-1 (PAMG-1)meet the criteria of high concentration in amniotic fluid and low concentration in other physiological fluids ${ }^{29,30}$. Therefore in the past year the focus of the research has been on these two tests ${ }^{31-36}$. Other proteins, such as soluble intercellular adhesion molecule-1 (sICAM-1) and Axl receptor thyrosine kinase (Axl) might be used as biomarkers in the future ${ }^{37^{*}}$. 


\section{A bedside test to improve a doctor's confidence}

Neil and Wallace ${ }^{34}$ studied the clinical utility of PAMG-1 testing in daily practice. They questioned how often and in whom a bedside test might enhance the clinical diagnosis of PPROM and change clinical management. In a prospective observational study they included 184 women (100 term pregnancies and 84 preterm pregnancies) in a 12-month period. Based on history and clinical examination (speculum examination) the attending obstetrician was certain with the diagnosis in $53 \%$ of the women and uncertain in $47 \%$. Obstetricians were more confident with preterm women than with term women ( $p=0.02$ ). After PAMG-1 testing the confidence of the obstetrician in the diagnosis ROM or no ROM increased. In $92 \%$ of the women the obstetrician was certain with his/her diagnosis and in $8 \%$ uncertain $(p<0.0001)$. Diagnosis and management was changed after PAMG-1 test especially in the proposed intact membranes group (toward proposed ruptured membranes, 14 out of 82 cases, 17\%). The study did not test the accuracy of the PAMG-1 test, nor did it follow the women until delivery, not giving any insight in the effect on outcome. Results on the accuracy of PAMG-1 in this study should therefore be interpreted with caution. This study however does show the need for clinicians to increase his/her confidence by using a bedside test ${ }^{34}$.

\section{Diagnostic accuracy studies}

Pollet-Villard et al., studied in vitro the sensitivity of IGFBP-1 and PAMG-1 using different detection limits after dilution of amniotic fluid in a comparative study ${ }^{35^{*}}$. They recruited 41 women over 37 weeks of gestational age who were scheduled for a caesarean section. During the caesarean section $0.5 \mathrm{ml}$ samples of amniotic fluid were collected with a syringe before rupture of the membranes and fetal extraction. The samples were diluted with saline solution $(\mathrm{NaCl} 0.9 \%)$ in a 1:10, 1:20, 1:40, 1:80, 1:160, 1:320 and 1:640 dilution series. For each dilution both IGFBP-1 and PAMG-1 tests were performed. Up to a dilution of 1:40 PAMG-1 showed a sensitivity of $100 \%$ whereas the sensitivity for IGFBP-1 dropped from 100 to $97.5 \%$ to $88 \%$ for $1: 10,1: 20$ and $1: 40$ dilution, respectively. For the dilution of 1:40 this difference was significant $(p<0.05)$. This study tried to mimick the vaginal dilution of amniotic fluid in the vagina after PPROM. However, they only took samples for the term population and it might be questionable whether dilution with $\mathrm{NaCl} 0.9 \%$ will actually mimic the clinical condition. Nevertheless in this in vitro dilution study PAMG-1 has a higher sensitivity and better reproducibility than IGFBP- $1^{35^{*}}$.

Two recent papers studied placental alpha microglobulin-1 (PAMG-1) for the detection of rupture of membranes ${ }^{31,33}$. The first study was a prospective observational study in 199 women (gestational age 17-42 weeks) with uncertain signs or symptoms of ROM ${ }^{33}$. Rupture of membranes was first diagnosed using a the conventional method with 2 out 
of 3 of the following criteria: positive (1) visual leaking or pooling, (2) positive nitrizine test, (3) amniotic fluid index (AFI) $<5 \mathrm{~cm}$ PAMG-1 testing was performed after initial diagnosis was made and the investigator was not blinded. Final diagnosis of ROM was made on medical records after delivery. PAMG-1 test was found to be more sensitive $(94.4 \%$ vs. $72.2 \%, p=0.006)$ but had the same specificity $(98.6 \%$ vs. $97.9 \%)$ compared to conventional testing. Due to the costs of ultrasound examination, PAMG-1 testing alone was significantly less expensive than conventional testing ${ }^{33}$. The second study was an unblended comparative prospective study in 150 term women ( $<37$ weeks), 75 of whom had definite ROM, based on history (sudden gush), pooling, positive nitrazine and ferning and visual fluid passing the cervical canal during speculum examination, the remaining 75 women had no signs of ROM and were scheduled for induction of labour $^{31}$. PAMG-1 testing in women with certain ROM had a sensitivity of $97 \%$ versus $84 \%$ for ferning and $87 \%$ for nitrazine test, specificity was $99 \%, 79 \%$ and $81 \%$ respectively ${ }^{31}$.

Two other studies compared IGFBP-1 and PAMG-1 testing for diagnosis of ROM ${ }^{32,36}$. In the first prospective observational study 179 women between 16 and 41 weeks of gestation were included ${ }^{32}$. ROM was primarily diagnosed using a conventional method (pooling, positive ferning, positive nitrazine testing and AFI measurement). The definite diagnosis was made afterwards by two of the researches, unaware of the IGFPB-1 and PAMG-1 test result, based on duration of latency, results of (repeated) speculum examination, (repeated) ferning, nitrazine and decreased AFI by follow-up as well as clinical signs of fetal distress or chorioamnionitis. The presence of at least two of the above was needed for diagnosis of $\mathrm{ROM}^{32}$. The investigators found that the sensitivity (94\%, 90\%, 87\%, for PAMG-1, ILGFBP-1 and conventional testing, respectively) and specificity (98\%, 98\% and $95 \%$, respectively) were high and not statistically different. Related to ferning alone IGFBP-1 and PAMG-1 were significantly more accurate. However, as the researchers commented, ferning or nitrazine testing alone have been shown to be less accurate and are only used in a combined conventional method ${ }^{32}$. The second study compared ILGBP-1, PAMG-1 and nitrazine testing for diagnosing PROM. In a prospective observational study 100 consecutive women between 17 and 37 weeks of gestation with signs and symptoms of ROM were included. [36] ROM was diagnosed if three of the following were present: definite pooling, oligohydramion at ultrasound, signs and symptoms of chorioamnionitis, preterm delivery within a week of presentation along with a convincing history of leaking as judged by the attending clinician. Medical records were reviewed after delivery ${ }^{36}$. PAMG-1 had a sensitivity of $93 \%$ and specificity of $100 \%$; IGFPB-1 had a sensistivity of $88 \%$ and specificity of $94 \%$, the difference between both test was not statistically significant. Compared to nitrazine testing alone PAMG-1 and IGFPB-1 were significantly more accurate ${ }^{36}$.

In another small observational study vaginal creatine was studied for diagnosing ROM in definite suspected- and absent ROM. It was concluded that vaginal creatine might be 
useful in diagnosing ROM but material and methods of the study were poorly described, therefore no results are mentioned in this review ${ }^{38}$.

\section{Future testing methods}

To date, PAMG-1 and IGFBP-1 are the most commonly used bedside test strips for diagnosing ROM. There is however some evidence that PAMG-1 might also be a marker for short time-to-delivery ${ }^{39}$. Fragmented and phosphorylated forms of IGFBP-1 are associated to predict preterm labour ${ }^{40,41}$. Like other diagnostic tests in the past, it might be possible that the sensitivity and specificity of PAMG-1 and IGFBP-1 will turn out to be not as high as reported to date.

Obviously, researchers are working on new tests which might be more accurate than currently available ones ${ }^{37^{*}}$. Wang et al used a cytokine/chemokinine antibody array in order to identify proteins which are high in amniotic fluid (AF) and low in cervicalvaginal fluid (CVF) and tested these protein in 110 patients with unequivocal ROM and 110 controls $^{37 *}$. From the 174 cytokines which were studied in the kit, sICAM1, Axl, IGFBP-1, MCP-1, MIP-1 $\delta$, TIMP-1 and CD14 were found most interesting. The authors decided to focus on sICAM-1 (soluble intercellular adhesion molecule-1), AxI (AxI receptor tyrosine kinase) and IGFBP-1. SICAM, AxI and IGFBP-1 were respectively 85, 482 and 72 fold higher in AF than in CVF. sICAM and Axl maybe usefull as diagnostics for ROM where sICAM seems to be a better candidate for the development of a bedside test, because the technology to manufacture this test is widely accepted, reliable and inexpensive $\mathrm{i}^{37^{*}}$.

\section{Is there a need for a bedside test?}

There is growing evidence that there is less need for immediate induction of labor when membranes rupture late prematurely ${ }^{42,43}$. This makes it questionable if for the near term population a bedside test is needed for a small minority of patients in which the clinician cannot certainly make a diagnosis based on conventional testing. However, in contrast early PPROM is associated with high perinatal morbidity and mortality. Preterm delivery is a frequent sequel of this complication and it is estimated that approximately $25-40 \%$ of preterm deliveries are preceded by PPROM. Although early preterm delivery (<32 weeks' gestation) occurs in only $1-2 \%$ of total births it is estimated to account for nearly $50 \%$ of all long-term neurological morbidity and about $60 \%$ of perinatal mortality ${ }^{44}$.

In this perspective correct diagnosis in equivocal cases is mandatory since a correct diagnosis would bring down unnecessary burden for the health system. False positive test results could lead to overtreatment (hospital admittance, corticosteroids and 
antibiotics), whilst a missed diagnosis of PPROM could delay administration of corticosteroids. In equivocal cases diagnosis of early PPROM is often hindered by vaginal bleeding. In a patient with mild vaginal bleeding in the second trimester the perspective in case of (masked) PPROM is significantly different, and a validated test in this case would be valuable.

\section{Conclusion}

Since we published a systematic review on the diagnostic tests for rupture of membranes ${ }^{12^{*}}$ several new studies have been published ${ }^{31,32,34-38}$. Due to the lack of a noninvasive gold standard, the use of a second best "silver standard" varies amongst different studies as well as the included population (preterm, term) and complaints (equivocal or unequivocal ROM). There were no randomised controlled trials, all studies were prospective and observational. Studies had small sample sizes (maximum 199 participants ${ }^{33}$ ) and therefore it is difficult to compare different tests with each other. PAMG-1 seems to be the most sensitive and specific test, and is subject of the only study with a design including the real gold standard dye-infusion results still being under way. New tests are being developed ${ }^{37^{*}}$. But as long as current and newly developed tests are not tested against the gold standard, results of new studies will always be issue of debate. Furthermore in our opinion studies should be more focused on the early PROM group. 


\title{
References and recommended reading
}

\author{
Papers of particular interest, published within the annual period of review, have been \\ highlighted as: \\ * of special interest \\ ${ }^{* *}$ of outstanding interest
}

1. Gunn GC, Mishell DR Jr, Morton DG. Premature rupture of the fetal membranes. A review. Am J Obstet Gynecol 1970;106:469-83.

2. Mead PB. Management of the patient with premature rupture of the membranes. Clin Perinatol 1980; 7:243-55.

3. Furman B, Shoham-Vardi I, Bashiri A, Erez O, Mazor M. Clinical significance and outcome of preterm prelabor rupture of membranes: Population-based study. Eur J Obstet Gynecol Reprod Biol 2000; 92:209-16.

4. Ladfors L, Mattsson LA, Eriksson M, Fall O. Is a speculum examination sufficient for excluding the diagnosis of ruptured fetal membranes? Acta obstetricia et gynecologica Scandinavica 1997;76:739-42.

5. Friedman ML, McElin TW. Diagnosis of ruptured fetal membranes. Clinical study and review of the literature. Am J Obstet Gynecol 1969;104:544-50.

6. Mercer BM. Preterm premature rupture of the membranes. Obstet Gynecol 2003;101:78-193.

7. Baptisti A. Chemical test for the determination of ruptured membranes. Am J Obstet Gynecol 1938;87: 688-90.

8. de Haan HH, Offermans PM, Smits F, Schouten HJ, Peeters LL. Value of the fern test to confirm or reject the diagnosis of ruptured membranes is modest in nonlaboring women presenting with nonspecific vaginal fluid loss. Am J Perinatol 1994;11:46-50.

9. Gorodeski IG, Haimovitz L, Bahari CM. Reevaluation of the ph, ferning and nile blue sulphate staining methods in pregnant women with premature rupture of the fetal membranes. J Perinat Med 1982; 10:286-92.

10. Erdemoglu E, Mungan T. Significance of detecting insulin-like growth factor binding protein-1 in cervicovaginal secretions: Comparison with nitrazine test and amniotic fluid volume assessment. Acta Obstet Gynecol Scand 2004;83:622-6.

11. Royal College of Obstetricians and Gynaecologists. Gynaecological examinations. Guidelines for specialist practice. RCOG, London 2002.

12. van der Ham DP, van Melick MJ, Smits L, Nijhuis JG, Weiner CP, van Beek JH, Mol BW, Willekes C. Methods for the diagnosis of rupture of the fetal membranes in equivocal cases: A systematic review. Eur J Obstet Gynecol Reprod Biol 2011;157:123-7.

* In this systematic review all methods for diagnosing rupture of membranes in equivocal cases were reviewed until September 2010. Only three small studies could be included because they were the only studies which focused on equivocal cases and met nowadays standards for diagnostic accuracy test studies.

13. Fujimoto S, Kishida T, Sagawa T, Negishi H, Okuyama K, Hareyama H, Makinoda S. Clinical usefulness of the dye-injection method for diagnosing premature rupture of the membranes in equivocal cases. J Obstet Gynaecol 1995;21:215-20.

14. Jeurgens-Borst AJ, Bekkers RL, Sporken JM, van den Berg PP. Use of insulin like growth factor binding protein-1 in the diagnosis of ruptured fetal membranes. Eur J Obstet Gynecol Reprod Biol 2002;102: 11-4.

15. Yamada H, Kishida T, Negishi H, Sagawa T, Yamaguchi M, Sato C, Nakamura I, Sato H, Sakai K, Yamaguchi T, Fujimoto $S$. Comparison of an improved afp kit with the intra-amniotic psp dye-injection method in equivocal cases of preterm premature rupture of the fetal membranes. J Obstet Gynaecol Res 1997;23: 307-11. 
16. Bossuyt PM, Reitsma JB, Bruns DE, Gatsonis CA, Glasziou PP, Irwig LM, Lijmer JG, Moher D, Rennie D, de Vet HC. Towards complete and accurate reporting of studies of diagnostic accuracy: The stard initiative. BMJ 2003;326:41-4.

17. Deville WL, Buntinx F, Bouter LM, Montori VM, de Vet HC, van der Windt DA, Bezemer PD. Conducting systematic reviews of diagnostic studies: Didactic guidelines. BMC Med Res Methodol 2002;2:9.

18. Rutjes AW, Reitsma JB, Coomarasamy A, Khan KS, Bossuyt PM. Evaluation of diagnostic tests when there is no gold standard. A review of methods. Health Technol Assess 2007;11:iii, ix-51.

19. Whiting P, Rutjes AW, Reitsma JB, Bossuyt PM, Kleijnen J. The development of quadas: A tool for the quality assessment of studies of diagnostic accuracy included in systematic reviews. BMC Med Res Methodol 2003;3:25.

20. Cowett RM, Hakanson DO, Kocon RW, Oh W. Untoward neonatal effect of intraamniotic administration of methylene blue. Obstet Gynecol 1976;48:74S-5S.

21. McEnerney JK, McEnerney LN. Unfavorable neonatal outcome after intraamniotic injection of methylene blue. Obstet Gynecol 1983;61:35S-7S.

22. Smith RP. A technic for the detection of rupture of the membranes. A review and preliminary report. Obstet Gynecol 1976;48:172-6.

23. Simhan HN, Canavan TP. Preterm premature rupture of membranes: Diagnosis, evaluation and management strategies. BJOG 2005;112:32-7.

24. Silva E, Martinez J. Diagnosing rom: A comparison of the gold standard, indigo carmine amnioinfusion, to the rapid immunoassay, the amnisure rom test. J Perinat Med 2009;37:956.

25. Di Renzo GC, Roura LC, Facchinetti F, Antsaklis A, Breborowicz G, Gratacos E, Husslein P, Lamont R, Mikhailov A, Montenegro N, Radunovic N, et al. Guidelines for the management of spontaneous preterm labor: Identification of spontaneous preterm labor, diagnosis of preterm premature rupture of membranes, and preventive tools for preterm birth. J Matern Fetal Neona 2011;24:659-67.

26. Riboni F, Vitulo A, Plebani M, Dell'avanzo M, Battagliarin G, Paternoster D: Combination of biochemical markers in predicting pre-term delivery. Arch Gynecol Obstet 2012;285:61-6.

27. Eriksen NL, Parisi VM, Daoust S, Flamm B, Garite TJ, Cox SM. Fetal fibronectin: A method for detecting the presence of amniotic fluid. Obstet Gynecol 1992;80:451-4.

28. Hellemans $P$, Verdonk $P$, Baekelandt $M$, Joostens $M$, Francx $M$, Gerris J. Preliminary results with the use of the rom-check immunoassay in the early detection of rupture of the amniotic membranes. Eur J Obstet Gynecol Reprod Biol 1992;43:173-9.

29. Cousins LM, Smok DP, Lovett SM, Poeltler DM. Amnisure placental alpha microglobulin-1 rapid immunoassay versus standard diagnostic methods for detection of rupture of membranes. Am J Perinatol 2005;22:317-20.

30. Rutanen EM, Karkkainen TH, Lehtovirta J, Uotila JT, Hinkula MK, Hartikainen AL. Evaluation of a rapid strip test for insulin-like growth factor binding protein-1 in the diagnosis of ruptured fetal membranes. Clin Chim Acta 1996;253:91-101.

31. Abdelazim IA, Makhlouf HH. Placental alpha microglobulin-1 (amnisure((r)) test) for detection of premature rupture of fetal membranes. Arch Gynecol Obstet 2012;285:985-9.

32. Albayrak M, Ozdemir I, Koc O, Ankarali H, Ozen O. Comparison of the diagnostic efficacy of the two rapid bedside immunoassays and combined clinical conventional diagnosis in prelabour rupture of membranes. Eur J Obstet Gynecol Reprod Biol 2011;158:179-82.

33. Birkenmaier A, Ries JJ, Kuhle J, Burki N, Lapaire O, Hosli I. Placental alpha-microglobulin-1 to detect uncertain rupture of membranes in a european cohort of pregnancies. Arch Gynecol Obstet 2011;285: 21-5.

34. Neil PR, Wallace EM. Is amnisure( $r$ ) useful in the management of women with prelabour rupture of the membranes? The Australian \& New Zealand journal of obstetrics \& gynaecology (2010) 50(6):534-538.

35. Pollet-Villard M, Cartier R, Gaucherand P, Doret $M$ : Detection of placental alpha microglobulin-1 versus insulin-like growth factor-binding protein-1 in amniotic fluid at term: A comparative study. Am J Perinatol 2011;28:489-94.

* This in vitro comparative study decribes the sensitivity and specificity of IGFBP-1 versus PAMG-1 in amniotic fluid in different dillutions. PAMG-1 has a lower detection limit, shorter response time and a higher sensitivity compared to IGFPB-1. 
36. Tagore S, Kwek K. Comparative analysis of insulin-like growth factor binding protein-1 (igfbp-1), placental alpha-microglobulin-1 (pamg-1) and nitrazine test to diagnose premature rupture of membranes in pregnancy. J Perinatal Medicine 2010;38:609-12.

37. Wang T, Zhou R, Zhang L, Wang Y, Song C, Lin W, Niu X, Lin Y, Hu H. Proteins in leaked amniotic fluid as biomarkers diagnostic for prelabor rupture of membranes. Proteomics Clin Appl 2011;5:415-21.

* In this paper a cytokine/chemokine antibody array which could simultaneously detect 174 cytokines was used to identify possible predictors for amniotic fluid. Soluble adhesion molecule-1 (sICAM-1) and Axl receptor tyrosine kinase (Axl) seems promising new detectors for ROM.

38. Zanjani MS, Haghighi L. Vaginal fluid creatinine for the detection of premature rupture of membranes. J Obstet Gynaecol Res 2012;38:505-8.

39. Lee SM, Lee J, Seong HS, Lee SE, Park JS, Romero R, Yoon BH. The clinical significance of a positive amnisure test in women with term labor with intact membranes. J Matern Fetal Neona 2009;22:305-10.

40. Lee J, Lee SM, Oh KJ, Park CW, Jun JK, Yoon BH. Fragmented forms of insulin-like growth factor binding protein-1 in amniotic fluid of patients with preterm labor and intact membranes. Reprod Sci 2011; 18:842-9.

41. Cooper S, Lange I, Wood S, Tang S, Miller L, Ross S. Diagnostic accuracy of rapid phigfbp-I assay for predicting preterm labor in symptomatic patients. J Perinatol 2012;32:460-5.

42. van der Ham DP, Vijgen SM, Nijhuis JG, van Beek JJ, Opmeer BC, Mulder AL, Moonen R, Groenewout M, van Pampus MG, Mantel GD, Bloemenkamp KW, et al. Induction of labor versus expectant management in women with preterm prelabor rupture of membranes between 34 and 37 weeks: A randomized controlled trial. PLoS Medicine 2012;9:e1001208.

43. Buchanan SL, Crowther CA, Levett KM, Middleton P, Morris J. Planned early birth versus expectant management for women with preterm prelabour rupture of membranes prior to 37 weeks' gestation for improving pregnancy outcome. Cochrane Database Syst Rev 2010:CD004735.

44. Goldenberg RL. The management of preterm labor. Obstet Gynecol 2002;100:1020-37. 



\section{Chapter 4}

Is it useful to measure C-reactive protein and leukocytes in patients with prelabour rupture of membranes?

van der Heyden JL, van Teeffelen ASP, Coolen ACG, Halbertsma FJ, Aardenburg R, Mertens HJMM, Mol BW

Am J Perinatol 2010;27:543-547 


\section{Abstract}

Neonatal infection is the main complication of prelabour rupture of membranes (PROM). We studied the accuracy of measuring C-reactive protein (CRP) and leukocytes in maternal serum to predict neonatal infection.

We performed a retrospective cohort study in two hospitals in the Netherlands between 2003 and 2006. We included consecutive women hospitalized for PROM. In both hospitals, CRP and leukocytes were measured routinely in maternal serum every 2 days until delivery. End points considered were clinical neonatal infection and proven neonatal sepsis. The accuracy of CRP and leukocytes was assessed using receiver operating characteristics (ROC) analysis.

We included 299 women with PROM, 12 of whom had a twin pregnancy. Gestational age at inclusion varied between 26 weeks and 0 days and 41 weeks and 5 days with a median of 37 weeks and 3 days. In 47 women (16\%), the neonate developed a clinical infection. The areas under the ROC curve of CRP and leukocytes in the prediction of clinical neonatal infection were 0.61 and 0.62 , respectively. Of the 47 infected neonates, six neonates $(2 \%)$ had a proven neonatal sepsis. In the mothers of these septic neonates, maternal CRP did not rise above 50 $\mathrm{mg} / \mathrm{L}$ and leukocyte values varied between 9.8 and $25.8 \times 10^{9} / \mathrm{l}$.

In women with PROM, CRP and leukocytes should not be measured routinely. 


\section{Introduction}

Prelabour rupture of membranes (PROM) is defined as rupture of the membranes without the start of labour for at least 24 hours. The estimated incidence of PROM after 26 weeks of gestation is $10 \%{ }^{1}$. The main complication of PROM is intrauterine infection. If the neonate is born immediately after PROM, the risk of sepsis is $2.5 \%$, whereas it is thought to increase to $7.5 \%$ in cases of expectant management ${ }^{2-4}$.

To determine the risk of neonatal infection before birth, several risk factors can be considered. Maternal fever, fetal tachycardia and green or fetid amniotic fluid are all associated with the presence of infection. Apart from these risk factors, it is thought that measuring C-reactive protein (CRP) and/or white blood cells (leukocytes) might be of value for early detection of neonatal infection in these patients ${ }^{5,6}$.

In the literature, conflicting results on the use of CRP in the prediction of infection in women with PROM have been reported ${ }^{5-7}$. In 2007, Trochez-Martinez et al. performed a systematic review and found no clear evidence that supported the use of CRP for the early diagnosis of chorioamnionitis ${ }^{8}$. However, the association between CRP and neonatal infection was not assessed due to a lack of studies on the subject.

In view of this lack of knowledge, the objective of the present study was to determine the accuracy of CRP and leukocytes measured in maternal serum in the prediction of neonatal infection.

\section{Methods}

We performed a retrospective cohort study between 2003 and 2006 in the Orbis Medical Center Sittard and Máxima Medical Center Veldhoven. Both hospitals are large, nonacademic teaching hospitals in the south of the Netherlands. We included consecutive women with PROM, with a gestational age between 26 and 42 weeks. These women were identified from local electronic databases with data on all deliveries. In both hospitals, in women with PROM before 37 weeks' gestation, CRP and leukocytes were measured routinely in maternal serum twice a week until delivery. In women with PROM at term, CRP and leukocytes were measured 24 hours after rupture of the membranes and labour was induced after 48 hours. The measurements of CRP and leukocytes were used in combination with other data. The decision to induce labour or to continue expectant management (the probability of the presence of an intrauterine infection) was based on maternal fever, fetid or green amniotic fluid, tachycardia of the fetus, as well as on the results of CRP and leukocytes. In one of the hospitals (only in the Máxima Medical Center Veldhoven), antibiotics (erythromycin $250 \mathrm{mg} 4$ times daily for 10 days) were given to patients with PROM before 37 weeks' gestation ${ }^{9}$. The difference in this policy is a result of the guideline of the Dutch Society for Obstetrics and Gynecology, which does not give a clear recommendation on the use 
of antibiotics in patients with PROM before 37 weeks' gestation. In both hospitals, patients with PROM before 34 weeks' gestation received intramuscular corticosteroid injections. Maternal CRP was measured with a turbidimetric immuno-assay (Roche Modular $^{\circledR}$, Basel, Switzerland). Leukocytes were measured with a flow cytometric test (impedance measurement from Beckman Coulter $^{\circledR}$, Brea, CA). Patients in whom CRP and leukocytes had not been measured were not included. For every patient with PROM, we collected data about the pregnancy, vaginal culture, maternal temperature, clinical infection in the neonate, admission to hospital and use of antibiotics in the neonate in a case record form.

End points were clinical neonatal infection and proven neonatal sepsis. According to the International Pediatric Sepsis Consensus Conference $2005^{10}$, infection is suspected or proven (by positive culture, tissue stain, or polymerase chain reaction test) caused by any pathogen. Evidence of clinical infection includes symptoms with a high probability of infection, like positive findings on clinical exam, imaging, or laboratory tests. For signs of infection at clinical examination we used respiratory distress, tachypnea, lethargy (silent or hypotonic neonate), feeding problems, hyperthermia or hypothermia. Laboratory signs of infection were increased CRP, leukocytosis, or leukocytopenia ${ }^{10}$.

Neonatal sepsis is defined as neonatal infection with cardiorespiratory instability or a positive blood culture caused by any pathogen.

\section{Statistical analysis}

The distribution of each of the variables was compared between the neonates with and neonates without infection. For continuous variables, we calculated means or medians in both groups. For statistical comparison, we used the appropriate statistical test depending on normality of the distributions.

Subsequently, for both CRP and leucocytes we performed receiver operating characteristic (ROC) analysis, in which infection was considered the disease. For comparison, the accuracy of maternal temperature for neonatal infection or sepsis was considered. The article was reported using the STARD-guidelines for the report of diagnostic research ${ }^{11}$.

\section{Results}

We included 386 women with PROM, of whom 65 women were excluded, because CRP and leukocytes were not determined in these women. In 22 women, PROM had occurred before 26 weeks of gestation, leaving 299 women eligible for analysis (see Figure 4.1). Gestational age at inclusion varied from 26 weeks and 0 days to 41 weeks and 5 days with a median of 37 weeks and 3 days. Baseline characteristics are shown in 
Table 4.1. In 47 women (16\%), the neonate developed a clinical infection, of which six children (2\%) had an early onset neonatal sepsis. The babies from the other 252 women did not develop an infection.

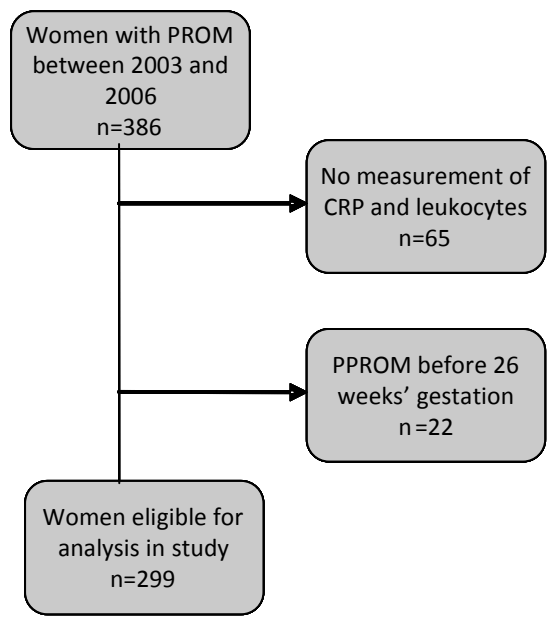

Figure 4.1 Inclusion of patients. CRP, C-reactive protein; PPROM, preterm prelabour rupture of membrane; PROM, prelabour rupture of membranes.

Table 4.1 Baseline characteristics.

\begin{tabular}{lcc}
\hline Characteristic & Number & $\begin{array}{c}\text { Number in women whose } \\
\text { neonate had sepsis }\end{array}$ \\
\hline Maternal age, y (mean and standard deviation) & 30.4 years $( \pm 4.6)$ & 28.3 years \\
Nulliparous women & $196(65.6 \%)$ & $5(83.3 \%)$ \\
Multiparous women & $103(34.4 \%)$ & $1(16.7 \%)$ \\
Gestational age (median and range) & $37 \mathrm{wk}, 3 \mathrm{~d}$ & $36 \mathrm{wk}, 2 \mathrm{~d}$ \\
& $(26 \mathrm{wk}-41 \mathrm{wk}, 5 \mathrm{~d})$ & $(31 \mathrm{wk}, 1 \mathrm{~d}-40 \mathrm{wk}, 4 \mathrm{~d})$ \\
Singletons & $287(96.0 \%)$ & $6(100 \%)$ \\
Twins & $12(4.0 \%)$ & $0(0 \%)$ \\
Positive vaginal culture & $123(41.1 \%)$ & $5(83.3 \%)$ \\
Women who smoked & $27(9.0 \%)$ & $1(16.7 \%)$ \\
\hline
\end{tabular}

Values are expressed as absolute numbers with percentage, median with range or mean with standard deviation where appropriate.

In the 252 women with babies who did not develop infection, the last measured CRP in maternal serum before birth was minimum $1 \mathrm{mg} / \mathrm{l}$ and maximum $70 \mathrm{mg} / \mathrm{l}$ (median $8 \mathrm{mg} / \mathrm{l}$ ) and the median leukocyte value was 13.0 (range 5.7 to $31.2 \times 10^{9} / \mathrm{l}$ ).

Of six children with early onset sepsis, one neonate suffered from Listeria meningitis and sepsis. Two children showed a hemolytic Streptococcus group B in the blood culture. One neonate had Staphylococcus epidermidis and one had Staphylococcus 
capitis in the blood culture. One neonate had a neonatal infection and was hypothermic. The $S$. epidermidis in the blood culture might have been caused by contamination. However, this neonate also showed clinically signs of sepsis. In these six neonates with early onset sepsis, last measured CRP in maternal serum before birth did not rise above $50 \mathrm{mg} / \mathrm{l}$ and leukocyte values varied between 9.8 and $25.8 \times 10^{9} / \mathrm{l}$. We did not observe an effect of the use of antibiotics on the occurrence of sepsis.

In 47 women (16\%), the neonate developed a clinical infection. The mean values of $\mathrm{CRP}$, leukocytes and temperature in mothers of a child with clinical infection are shown in Table 4.2. Figures 4.2A and 4.2B show the ROC curves for CRP and leukocytes.

The area under the ROC curve for CRP and leukocytes in the diagnosis of clinical infection was 0.61 and 0.62 , respectively.

Table 4.2 Clinical neonatal infection.

\begin{tabular}{lcc}
\hline & Positive $(n=47)$ & Negative $(n=252)$ \\
\hline C-reactive protein $(\mathrm{mg} / \mathrm{l})$ & 21.7 & 11.7 \\
Leukocytes $\left(\times 10^{9}\right)$ & 16.0 & 14.0 \\
Maximal maternal temperature $\left({ }^{\circ} \mathrm{C}\right)$ & 37.2 & 36.8 \\
\hline
\end{tabular}

Results are mean values.
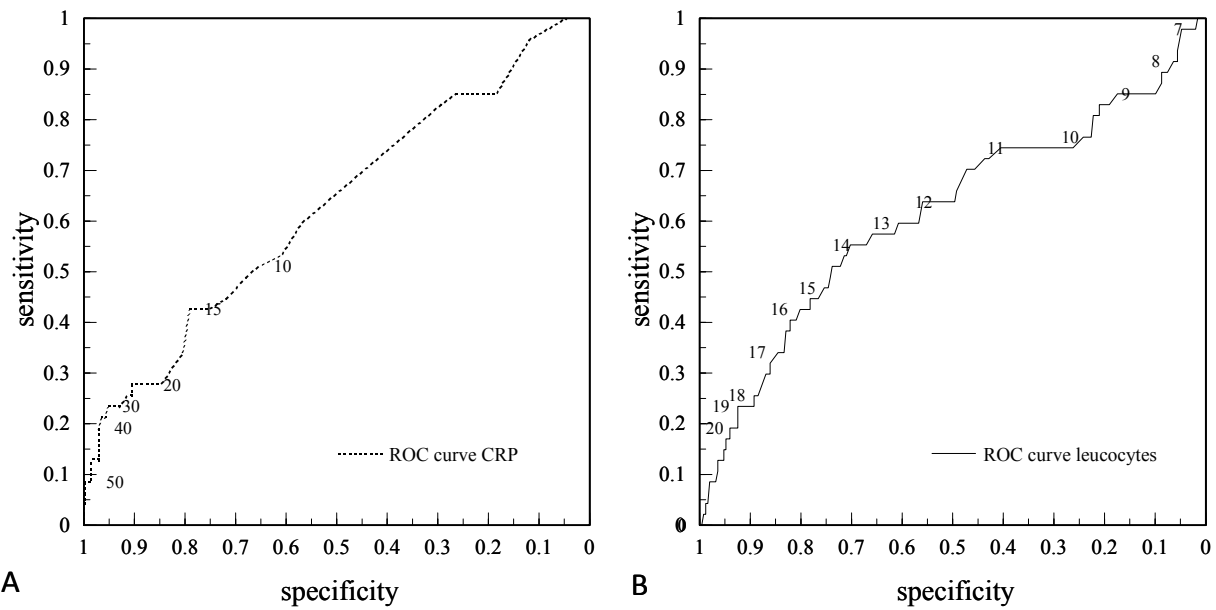

Figure 4.2 (A) Receiver operating characteristics (ROC) curve of C-reactive protein (CRP). Along the ROC curves, we have pointed the cutoff values. (B) ROC curve of leukocytes.

Figure 4.3 shows the ROC curve for the last maternal temperature measured before delivery in a similar plot as the curves for CRP and leukocytes. The area under the ROC curve was 0.61 , and there was no clear clinical useful cutoff point for maternal temperature to diagnose neonatal sepsis. 
Of the 299 included patients, 15 had a birth weight below the 10th percentile, of which three neonates had signs of infection. In these three neonates, maternal CRP values were $16 \mathrm{mg} / \mathrm{l}, 17 \mathrm{mg} / \mathrm{l}$ and $9 \mathrm{mg} / \mathrm{l}$, respectively, whereas in the 12 low-birth-weight neonates without signs of infection, maternal CRP values varied from $3 \mathrm{mg} / \mathrm{l}$ to $27 \mathrm{mg} / \mathrm{l}$. Thus, we did not find an indication that measuring CRP was useful in small-forgestational-age infants.

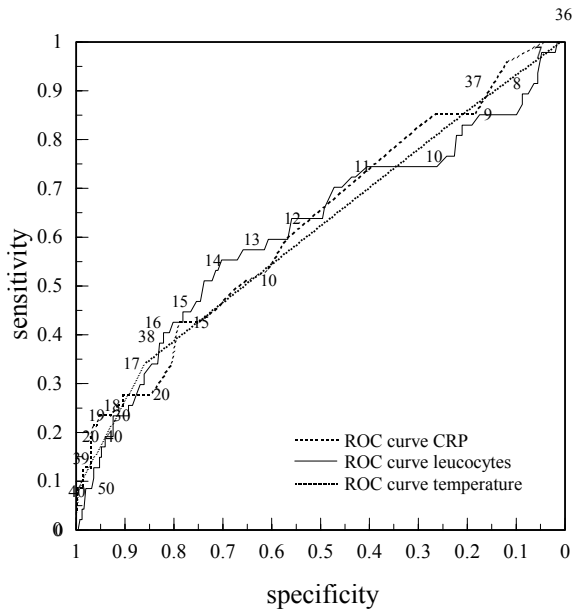

Figure 4.3 Combined receiver operating characteristic (ROC) curves of C-reactive protein (CRP), leukocytes and maternal temperature.

\section{Discussion}

We studied almost 300 women with PROM between 26 and 42 weeks' gestation. In the six children with early onset sepsis, maternal CRP last measured before birth did not rise above $50 \mathrm{mg} / \mathrm{l}$ and leukocyte values varied between 9.8 and $25.8 \times 10^{9} / \mathrm{l}$. CRP and leukocytes had an area under the ROC curve of only 0.61 and 0.62 in the prediction of clinical infection.

A possible limitation of this study is its retrospective character. In the study period, CRP and leukocytes might have been used in the decision to induce labour or to stop tocolysis. Although exact data on the number of patients in whom this occurred are not known, we do not think that this has a major impact on our results. Another limitation might be the subjectivity of the term "clinical infection". What some physicians might call a clinical infection might be interpreted as symptom(s) due to another cause by other physicians.

We tried to overcome this by making a list of possible symptoms of infection (e.g. tachypnea, feeding problems or hypothermia). If we could not find another explanation for these symptoms, we considered the symptom(s) as a clinical infection. Moreover, 
the diagnosis of clinical infection was made independently from the results of CRP and leukocytes.

Among the 386 included patients, 56 did not have CRP and leukocytes measured. As this was a retrospective study, it is inevitable that some data are missing. It is possible that some patients had contractions and delivered before these parameters could be measured. These missing values occurred at random rather than systematically.

The fact that the results of CRP and leukocytes were known to the clinician might have caused bias. However, the complete absence of an association between CRP and leukocytes on one hand and the occurrence of sepsis on the other hand can not be explained completely by this bias.

As this was a retrospective study with limited resources, we did not perform a power calculation prior to our study, but rather decided to collect data over the period 2003 to 2006 as this was within our possibilities. Few studies on diagnostic accuracy report considerations of sample size ${ }^{12}$. A post hoc power calculation showed that the sample size of 47 cases with suspected infection was large enough to rule out with $95 \%$ certainty that the sensitivity of either CRP or leukocytes was higher than $64 \%$. This is sufficient to conclude that the test is not useful in clinical practice. Similarly, the specificity was at maximum $56 \%$.

Previous studies have reported the predictive capacity of CRP and leukocyte measurement in patients with PROM in respect to chorioamnionitis. Conflicting results were found, but overall CRP was shown not to be predictive for the early diagnosis of chorioamnionitis. Only Hirsch et al studied the association between CRP and neonatal infection and hypothesized that CRP might help determine the risk of infection, especially in infants with low birth weight ${ }^{7}$.

At present, the effectiveness of induction of labour and expectant management in women with PPROM near term are evaluated in several multicenter trials ${ }^{4,13}$. In the PPROMEXIL trial, CRP and leukocytes in maternal serum are also measured. These data might provide new insight in the potential value of measuring CRP and leukocytes in maternal serum.

Because we found no evidence that measuring CRP and leukocytes in women with PROM is useful in the prediction of neonatal infection, we recommend that these parameters not be measured routinely these parameters in women with PROM. Particularly, these parameters should not be used to in the decision to induce labour or to maintain expectant management. Other factors, such as fetal tachycardia, fetid and/or green amniotic fluid, and maternal fever might be better indicators of intrauterine infection. Based on our study, we conclude that in women with PROM, CRP and white blood cells measured in maternal serum are poor predictors of neonatal infection. These parameters should therefore not be measured routinely in women with PROM. 


\section{References}

1. Modena $A B$, Kaihura $C$, Fieni S. Prelabour rupture of the membranes: recent evidence. Acta Biomed. 2004;75:5-10.

2. Neerhof MG, Cravello C, Haney El, Siver RK: Timing of labour induction after premature rupture of membranes between 32 and 36 weeks gestation. Am J Obstet Gynecol 1999;180:349-52.

3. Lieman JM, Brumfield CG, Carlo W: Preterm premature rupture of membranes: Is there an optimal gestational age for delivery? Obstet Gynecol 2005;105:12-7.

4. van der Ham DP, Nijhuis JG, Mol BW, van Beek JJ, Opmeer BC, Bijlenga D, Groenewout M, Arabin B, Bloemenkamp KW, van Wijngaarden WJ, Wouters MG, Pernet PJ, Porath MM, Molkenboer JF, Derks JB, Kars MM, Scheepers HC, Weinans MJ, Woiski MD, Wildschut HI, Willekes C. Induction of labour versus expectant management in women with preterm prelabour rupture of membranes between 34 and 37 weeks (the PPROMEXIL-trial). BMC Pregnancy Childbirth 2007;7:11.

5. Hirsch W, Koppitz D, Morack G, Gerhardt C. C-reactive protein in the maternal serum and risk of fetal infection in premature rupture of the fetal membranes and threatened premature labour. Zentralbl Gynakol 1989;111: 1411-6.

6. Salzer HR, Genger H, Muhar U. C-reactive protein: an early marker for neonatal bacterial infection due to prolonged rupture of amniotic membranes and/of amnionitis. Acta Obstet Gynaecol Scand 1987;66: 365-7.

7. Farb HF, Arnesen M, Geistler P, Knox GE. C-reactive protein with premature rupture of membranes and premature labour. Obstet Gynecol 1983;62:49-51.

8. Trochez-Martinez RD, Smith P, Lamont RF. Use of C-reactive protein as a predictor of chorioamnionitis in preterm prelabour rupture of membranes: a systematic review. BJOG 2007;114:796-801.

9. Kenyon S, Boulvain M, Neilson J. Antibiotics for preterm rupture of membranes. Cochrane Database Syst Rev 2003:CD001058.

10. Goldstein B, Giroir B, Randolph A. International pediatric sepsis consensus conference: Definitions for sepsis and organ dysfunction in pediatrics. Pediatr Crit Care Med 2005;6:2-8.

11. Bossuyt PM, Reitsma JB. Standards for Reporting of Diagnostic Accuracy; The STARD initiative. Lancet 2003;361:71.

12. Bachmann LM, Puhan MA, ter Riet G, Bossuyt PM. Sample sizes of studies on diagnostic accuracy: literature survey. BMJ 2006;332:1127-9.

13. Morris JM, Roberts CL, Crowther CA, Buchanan SL, Henderson-Smart DJ, Salkeld G. Protocol for the immediate delivery versus expectant care of women with preterm prelabour rupture of the membranes close to term (PPROMT) Trial (ISRCTN44485060). BMC Pregnancy Childbirth 2006;6:9 



\section{Chapter 5}

The accuracy of clinical parameters in the prediction of perinatal pulmonary hypoplasia secondary to midtrimester prelabour rupture of fetal membranes: A meta-analysis

van Teeffelen ASP, van der Ham DP, Oei SG, Porath MM, Willekes C, Mol BW

Eur J Obstet Gynecol Reprod Biol 2010;148:3-12 


\section{Abstract}

Prediction of pulmonary hypoplasia in women with midtrimester prelabour rupture of membranes (PPROM) is important for optimal management. We performed a systematic review to assess the capacity of clinical parameters to predict pulmonary hypoplasia. A systematic literature search in Embase and Medline was performed to identify articles published on pulmonary hypoplasia in relation to midtrimester PPROM. Articles were selected when they reported on one of the following clinical parameters - gestational age at PPROM, latency period and degree of oligohydramnios - , and when they allowed the construction of a two by two table comparing at least one of three clinical parameters to the occurrence of pulmonary hypoplasia. The selected studies were scored on methodological quality, and sensitivity and specificity of the tests in the prediction of pulmonary hypoplasia and lethal pulmonary hypoplasia were calculated. Overall performance was assessed by summary Receiver Operating Characteristic (sROC) curves that were constructed with bivariate meta-analysis. We detected 28 studies that reported on the prediction of pulmonary hypoplasia. Prediction of lethal pulmonary hypoplasia could be analysed separately in 21 of these studies. The quality of the included studies was poor. The estimated SROC curves showed that gestational age at PPROM performed significantly better than the two other parameters in the prediction of pulmonary hypoplasia. The accuracy in the prediction of lethal pulmonary hypoplasia was similar. In women with midtrimester PPROM, pulmonary hypoplasia can be predicted from the gestational age at PPROM. This information should be used in the management of women with early PPROM. 


\section{Introduction}

Midtrimester prelabour rupture of membranes is associated with an increased risk of altered pulmonary development leading to pulmonary hypoplasia. In fetal lung development a critical interval, the canalicular phase, exists between 16 an 28 weeks gestation. Preterm prelabour rupture of membranes (PPROM) before 26 to 28 weeks can delay lung development and can cause pulmonary hypoplasia ${ }^{1}$.

Pulmonary hypoplasia poses a serious threat due to its high mortality and morbidity rate. It can occur as severe respiratory failure leading to early neonatal death, as respiratory insufficiency with pulmonary haemorrhage, bronchopulmonary dysplasia, or subacute lung disease, or as mild and even transient respiratory disease ${ }^{2}$. Perinatal mortality approximates $70 \%$ in most series $(55-100 \%)^{3}$.

In a review of 11 studies on midtrimester PPROM, the reported incidence of pulmonary hypoplasia secondary to midtrimester PPROM ranged widely from 1 to $48 \%{ }^{4}$. In another review the reported incidence also varied widely from 0 to $24 \%{ }^{1}$. This wide range in prevalence is partly explained by the absence of uniform pathological and clinical definitions. Histological findings form the basis of the diagnosis, but autopsy is not always allowed or reported uniformly or informed consent is not obtained ${ }^{2}$. An international recognized definition of pulmonary hypoplasia does not exist, and it rather is a diagnosis par exclusionam ${ }^{5}$. Congenital pneumonia, Infant respiratory distress syndrome (IRDS) and pulmonary hypoplasia sometimes occur simultaneously, and have overlapping symptoms ${ }^{1}$. Moreover, there are methodological problems, such as differences in follow-up and lack of blinding.

Once midtrimester PPROM has occurred, an assessment of the probability of pulmonary hypoplasia is important both for clinical decision making and counselling of patients. Previous studies have shown that gestational age at the time of rupture of the membranes has a strong relation with the occurrence of pulmonary hypoplasia ${ }^{6,7}$. Other factors associated with pulmonary hypoplasia are the duration of the rupture of the membranes, and the degree of oligohydramnios ${ }^{8}$. To our knowledge, the predictive capacity of these clinical parameters for the presence of hypoplasia has not been assessed systematically. Therefore, we performed a meta-analysis on this subject. The aim of the present analysis was to assess the predictive capacity of clinical parameters in the prediction of pulmonary hypoplasia.

\section{Materials and methods}

We searched for studies that reported on neonatal outcome after midtrimester rupture of fetal membranes. We performed an electronic search of MEDLINE (Inception to 03/2008) and EMBASE (Inception to 03/2008), and checked reference lists of known 
reviews and primary articles to identify cited articles not captured by electronic searches. There were no language restrictions.

To be included, studies had to fulfil the following criteria. The study had to report on the outcome of pregnancies complicated by PPROM between 14 and 28 weeks of gestational age.

Neonatal outcomes after midtrimester PPROM had to include the presence of pulmonary hypoplasia. The diagnosis of pulmonary hypoplasia could either be based on clinical and radiological findings or on findings at autopsy. In the analysis we distinguished two types of hypoplasia, i.e. lethal hypoplasia and any form of hypoplasia. Lethal hypoplasia was defined as hypoplasia resulting in the death of the fetus or neonate due to hypoplasia. Fetuses with autopsy proven lung hypoplasia after early pregnancy termination were also included in the lethal group. Any form of hypoplasia was defined as the sum of lethal hypoplasia and non-lethal hypoplasia. For each study, we calculated the prevalence of any form of pulmonary hypoplasia, and if possible of lethal pulmonary hypoplasia.

Studies also had to report on one of the three clinical parameters gestational age at PPROM, latency between PPROM and delivery, or oligohydramnios. The method by which oligohydramnios was defined was also documented, if applicable.

The following characteristics of each study were registered: (1) sampling (consecutive versus other), (2) data collection (prospective versus retrospective), (3) study design (cohort study versus case-control study), (4) blinding (present or absent), (5) verification bias and (6) selection bias ${ }^{9}$. Study characteristics were scored by two of the authors (ASPVT and DvdH). In case of disagreement, the judgement of a third author (BWM) was decisive.

\section{Analysis}

\section{Data analysis}

For each study, we constructed a two by two table cross-classifying one or more of the three clinical parameters and the presence of any form of pulmonary hypoplasia, and if possible, of lethal pulmonary hypoplasia separately. Two-by-two tables were constructed independently by two of the authors (ASPvT and DvdH). In case of disagreement, the judgement of a third author (BWM) was decisive.

To visualise data we plotted for each model combinations of sensitivity and specificity in Receiver Operating Characteristic (ROC) plots. A bivariate meta-regression model was used to calculate pooled estimates of sensitivity and specificity for risk score cut-off values and to fit a summary ROC (sROC) curve. This method has been extensively described elsewhere ${ }^{10-13}$.

Briefly, rather than using a single outcome measure per study, like the diagnostic odds ratio, the bivariate model preserves the two-dimensional nature of diagnostic data in a single model. This model incorporates the correlation that may exist between 
sensitivity and specificity within studies due to possible differences in threshold between studies. The bivariate model uses a random effects approach for both sensitivity and specificity, allowing for heterogeneity beyond chance due to clinical or methodological differences between studies. In addition, the model acknowledges the difference in precision by which sensitivity and specificity have been measured in each study. This means that studies with a larger number of pregnancies resulting in pulmonary hypoplasia receive more weight in the calculation of the pooled estimate of sensitivity, while studies with more patients without hypoplasia are more influential in the pooling of specificity.

In case the sensitivity-specificity points were grouped alongside an imaginable underlying ROC-curve (i.e. studies with high sensitivity had relatively low specificity and vice versa), a SROC-curve was estimated, again using the bivariate model.

In case we looked at groups of studies that reported on the sensitivity-specificity points of multiple studies reporting on single cut-off value, for example a gestational age of 20 to 22 weeks, were grouped around an imaginable summary point-estimate, the pooled sensitivity and specificity were estimated with the bivariate model. This was done for gestational age below 18 weeks, 20 to 22 weeks, 23 to 24 weeks and above 25 weeks. For the latency period, i.e. the period between rupture of membranes and birth, we did so for more than 28 days, for more than 42 days and for more than 60 days. The way oligohydramnios was documented differed in the studies. Amniotic fluid index (AFI) technique, according to Rutherford ${ }^{14}$ has been used as well as the single deepest pocket (SDP) technique according to Chamberlain ${ }^{15}$. Also the amount nor the timing of measurements done throughout the latency period was uniform. Some authors used single measurements of amniotic fluid, whereas others used the mean or median of repeated measurements throughout the latency period. As our aim was to get a general impression on the prognostic accuracy of oligohydramnios, we considered any of the two definitions of oligohydramnios as abnormal test result.

The analysis was performed for the outcome 'any form of pulmonary hypoplasia'. After this a separate analysis was done on studies that allowed construction of two by two tables on the outcome 'lethal pulmonary hypoplasia'.

Finally, we compared the predictive capacity of all parameters with each other. The constructed SROC-curves for all parameters in the prediction of neonatal pulmonary hypoplasia were tested for statistical significant differences by entering the tests as covariate in the bivariate regression model. A p-value of $<0,05$ was supposed to indicate a significant difference of one parameter as compared to the other.

\section{Results}

Figure 5.1 summarises the literature identification and selection process. For the three parameters "gestational age at time of rupture", "latency" and "degree of 
oligohydramnios", the computerised search detected 694 articles on pulmonary hypoplasia of which 108 were retrieved after reading the abstracts. After reading the full papers, eight articles were excluded since they did not contain original data, six articles were excluded since they did not report on the predefined study population, eight articles were excluded since they were therapeutical intervention studies, 28 articles were excluded since they did not report on the presence of pulmonary hypoplasia, and 30 studies were excluded since two by two tables could not be derived, leaving 28 articles that were available for analysis on any form of hypoplasia. From these 28 studies, 21 studies allowed construction of two by two tables on lethal pulmonary hypoplasia. There were 22 studies that reported on gestational age at PPROM, 13 that reported on latency, and nine that reported on oligohydramnios. The total number of pregnancies included in these studies was 1337 . For the analysis on lethal hypoplasia the number of studies available was 19, 12 and five, respectively with in total 694 pregnancies.

\begin{tabular}{|c|c|c|}
\hline \multicolumn{2}{|c|}{$\begin{array}{l}\text { Total citations identified from electronic searches to capture primary articles on neonatal } \\
\text { outcome after midtrimester rupture of fetal membranes: }\end{array}$} & \multirow{2}{*}{$\begin{array}{l}\mathrm{n}=694 \\
\mathrm{n}=601\end{array}$} \\
\hline & $\begin{array}{l}\text { Citations excluded after screening titles and/or } \\
\text { abstracts: }\end{array}$ & \\
\hline \multicolumn{2}{|l|}{$\begin{array}{l}\text { Primary articles on neonatal outcome } \\
\text { Cross references articles retrieved: } \\
\text { Total: }\end{array}$} & $\begin{array}{l}\mathrm{n}=93 \\
\mathrm{n}=15 \\
\mathrm{n}=108\end{array}$ \\
\hline & $\begin{array}{l}\text { Articles excluded with reasons } \\
\text { Lack of data to construct } 2 \times 2 \text { table: } \\
\text { Lack of original data (reviews, letters etc.): } \\
\text { No reporting on pulmonary hypoplasia: } \\
\text { Study population not right: } \\
\text { Therapeutics intervention study: } \\
\text { Total excluded: }\end{array}$ & $\begin{array}{l}\mathrm{n}=30 \\
\mathrm{n}=8 \\
\mathrm{n}=28 \\
\mathrm{n}=6 \\
\mathrm{n}=8 \\
\mathrm{n}=80\end{array}$ \\
\hline \multicolumn{2}{|c|}{$\begin{array}{l}\text { Primary articles on any type of pulmonary hypoplasia after midtrimester rupture of fetal } \\
\text { membranes: }\end{array}$} & $\mathrm{n}=28$ \\
\hline & $\begin{array}{l}\text { No possibility to construct } 2 \times 2 \text { table on lethal } \\
\text { pulmonary hypoplasia: }\end{array}$ & $\mathrm{n}=7$ \\
\hline Primary articles on lethal pulmonary & oplasia after midtrimester rupture of fetal membra & $n=21$ \\
\hline
\end{tabular}

Figure 5.1 Process of literature identification and selection. 
In three studies the upper limit of the range of the risk period extended beyond 28 weeks $^{17,27,37}$. However, these studies were included since the large majority of patients was included at a gestational age below 28 weeks. Study characteristics of the 28 included studies are listed in Table 5.1. In 17 of the studies sampling of data was consecutive. Data collection was prospective in 18 studies, and 25 studies were designed as cohort studies. In only two studies blinding was performed. In the study of Laudy et al. $^{27}$ the radiologist was blinded to the sonographic measurements and the neonatal outcome, whereas in the study of Blott et al. ${ }^{16}$ the doctors establishing the diagnosis were unaware of the ultrasound findings i.e. the amount of amniotic fluid. Selection bias was present in 20 studies and absent in five studies, whereas in three it was unclear whether this was present. Selection biases most frequently seen were exclusion of stillbirths, exclusion of terminated pregnancies, inclusion of fetuses with severe malformations, and limitation of studies to pregnancies with established oligohydramnios. Verification bias was present in 10 studies. Fourteen studies did not have verification bias whereas in four studies presence of verification bias was unclear. Study characteristics are summarized in Figure 5.2.

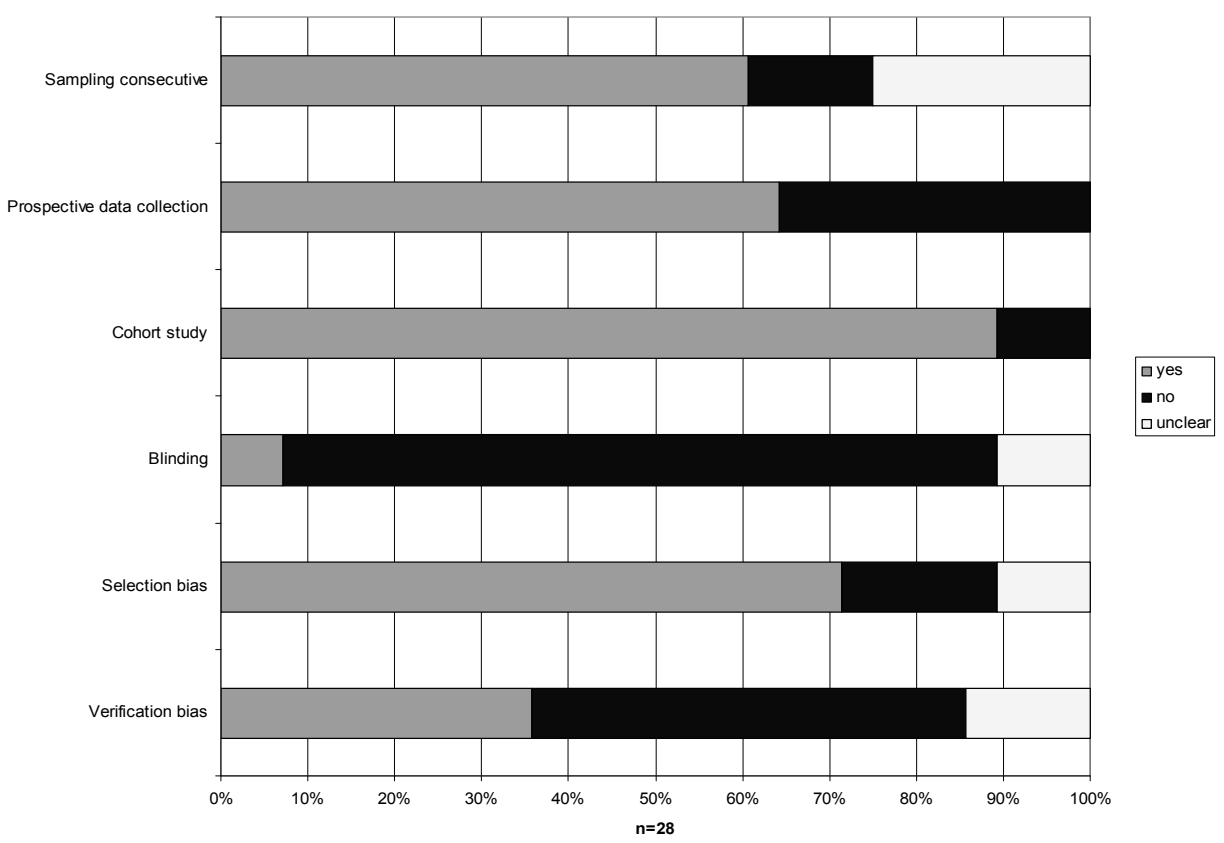

Figure 5.2 Study characteristics of the 28 detected studies. 


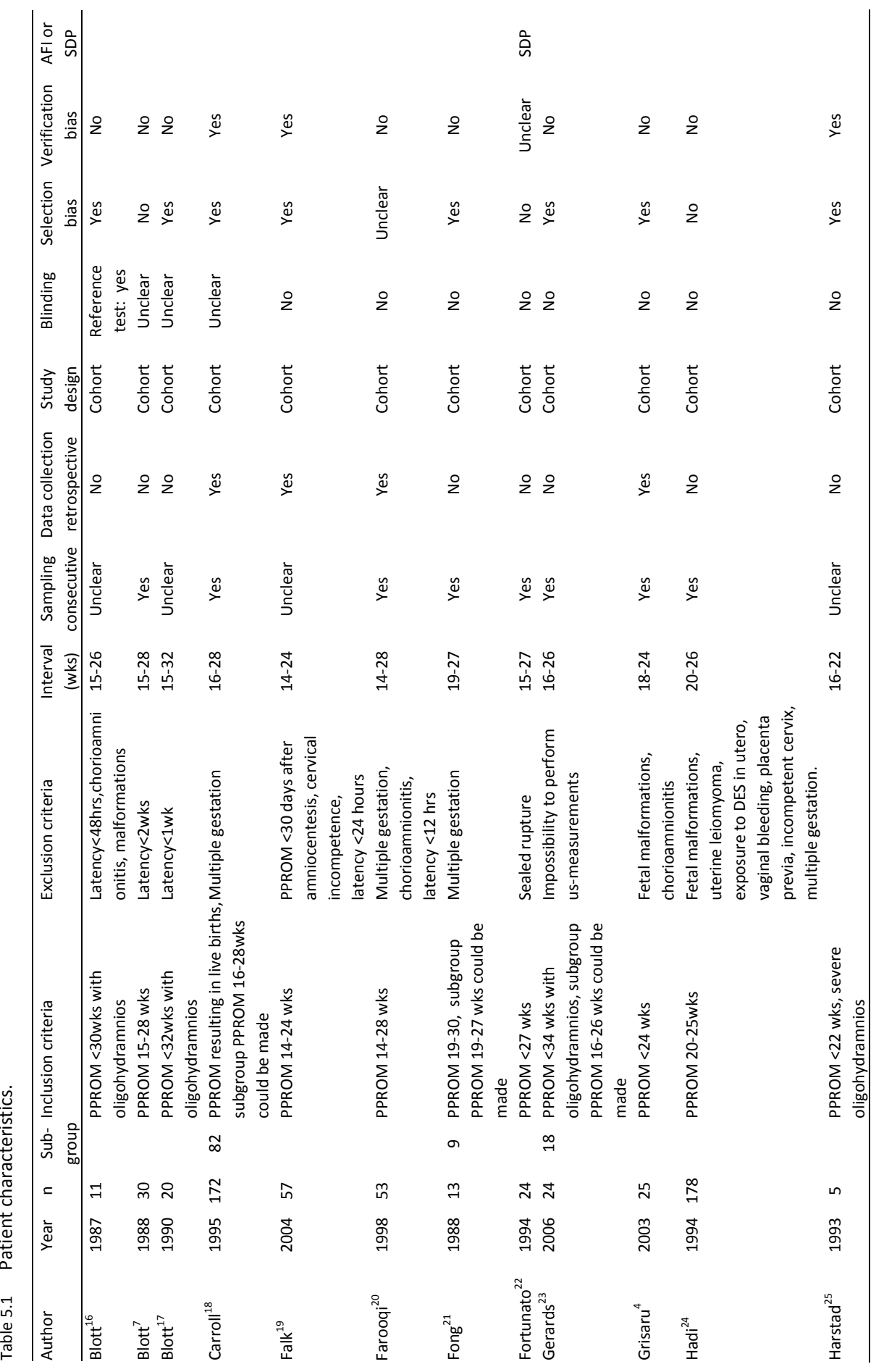




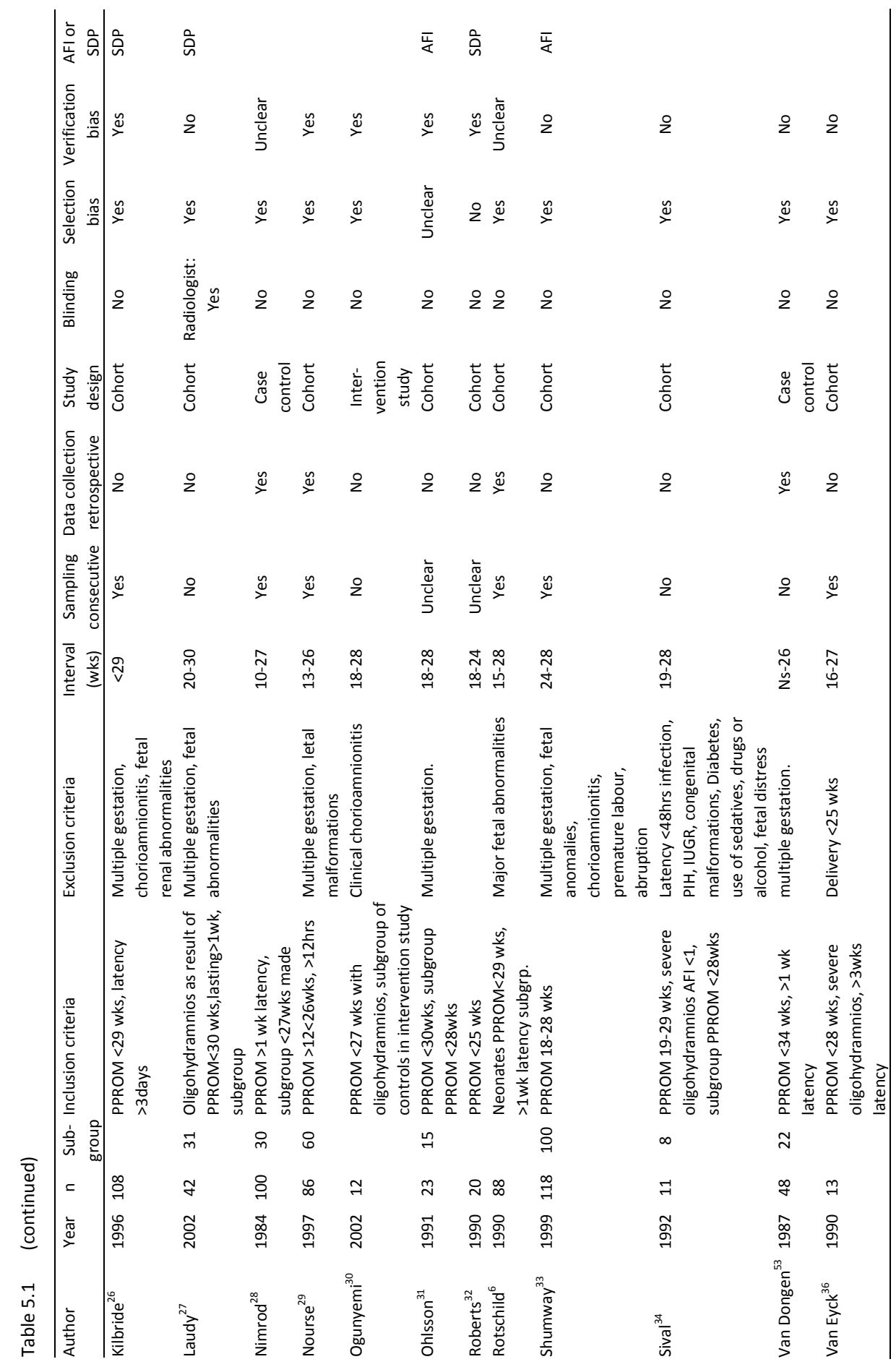




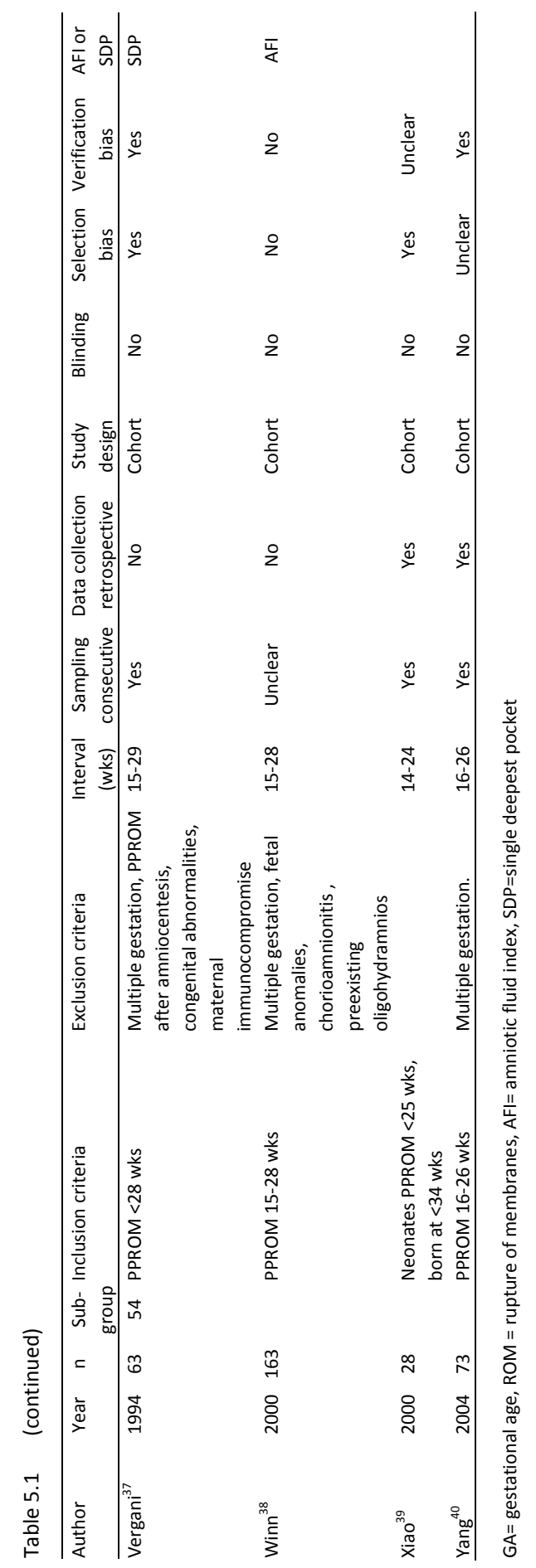


The sensitivities and specificities for gestational age at PPROM, for latency between rupture membranes and date of birth, and for oligohydramnios in the prediction of any form of pulmonary hypoplasia are summarised in Table 5.2. A plot of sensitivityspecificity points and a sROC-curve for predictive capacities of gestational age at PPROM for any form of pulmonary hypoplasia is shown in Figure 5.3A. Two studies reporting on a gestational age at PPROM below 18 weeks showed a sensitivity of $62 \%$ and a specificity of $73 \%$. For 20 to 22 weeks this was 70 and $73 \%$, for 23 to 24 weeks this was 90 and 58\%, whereas for cut-off values of 25 weeks and higher this was 96 and $48 \%$, respectively.

Table 5.2 Results for any type of pulmonary hypoplasia.

\begin{tabular}{|c|c|c|c|c|c|c|c|c|c|c|c|}
\hline \multirow[t]{2}{*}{ Author } & \multirow{2}{*}{$\begin{array}{l}\text { Number } \\
\text { of babies } \\
\text { with PH }\end{array}$} & \multirow[t]{2}{*}{$\mathrm{n}$} & \multicolumn{3}{|c|}{ Gestational age at rupture } & \multicolumn{3}{|c|}{ Latency } & \multicolumn{3}{|c|}{$\begin{array}{c}\text { Oligohydramnios } \\
\text { (by AFI or SDP method) }\end{array}$} \\
\hline & & & $\begin{array}{l}\text { cut-off in } \\
\text { weeks }\end{array}$ & $\begin{array}{l}\text { sensiti- } \\
\text { vity }\end{array}$ & $\begin{array}{c}\text { specifi- } \\
\text { city }\end{array}$ & $\begin{array}{l}\text { cut-off } \\
\text { in days }\end{array}$ & $\begin{array}{c}\text { sensiti- } \\
\text { vity }\end{array}$ & $\begin{array}{l}\text { specifi- } \\
\text { city }\end{array}$ & $\begin{array}{l}\text { cut-off in } \\
\text { oligo-hydra- } \\
\text { mnios }\end{array}$ & $\begin{array}{c}\text { sensiti- } \\
\text { vity }\end{array}$ & $\begin{array}{c}\text { specifi- } \\
\text { city }\end{array}$ \\
\hline \multirow[t]{3}{*}{ Blott '87 } & 5 & 11 & $<20$ & 0.60 & 0.50 & $>28$ & 0.40 & 0.33 & & & \\
\hline & & & $<27$ & 1.00 & 0.00 & $>42$ & 0.40 & 0.50 & & & \\
\hline & & & & & & $>70$ & 0.20 & 0.83 & & & \\
\hline \multirow[t]{5}{*}{ Blott ' 88} & 8 & 30 & $<16$ & 0.38 & 1.00 & $>28$ & 1.00 & 0.23 & & & \\
\hline & & & $<18$ & 0.63 & 0.73 & $>42$ & 0.75 & 0.36 & & & \\
\hline & & & $<20$ & 0.88 & 0.68 & $>56$ & 0.75 & 0.68 & & & \\
\hline & & & $<22$ & 1.00 & 0.59 & & & & & & \\
\hline & & & $<24$ & 1.00 & 0.41 & & & & & & \\
\hline Blott '90 & 5 & 20 & $<25$ & 1.00 & 0.60 & & & & & & \\
\hline \multirow[t]{4}{*}{ Carroll } & 16 & 82 & $<20$ & 0.56 & 0.88 & $>30$ & 0.81 & 0.48 & & & \\
\hline & & & $<24$ & 1.00 & 0.45 & $>60$ & 0.56 & 0.64 & & & \\
\hline & & & $<28$ & 1.00 & 0.00 & $>90$ & 0.13 & 0.82 & & & \\
\hline & & & & & & $>120$ & 0.00 & 0.96 & & & \\
\hline \multirow[t]{2}{*}{ Falk } & 3 & 57 & $<20$ & 1.00 & 0.67 & & & & & & \\
\hline & & & $<24$ & 1.00 & 0.00 & & & & & & \\
\hline \multirow[t]{3}{*}{ Farooqi } & 9 & 53 & $<20$ & 0.67 & 0.91 & $>28$ & 1.00 & 0.77 & & & \\
\hline & & & $<26$ & 1.00 & 0.43 & $>42$ & 0.89 & 0.64 & & & \\
\hline & & & $<28$ & 1.00 & 0.00 & $>56$ & 0.67 & 0.93 & & & \\
\hline \multirow[t]{3}{*}{ Fong } & 6 & 9 & $<22$ & 0.50 & 0.67 & $>28$ & 1.00 & 0.33 & & & \\
\hline & & & $<27$ & 1.00 & 0.00 & $>42$ & 1.00 & 0.00 & & & \\
\hline & & & & & & $>56$ & 0.67 & 1.00 & & & \\
\hline Fortunato & 1 & 24 & & & & & & & $\mathrm{SDP} \leq 1 \mathrm{~cm}$ & 1.00 & 0.70 \\
\hline \multirow[t]{2}{*}{ Gerards } & 6 & 18 & $<20$ & 0.33 & 0.58 & & & & & & \\
\hline & & & $<26$ & 1.00 & 0.25 & & & & & & \\
\hline \multirow[t]{2}{*}{ Grisaru } & 3 & 25 & $<22$ & 0.33 & 0.59 & & & & & & \\
\hline & & & $<24$ & 1.00 & 0.00 & & & & & & \\
\hline Hadi & 2 & 178 & & & & & & & $\mathrm{SDP} \leq 2 \mathrm{~cm}$ & 1.00 & 0.61 \\
\hline \multirow[t]{3}{*}{ Harstad } & 2 & 5 & $<21$ & 0.50 & 0.67 & $>28$ & 0.50 & 0.33 & & & \\
\hline & & & $<23$ & 1.00 & 0.00 & $>56$ & 0.50 & 0.33 & & & \\
\hline & & & & & & $>112$ & 0.50 & 1.00 & & & \\
\hline \multirow[t]{2}{*}{ Kilbride } & 23 & 108 & & & & & & & $\mathrm{SDP}<1 \mathrm{~cm}$ & 0.70 & 0.75 \\
\hline & & & & & & & & & $\mathrm{SDP}<2 \mathrm{~cm}$ & 0.83 & 0.60 \\
\hline
\end{tabular}


Table 5.2 (continued)

\begin{tabular}{|c|c|c|c|c|c|c|c|c|c|c|c|}
\hline \multirow[t]{2}{*}{ Author } & \multirow{2}{*}{$\begin{array}{l}\text { Number } \\
\text { of babies } \\
\text { with PH }\end{array}$} & \multirow[t]{2}{*}{$\mathrm{n}$} & \multicolumn{4}{|c|}{ Gestational age at rupture } & \multicolumn{2}{|l|}{ Latency } & \multicolumn{3}{|c|}{$\begin{array}{c}\text { Oligohydramnios } \\
\text { (by AFI or SDP method) }\end{array}$} \\
\hline & & & $\begin{array}{l}\text { cut-off in } \\
\text { weeks }\end{array}$ & $\begin{array}{l}\text { sensiti- } \\
\text { vity }\end{array}$ & $\begin{array}{l}\text { specifi- } \\
\text { city }\end{array}$ & $\begin{array}{l}\text { cut-off } \\
\text { in days }\end{array}$ & $\begin{array}{l}\text { sensiti- } \\
\text { vity }\end{array}$ & $\begin{array}{l}\text { specifi- } \\
\text { city }\end{array}$ & $\begin{array}{l}\text { cut-off in } \\
\text { oligo-hydra- } \\
\text { mnios }\end{array}$ & $\begin{array}{l}\text { sensiti- } \\
\text { vity }\end{array}$ & $\begin{array}{l}\text { specifi- } \\
\text { city }\end{array}$ \\
\hline \multirow[t]{3}{*}{ Laudy } & 9 & 31 & $<20$ & 0.78 & 0.77 & $>28$ & 1.00 & 0.41 & $\mathrm{SDP} \leq 1 \mathrm{~cm}$ & 0.78 & 0.82 \\
\hline & & & $<24$ & 1.00 & 0.45 & $>42$ & 1.00 & 0.50 & $S D P \leq 2 \mathrm{~cm}$ & 1.00 & 0.32 \\
\hline & & & $<26$ & 1.00 & 0.32 & $>56$ & 0.89 & 0.59 & & & \\
\hline \multirow[t]{2}{*}{ Nimrod '84 } & 8 & 30 & $<20$ & 0.25 & 0.82 & & & & & & \\
\hline & & & $<26$ & 1.00 & 0.00 & & & & & & \\
\hline \multirow[t]{2}{*}{ Nourse } & 10 & 60 & $<24$ & 1.00 & 0.78 & & & & & & \\
\hline & & & $<27$ & 1.00 & 0.00 & & & & & & \\
\hline \multirow[t]{3}{*}{ Ogunyemi } & 2 & 12 & $<22$ & 0.50 & 0.70 & $>14$ & 1.00 & 0.60 & & & \\
\hline & & & $<25$ & 1.00 & 0.10 & $>28$ & 0.50 & 0.80 & & & \\
\hline & & & $<28$ & 1.00 & 0.00 & $>42$ & 0.50 & 0.90 & & & \\
\hline \multirow[t]{3}{*}{ Ohlsson '91 } & 3 & 15 & $<22$ & 1.00 & 0.92 & $>28$ & 1.00 & 0.58 & $A F \mid<1 \mathrm{~cm}$ & 0.00 & 0.80 \\
\hline & & & $<26$ & 1.00 & 0.33 & $>42$ & 1.00 & 0.75 & $\mathrm{AFI}<5 \mathrm{~cm}$ & 1.00 & 0.25 \\
\hline & & & & & & $>56$ & 0.00 & 0.83 & & & \\
\hline \multirow[t]{3}{*}{ Roberts } & 12 & 20 & $<21$ & 0.25 & 1.00 & $>28$ & 0.42 & 0.75 & $\mathrm{SDP}<1 \mathrm{~cm}$ & 0.75 & 1.00 \\
\hline & & & $<23$ & 0.75 & 0.87 & $>42$ & 0.17 & 0.87 & $\mathrm{SDP}<2 \mathrm{~cm}$ & 1.00 & 0.37 \\
\hline & & & $<25$ & 1.00 & 0.00 & $>56$ & 0.17 & 0.87 & & & \\
\hline \multirow[t]{3}{*}{ Rotschild } & 14 & 88 & $<20$ & 0.36 & 0.96 & $>28$ & 0.75 & 0.25 & & & \\
\hline & & & $<22$ & 0.50 & 0.92 & $>42$ & 0.63 & 0.67 & & & \\
\hline & & & $<24$ & 0.57 & 0.84 & $>56$ & 0.50 & 0.83 & & & \\
\hline Shumway & 18 & 100 & & & & & & & $\mathrm{AFI}<5 \mathrm{~cm}$ & 0.72 & 0.45 \\
\hline \multirow[t]{3}{*}{ Sival } & 6 & 8 & $<22$ & 0.17 & 1.00 & $>28$ & 0.67 & 0.50 & & & \\
\hline & & & $<24$ & 0.67 & 0.50 & $>42$ & 0.50 & 0.50 & & & \\
\hline & & & $<26$ & 1.00 & 0.00 & $>56$ & 0.17 & 0.50 & & & \\
\hline \multirow[t]{2}{*}{ VanDongen } & 4 & 22 & $<20$ & 0.75 & 0.83 & & & & & & \\
\hline & & & $<26$ & 1.00 & 0.00 & & & & & & \\
\hline \multirow[t]{3}{*}{ Van Eyck } & 5 & 13 & $<20$ & 0.40 & 0.87 & $>42$ & 1.00 & 0.37 & & & \\
\hline & & & $<24$ & 0.60 & 0.75 & $>56$ & 0.40 & 0.75 & & & \\
\hline & & & $<28$ & 1.00 & 0.00 & & & & & & \\
\hline Vergani & 15 & 54 & & & & & & & $\mathrm{SDP}<2 \mathrm{~cm}$ & 1.00 & 0.38 \\
\hline Winn & 21 & 163 & & & & & & & $A F \mid<1 \mathrm{~cm}$ & 0.52 & 0.74 \\
\hline \multirow[t]{2}{*}{ Xiao } & 7 & 28 & $<22$ & 0.71 & 0.71 & & & & & & \\
\hline & & & $<26$ & 1.00 & 0.00 & & & & & & \\
\hline \multirow[t]{2}{*}{ Yang } & 8 & 73 & $<22$ & 0.88 & 0.71 & & & & & & \\
\hline & & & $<26$ & 1.00 & 0.00 & & & & & & \\
\hline
\end{tabular}

$\mathrm{PH}=$ Pulmonary hypoplasia; SDP = Single deepest pocket; AFI = Amniotic fluid index .

A plot of sensitivity-specificity points and a sROC-curve for predictive capacities of latency between rupture membranes and date of birth for any form pulmonary hypoplasia is shown in Figure 5.3B. Eleven studies reporting on a latency period of 28 days had a sensitivity of $85 \%$ and a specificity of $56 \%$. For a latency period of 42 days this was 76 and $61 \%$, for a latency period of 56 days this was 66 and $72 \%$, whereas for a latency period of 60 days or higher this was 35 and $74 \%$. 
A plot of sensitivity-specificity points and a sROC-curve for predictive capacities of oligohydramnios for any form of pulmonary hypoplasia is shown in Figure 5.3C. Six studies reporting on oligohydramnios $<1 \mathrm{~cm}$ had a sensitivity of $60 \%$ and a specificity of $75 \%$. For oligohydramnios $<2 \mathrm{~cm}$ this was 93 and $56 \%$, respectively.
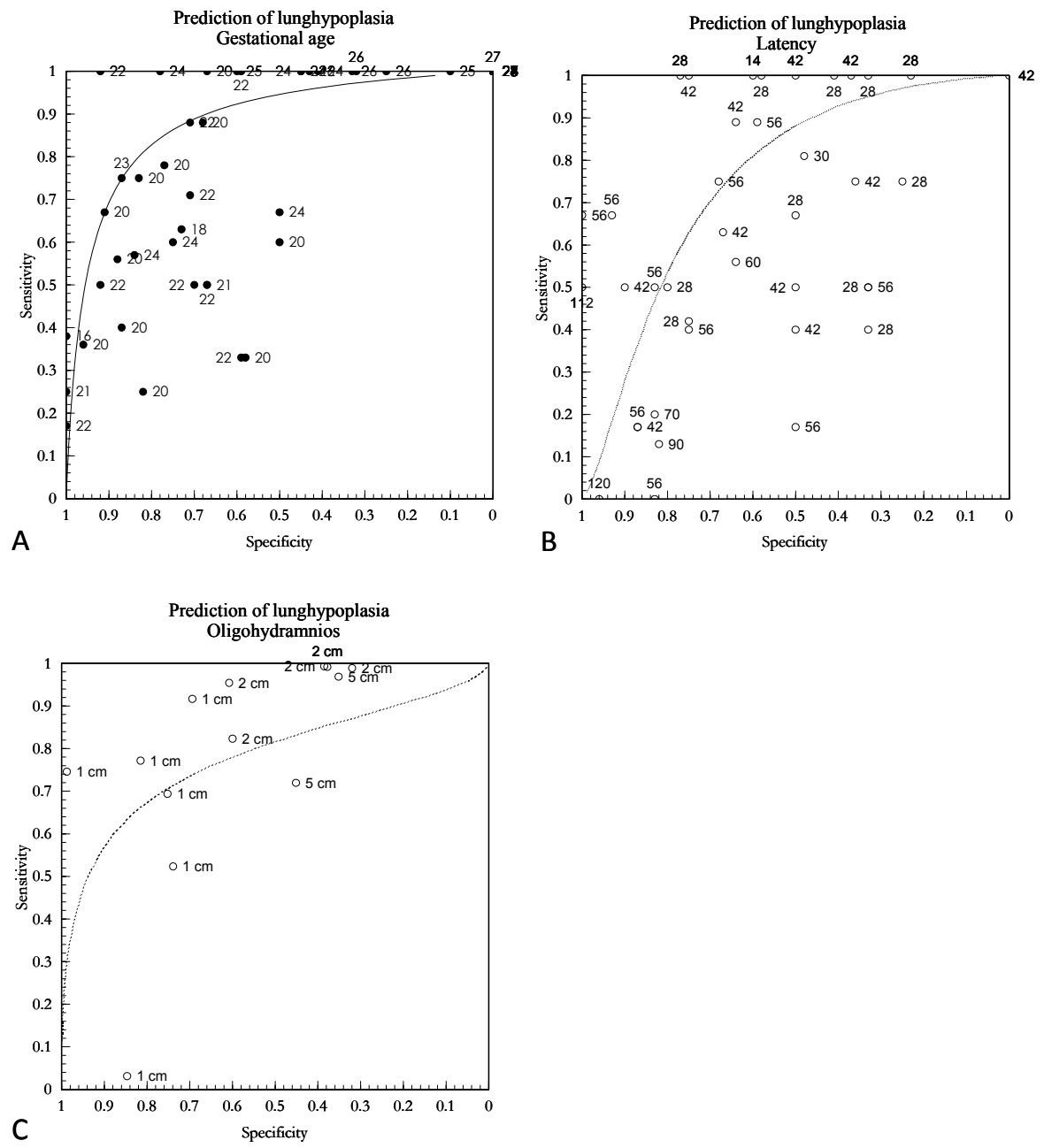

Figure 5.3 (A) Plot of sensitivity for 1 minus specificity - ROC plot for gestational age. Predictive capacities of gestational age at PPROM for any type of pulmonary hypoplasia. (B) Plot of sensitivity for 1 minus specificity - ROC plot for latency. Predictive capacities of latency between rupture membranes and date of birth for any type of pulmonary hypoplasia. (C) Plot of sensitivity for 1 minus specificity - ROC plot for oligohydramnion. Predictive capacities of oligohydramnion for any type of pulmonary hypoplasia. 
Figure 5.4 shows the three SROC curves for the prediction of any form of pulmonary hypoplasia together. The SROC curve for gestational age at PPROM performed better than both latency and oligohydramnios. The differences between the predictive capacities of the three parameters were statistically significant, with P-values of 0.0041 (gestational age versus latency) and 0.0329 (gestational age versus oligohydramnios), respectively.

The sensitivities and specificities of gestational age at PPROM, of latency between rupture of membranes and date of birth, and of oligohydramnios for prediction of the lethal form of pulmonary hypoplasia are summarised in Table 5.3. Figure 5.4 also shows the three $S R O C$ curves for the prediction of the lethal form of pulmonary hypoplasia.

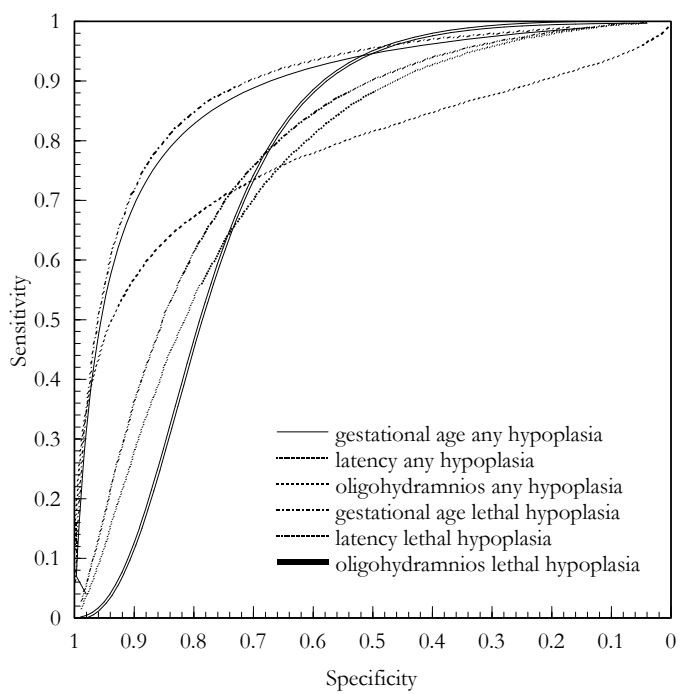

Figure 5.4 Receiver-operating-curve characteristic with the estimated summary ROC-curves for gestational age at PPROM, latency time and oligohydramnios for the prediction of lethal pulmonary hypoplasia and any hypoplasia. 
Table 5.3 Results for lethal pulmonary hypoplasia.

\begin{tabular}{|c|c|c|c|c|c|c|c|c|c|c|c|}
\hline \multirow[t]{2}{*}{ Author } & \multirow{2}{*}{$\begin{array}{l}\text { Number of } \\
\text { babies } \\
\text { with LPH }\end{array}$} & \multirow[t]{2}{*}{$\mathrm{n}$} & \multicolumn{3}{|c|}{ Gestational age at rupture } & \multicolumn{3}{|c|}{ Latency } & \multicolumn{3}{|c|}{$\begin{array}{l}\text { Oligohydramnios } \\
\text { (by AFI or SDP method) }\end{array}$} \\
\hline & & & $\begin{array}{l}\text { cut-off } \\
\text { levels in } \\
\text { weeks }\end{array}$ & $\begin{array}{l}\text { sensiti- } \\
\text { vity }\end{array}$ & $\begin{array}{l}\text { specifi- } \\
\text { city }\end{array}$ & $\begin{array}{l}\text { cut-off } \\
\text { levels in } \\
\text { days }\end{array}$ & $\begin{array}{l}\text { sensiti- } \\
\text { vity }\end{array}$ & $\begin{array}{l}\text { specifi- } \\
\text { city }\end{array}$ & $\begin{array}{l}\text { cut-off levels } \\
\text { in oligo- } \\
\text { hydra-mnios }\end{array}$ & $\begin{array}{l}\text { sensiti- } \\
\text { vity }\end{array}$ & $\begin{array}{l}\text { specifi- } \\
\text { city }\end{array}$ \\
\hline \multirow[t]{3}{*}{ Blott ' 87} & 5 & 11 & $<20$ & 0,60 & 0,50 & $>28$ & 0,40 & 0,67 & & & \\
\hline & & & $<27$ & 1,00 & 1,00 & $>42$ & 0,40 & 0,50 & & & \\
\hline & & & & & & $>70$ & 0,20 & 0,17 & & & \\
\hline \multirow[t]{5}{*}{ Blott '88 } & 8 & 30 & $<16$ & 0,38 & 0,00 & $>28$ & 1,00 & 0,77 & & & \\
\hline & & & $<18$ & 0,63 & 0,27 & $>42$ & 0,75 & 0,64 & & & \\
\hline & & & $<20$ & 0,88 & 0,32 & $>56$ & 0,75 & 0,32 & & & \\
\hline & & & $<22$ & 1,00 & 0,41 & & & & & & \\
\hline & & & $<24$ & 1,00 & 0,59 & & & & & & \\
\hline Blott '90 & 5 & 20 & $<25$ & 1,00 & 0,40 & & & & & & \\
\hline \multirow[t]{4}{*}{ Carroll } & 16 & 82 & $<20$ & 0,56 & 0,12 & $>30$ & 0,81 & 0,52 & & & \\
\hline & & & $<24$ & 1,00 & 0,55 & $>60$ & 0,56 & 0,36 & & & \\
\hline & & & $<28$ & 1,00 & 1,00 & $>90$ & 0,13 & 0,18 & & & \\
\hline & & & & & & $>120$ & 0,00 & 0,04 & & & \\
\hline \multirow[t]{2}{*}{ Falk } & 3 & 57 & $<20$ & 1,00 & 0,33 & & & & & & \\
\hline & & & $<24$ & 1,00 & 1,00 & & & & & & \\
\hline \multirow[t]{3}{*}{ Farooqi } & 7 & 53 & $<20$ & 0,86 & 0,09 & $>28$ & 1,00 & 0,26 & & & \\
\hline & & & $<26$ & 1,00 & 0,59 & $>42$ & 0,86 & 0,15 & & & \\
\hline & & & $<28$ & 1,00 & 1,00 & $>56$ & 0,57 & 0,11 & & & \\
\hline \multirow[t]{3}{*}{ Fong } & 4 & 9 & $<22$ & 0,75 & 0,20 & $>28$ & 1,00 & 0,80 & & & \\
\hline & & & $<27$ & 1,00 & 1,00 & $>42$ & 1,00 & 0,40 & & & \\
\hline & & & & & & $>56$ & 0,50 & 0,00 & & & \\
\hline \multirow[t]{2}{*}{ Gerards } & 6 & 18 & $<20$ & 0,33 & 0,42 & & & & & & \\
\hline & & & $<26$ & 1,00 & 0,75 & & & & & & \\
\hline \multirow[t]{2}{*}{ Grisaru } & 3 & 25 & $<22$ & 0,33 & 0,41 & & & & & & \\
\hline & & & $<24$ & 1,00 & 1,00 & & & & & & \\
\hline \multirow[t]{3}{*}{ Harstad } & 2 & 5 & $<21$ & 0,50 & 0,33 & $>28$ & 0,50 & 0,67 & & & \\
\hline & & & $<23$ & 1,00 & 1,00 & $>56$ & 0,50 & 0,67 & & & \\
\hline & & & & & & $>112$ & 0,50 & 0,00 & & & \\
\hline \multirow[t]{2}{*}{ Kilbride } & 23 & 108 & & & & & & & $\mathrm{SDP}<1 \mathrm{~cm}$ & 0,70 & 0,25 \\
\hline & & & & & & & & & $\mathrm{SDP}<2 \mathrm{~cm}$ & 0,83 & 0,40 \\
\hline \multirow[t]{3}{*}{ Laudy } & 9 & 31 & $<20$ & 0,78 & 0,23 & $>28$ & 1,00 & 0,59 & $\mathrm{SDP} \leq 1 \mathrm{~cm}$ & 0,78 & 0,18 \\
\hline & & & $<24$ & 1,00 & 0,55 & $>42$ & 1,00 & 0,50 & $\mathrm{SDP} \leq 2 \mathrm{~cm}$ & 1,00 & 0,68 \\
\hline & & & $<26$ & 1,00 & 0,68 & $>56$ & 0,89 & 0,41 & & & \\
\hline \multirow[t]{3}{*}{ Ogunyemi } & 2 & 12 & $<22$ & 0,50 & 0,30 & $>14$ & 1,00 & 0,40 & & & \\
\hline & & & $<25$ & 1,00 & 0,90 & $>28$ & 0,50 & 0,20 & & & \\
\hline & & & $<28$ & 1,00 & 1,00 & $>42$ & 0,50 & 0,10 & & & \\
\hline \multirow[t]{3}{*}{ Ohlsson '91 } & 3 & 15 & $<22$ & 1,00 & 0,08 & $>28$ & 1,00 & 0,42 & $\mathrm{AFI}<1 \mathrm{~cm}$ & 0,00 & 0,20 \\
\hline & & & $<26$ & 1,00 & 0,67 & $>42$ & 1,00 & 0,25 & $A F \mid<5 \mathrm{~cm}$ & 1,00 & 0,75 \\
\hline & & & & & & $>56$ & 0,00 & 0,17 & & & \\
\hline \multirow[t]{3}{*}{ Roberts } & 12 & 20 & $<21$ & 0,25 & 0,00 & $>28$ & 0,42 & 0,25 & $\mathrm{SDP}<1 \mathrm{~cm}$ & 0,75 & 0,00 \\
\hline & & & $<23$ & 0,75 & 0,13 & $>42$ & 0,17 & 0,13 & $\mathrm{SDP}<2 \mathrm{~cm}$ & 1,00 & 0,63 \\
\hline & & & $<25$ & 1,00 & 1,00 & $>56$ & 0,17 & 0,13 & & & \\
\hline
\end{tabular}


Table 5.3 (continued)

\begin{tabular}{|c|c|c|c|c|c|c|c|c|c|c|c|}
\hline \multirow[t]{2}{*}{ Author } & \multirow{2}{*}{$\begin{array}{l}\text { Number of } \\
\text { babies } \\
\text { with LPH }\end{array}$} & \multirow[t]{2}{*}{$\mathrm{n}$} & \multicolumn{3}{|c|}{ Gestational age at rupture } & \multicolumn{3}{|c|}{ Latency } & \multicolumn{3}{|c|}{$\begin{array}{c}\text { Oligohydramnios } \\
\text { (by AFI or SDP method) }\end{array}$} \\
\hline & & & $\begin{array}{l}\text { cut-off } \\
\text { levels in } \\
\text { weeks }\end{array}$ & $\begin{array}{c}\text { sensiti- } \\
\text { vity }\end{array}$ & $\begin{array}{l}\text { specifi- } \\
\text { city }\end{array}$ & $\begin{array}{l}\text { cut-off } \\
\text { levels in } \\
\text { days }\end{array}$ & $\begin{array}{c}\text { sensiti- } \\
\text { vity }\end{array}$ & $\begin{array}{l}\text { specifi- } \\
\text { city }\end{array}$ & $\begin{array}{l}\text { cut-off levels } \\
\text { in oligo- } \\
\text { hydra-mnios }\end{array}$ & $\begin{array}{c}\text { sensiti- } \\
\text { vity }\end{array}$ & $\begin{array}{c}\text { specifi- } \\
\text { city }\end{array}$ \\
\hline \multirow[t]{3}{*}{ Sival } & 4 & 8 & $<22$ & 0,00 & 0,25 & $>28$ & 0,50 & 0,75 & & & \\
\hline & & & $<24$ & 0,50 & 0,75 & $>42$ & 0,25 & 0,75 & & & \\
\hline & & & $<26$ & 1,00 & 1,00 & $>56$ & 0,00 & 0,50 & & & \\
\hline \multirow[t]{2}{*}{ VanDongen } & 4 & 22 & $<20$ & 0,75 & 0,17 & & & & & & \\
\hline & & & $<26$ & 1,00 & 1,00 & & & & & & \\
\hline \multirow[t]{3}{*}{ Van Eyck } & 4 & 13 & $<20$ & 0,50 & 0,11 & $>42$ & 0,75 & 0,56 & & & \\
\hline & & & $<24$ & 0,75 & 0,22 & $>56$ & 0,50 & 0,22 & & & \\
\hline & & & $<28$ & 1,00 & 1,00 & & & & & & \\
\hline Vergani & 14 & 54 & & & & & & & $S D P<2 \mathrm{~cm}$ & 1,00 & 0,63 \\
\hline \multirow[t]{2}{*}{ Xiao } & 5 & 28 & $<22$ & 1,00 & 0,26 & & & & & & \\
\hline & & & $<26$ & 1,00 & 1,00 & & & & & & \\
\hline Yang & 5 & 73 & $<22$ & 0,80 & 0,32 & & & & & & \\
\hline
\end{tabular}

$\mathrm{LPH}=$ Lethal pulmonary hypoplasia; SDP = Single deepest pocket; $\mathrm{AFI}=$ Amniotic fluid index.

\section{Discussion}

We included 28 studies that reported on the prediction of pulmonary hypoplasia in this review. Of these, 21 studies reported on lethal pulmonary hypoplasia specifically. The estimated SROC-curves showed that gestational age at PPROM performed significantly better than the two other parameters in the prediction of pulmonary hypoplasia. At a cut-off of 20 weeks, gestational age at PPROM had a sensitivity of $70 \%$ and a specificity of $73 \%$. At a gestational age of 25 weeks, sensitivity and specificity were 96 and $48 \%$ respectively. The accuracy of gestational age at PPROM in the prediction of lethal pulmonary hypoplasia was similar. Most of the studies that we have identified have focussed on pulmonary hypoplasia without restriction to the lethal form. This is important, as accurate prediction of lethal pulmonary hypoplasia before 24 weeks gives parents the chance to opt for termination of pregnancy. Moreover, this information could be of clinical relevance in women in whom discussions on interventions have to be made at gestational ages around viability of the child. In case the gestational age is low, and the risk of hypoplasia is very high, the decision for a pointless caesarean section could be delayed. For non-lethal pulmonary hypoplasia this is less straightforward, since termination of pregnancy is not justified as mild forms of pulmonary hypoplasia are also part of the clinical spectrum. Considering this, we aimed to assess the predictive capacities of the parameters in predicting pulmonary hypoplasia as well as lethal pulmonary hypoplasia. 
The aim of this study was to assess the risk of midtrimester PPROM. The upper limit of the canalicular fase is thought to be a gradual limit with the outer boundary at 28 weeks $^{2}$. Most studies on midtrimester PPROM have used 28 weeks as upper limit. Therefore, we chose 28 weeks as the upper limit of our inclusion interval rather than 26 weeks. However, we included three studies that exceeded the upper limit of the inclusion interval since the majority of patients in these studies was included at a gestational age below 28 weeks, and subgroups could not be made. The quality of the included studies was poor. This poor quality indicates that our estimates of sensitivity and specificity should not be considered as conclusive. However, we could not detect issues of poor quality that caused bias in a particular direction.

The assessment of oligohydramios varied in the frequency of measurements, the timing and the way they were defined (i.e. AFI or SDP). This makes definitive conclusions from this review on the role of oligohydramnios difficult. It has been suggested that spontaneous reaccumulation of amniotic fluid occurs in approximately $25 \%$ of cases of midtrimester PPROM ${ }^{24}$. Still, the presence of oligohydramnios on admission has been shown to correlate well with the average $\mathrm{AFI}^{26,37,38}$.

The way midtrimester PPROM was managed varied per study. Administration of tocolytics,

antibiotics and steroids was not applied uniformly. These interventions might have influenced the latency period. Treatment at a neonatal intensive care unit can decrease mortality figures. The studies we included range from 1984 until 2008. Advance in neonatal high care could have resulted in lower mortality figures in more recent studies, with subsequently a lower incidence in lethal pulmonary hypoplasia.

The reference test used in the various articles has, unfortunately, shown a great deal of variations and can be a source of heterogeneity. Clinical diagnosis of pulmonary hypoplasia is difficult to establish ${ }^{3}$. Some studies have mentioned the presence of a certain number of cases of pulmonary hypoplasia retrospectively. This implies no initial intention to identifying these cases. Other studies have intended to look for cases with pulmonary hypoplasia but not every diseased neonate was performed autopsy on. These and other studies did sometimes also not look for clinical signs of pulmonary hypoplasia. Finally the technique to diagnose pulmonary hypoplasia in autopsy varies widely. Three criteria used to define pulmonary hypoplasia are the lung weight/body weight ratio, the radial alveolar counts and the amount of DNA detected in lung tissue. Each of these three criteria are having their own advantages and disadvantages ${ }^{26,43}$. All these factors account for a considerable verification bias. However, these are the only available data and thus they provide the best available evidence at present.

There is debate about the possible interaction of latency and gestational age at rupture $8,37,38,44$. Theoretically, the effect of latency on the occurrence of pulmonary hypoplasia could be influenced by the gestational age at PPROM, since it has been observed that early PPROM is related to longer latency. Also, it has been observed that a higher degree of oligohydramnios is associated with a shorter latency ${ }^{37}$. There 
remains controversy on the role of latency on the occurrence of pulmonary hypoplasia. To our knowledge, at least two studies with larger sample sizes conclude that latency has an independent role ${ }^{26,38}$. Our review does not shed any more light on this issue.

It was shown that predictive capacities for lethal pulmonary hypoplasia and for pulmonary hypoplasia including the non-lethal form do not vary extensively. If the test is used in the decision for termination of pregnancy a positive predictive value close to $100 \%$ is required. This implies the need for a test (or combination of tests) with a very high (combined) specificity. Laudy ${ }^{27}$ was able to reach $100 \%$ positive predictive value combining clinical, biometric and Doppler parameters with a sensitivity of $71 \%$.

In conclusion, we found that gestational age at PPROM was a better predictor of pulmonary hypoplasia than latency and oligohydramnios. This is in line with the existing literature. The predictive capacities for pulmonary hypoplasia including the non-lethal form were similar. Obviously, better quality studies with larger samples on the issue are needed. In view of the low prevalence of midtrimester PPROM $(0,7 \%$ of pregnancies), this requires studies performed in a multicenter setting. Uniform definitions of pulmonary hypoplasia are a prerequisite at the start of such studies. 


\section{References}

1. Kilbride HW, Thibeault DW. Neonatal complications of preterm rupture of membranes. Clin Perinatol 2001;28:761-85.

2. Sherer DM, Davis JM, Woods JR Jr. Pulmonary hypoplasia: a review. Obstet Gynecol Surv 1990;45: 792-803.

3. Laudy JA, Wladimiroff JW. The fetal lung. 2: Pulmonary hypoplasia. Ultrasound Obstet Gynecol 2000;16:482-94

4. Grisaru-Granovsky S, Eitan R, Kaplan M, Samueloff A. Expectant management of midtrimester premature rupture of membranes: a plea for limits. J Perinatol 2003;23:235-9.

5. Geary C, Whitsett J. Inhaled nitric oxide for oligohydramnios-induced pulmonary hypoplasia: a report of two cases and review of the literature. J Perinatol 2002;22:82-5.

6. Rotschild A, Ling EW, Puterman ML, Farquharson D.Neonatal outcome after prolonged preterm rupture of the membranes.Am J Obstet Gynecol 1990;162:46-52.

7. Blott M, Greenough A. Neonatal outcome after prolonged rupture of the membranes starting in the second trimester. Arch Dis Child 1988;63:1146-50.

8. Schucker JL, Mercer BM. Midtrimester premature rupture of the membranes. Semin Perinatol 1996; 20:389-400.

9. Lijmer JG, Mol BW, Heisterkamp S, Bonsel GJ, Prins MH, van der Meulen JH, Bossuyt PM. Empirical evidence of design-related bias in studies of diagnostic tests. JAMA 1999;282:1061-6.

10. Van Houwelingen HC, Zwinderman KH, Stijnen T. A bivariate approach to meta-analysis. Stat Med 1993; 12:2273-84.

11. Van Houwelingen HC, Arends LR, Stijnen T. Advanced methods in meta-analysis: multivariate approach and meta-regression. Stat Med 2002 28;21:589-624.

12. Reitsma JB, Glas AS, Rutjes AW, Scholten RJ, Bossuyt PM, Zwinderman AH. Bivariate analysis of sensitivity and specificity produces informative summary measures in diagnostic reviews. J Clin Epidemiol 2005;58:982-90.

13. Arends LR, Hamza TH, Van Houwelingen HC, Heijenbrok KMH, Hunink MGM, Stijnen T. Multivariate random-effects meta-analysis of ROC-curves. Med Decis Making 2006.

14. Rutherford SE, Phelan JP, Smith CV, Jacobs N. The four-quadrant assessment of amniotic fluid volume: an adjunct to antepartum fetal heart rate testing. Obstet Gynecol 1987;70:353-6.

15. Chamberlain PF, Manning FA, Morrison I, Harman CR, Lange IR. Ultrasound evaluation of amniotic fluid volume. I. The relationship of marginal and decreased amniotic fluid volumes to perinatal outcome. Am J Obstet Gynecol 1984;150:245-9.

16. Blott M, Greenough A, Nicolaides KH, Moscoso G, Gibb D, Campbell S. Fetal breathing movements as predictor of favourable pregnancy outcome after oligohydramnios due to membrane rupture in second trimester. Lancet 1987;2:129-31.

17. Blott M, Greenough A, Nicolaides KH, Campbell S. The ultrasonographic assessment of the fetal thorax and fetal breathing movements in the prediction of pulmonary hypoplasia. Early Hum Dev 1990; 21:143-51.

18. Carroll SG, Blott M, Nicolaides KH. Preterm prelabour amniorrhexis: outcome of live births. Obstet Gynecol 1995;86:18-25.

19. Falk SJ, Campbell L, Lee-Parritz A, Cohen AP, Ecker J, Wilkins-Haug L, Lieberman E. Expectant management in spontaneous preterm premature rupture of membranes between 14 and 24 weeks' gestation. J Perinatol 2004;24:611-6.

20. Farooqi A, Holmgren PA, Engberg S, Serenius F. Survival and 2-year outcome with expectant management of second-trimester rupture of membranes. Obstet Gynecol 1998;92:895-901.

21. Fong K, Ohlsson A, Zalev A. Fetal thoracic circumference: a prospective cross-sectional study with realtime ultrasound. Am J Obstet Gynecol. 1988; 158(5):1154-60. Erratum in: Am J Obstet Gynecol 1990; 163:1363.

22. Fortunato SJ, Welt SI, Eggleston MK Jr, Bryant EC. Active expectant management in very early gestations complicated by premature rupture of the fetal membranes. J Reprod Med 1994;39:13-6. 
23. Gerards FA, Twisk JW, Fetter WP, Wijnaendts LC, Van Vugt JM. Two- or three-dimensional ultrasonography to predict pulmonary hypoplasia in pregnancies complicated by preterm premature rupture of the membranes. Prenat Diagn 2007;27:216-21.

24. Hadi HA, Hodson CA, Strickland D. Premature rupture of the membranes between 20 and 25 weeks' gestation: role of amniotic fluid volume in perinatal outcome. Am J Obstet Gynecol 1994;170:1139-44.

25. Harstad TW, Twickler DM, Leveno KJ, Brown CE. Antepartum prediction of pulmonary hypoplasia: an elusive goal? Am J Perinatol 1993;10:8-11.

26. Kilbride HW, Yeast J, Thibeault DW. Defining limits of survival: lethal pulmonary hypoplasia after midtrimester premature rupture of membranes. Am J Obstet Gynecol 1996;175:675-81.

27. Laudy JA, Tibboel D, Robben SG, de Krijger RR, de Ridder MA, Wladimiroff JW. Prenatal prediction of pulmonary hypoplasia: clinical, biometric, and Doppler velocity correlates. Pediatrics 2002;109:250-8.

28. Nimrod C, Varela-Gittings F, Machin G, Campbell D, Wesenberg R. The effect of very prolonged membrane rupture on fetal development. Am J Obstet Gynecol 1984;148:540-3.

29. Nourse CB, Steer PA. Perinatal outcome following conservative management of mid-trimester prelabour rupture of the membranes. J Paediatr Child Health 1997;33:125-30.

30. Ogunyemi D, Thompson W. A case controlled study of serial transabdominal amnioinfusions in the management of second trimester oligohydramnios due to premature rupture of membranes. Eur J Obstet Gynecol Reprod Biol 2002;102:167-72.

31. Ohlsson A, Fong K, Hannah M, Heyman Z, Gonen R, Rose T, Baboolal R. Prediction of lethal pulmonary hypoplasia and chorioamnionitis by assessment of fetal breathing. Br J Obstet Gynaecol 1991;98:692-7.

32. Roberts $A B$, Mitchell JM. Direct ultrasonographic measurement of fetal lung length in normal pregnancies and pregnancies complicated by prolonged rupture of membranes. Am J Obstet Gynecol 1990;163:1560-6.

33. Shumway JB, Al-Malt A, Amon E, Cohlan B, Amini S, Abboud M, Winn HN. Impact of oligohydramnios on maternal and perinatal outcomes of spontaneous premature rupture of the membranes at 18-28 weeks. J Matern Fetal Med 1999;8:20-3.

34. Sival DA, Visser GH, Prechtl HF. Fetal breathing movements are not a good indicator of lung development after premature rupture of membranes and oligohydramnios--a preliminary study. Early Hum Dev 1992;28:133-43.

35. van Dongen PW, Antonissen J, Jongsma HW, Sporken JM, Hein PR. Lethal lung hypoplasia in infants after prolonged rupture of membranes. Eur J Obstet Gynecol Reprod Biol 1987;25:287-92.

36. van Eyck J, van der Mooren K, Wladimiroff JW. Ductus arteriosus flow velocity modulation by fetal breathing movements as a measure of fetal lung development. Am J Obstet Gynecol 1990;163:558-66.

37. Vergani P, Ghidini A, Locatelli A, Cavallone M, Ciarla I, Cappellini A, Lapinski RH. Risk factors for pulmonary hypoplasia in second-trimester premature rupture of membranes. Am J Obstet Gynecol 1994;170:1359-64.

38. Winn HN, Chen M, Amon E, Leet TL, Shumway JB, Mostello D. Neonatal pulmonary hypoplasia and perinatal mortality in patients with midtrimester rupture of amniotic membranes--a critical analysis. Am J Obstet Gynecol 2000;182:1638-44.

39. Xiao ZH, André P, Lacaze-Masmonteil T, Audibert F, Zupan V, Dehan M. Outcome of premature infants delivered after prolonged premature rupture of membranes before 25 weeks of gestation. Eur J Obstet Gynecol Reprod Biol 2000;90:67-71.

40. Yang LC, Taylor DR, Kaufman HH, Hume R, Calhoun B. Maternal and fetal outcomes of spontaneous preterm premature rupture of membranes. J Am Osteopath Assoc 2004;104:537-42.

41. Taylor J, Garite TJ. Premature rupture of membranes before fetal viability. Obstet Gynecol 1984; 64:615-20.

42. Major CA, Kitzmiller JL. Perinatal survival with expectant management of midtrimester rupture of membranes. Am J Obstet Gynecol 1990;163:838-44.

43. Thibeault DW, Beatty EC Jr, Hall RT, Bowen SK, O'Neill DH. Neonatal pulmonary hypoplasia with premature rupture of fetal membranes and oligohydramnios. J Pediatr 1985;107:273-7.

44. Lauria MR, Gonik B, Romero R. Pulmonary hypoplasia: pathogenesis, diagnosis, and antenatal prediction. Obstet Gynecol 1995;86:466-75. 


\section{Chapter 6

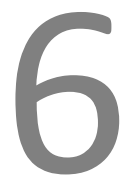

Accuracy of imaging parameters in the prediction of

lethal pulmonary hypoplasia secondary to mid-

trimester prelabour rupture of fetal membranes: a

systematic review and meta-analysis

van Teeffelen ASP, van der Heyden JL, Oei SG, Porath MM, Willekes C, Opmeer B, Mol BW

Ultrasound Obstet Gynecol 2012;39:495-499 


\section{Abstract}

In women who have suffered midtrimester prelabour rupture of membranes (PPROM) prediction of pulmonary hypoplasia is important for optimal management. We performed a systematic review to assess the capacity of imaging parameters to predict pulmonary hypoplasia. We searched articles that reported on biometrical parameters and allowed the construction of a two by two table comparing at least one of these parameters to the occurrence of pulmonary hypoplasia. The selected studies were scored on methodological quality, and we calculated sensitivity and specificity of the tests in the prediction of pulmonary hypoplasia and lethal pulmonary hypoplasia. Overall performance was assessed by summary Receiver Operating Characteristic (sROC) analyses that were performed with bivariate meta-analysis.

We detected 13 studies that reported on the prediction of lethal pulmonary hypoplasia. The quality of the included studies was poor to mediocre. The estimated SROC-curves for the chest circumference/abdominal circumference ratio and other parameters showed limited accuracy in the prediction of pulmonary hypoplasia.

In women with midtrimester PPROM, the available evidence indicates limited accuracy of biometric parameters in the prediction of pulmonary hypoplasia. 


\section{Introduction}

In fetal lung development there is a critical interval, the canalicular phase, between 16 and 28 weeks' gestation. Preterm prelabour rupture of membranes (PPROM) before 28 weeks can delay lung development thus causing pulmonary hypoplasia ${ }^{1}$. Pulmonary hypoplasia poses a serious threat due to its high mortality and morbidity rate. It can occur as severe respiratory failure leading to early neonatal death, as respiratory insufficiency with pulmonary haemorrhage, bronchopulmonary dysplasia, or subacute lung disease, or as mild and even transient respiratory disease ${ }^{2}$. Perinatal mortality approximates $70 \%$ in most series $(55-100 \%)^{3}$.

Once midtrimester PPROM has occurred, assessment of the probability of pulmonary hypoplasia is important both for clinical decision making and counselling of patients. In a recent meta-analysis we assessed the predictive capacity of clinical parameters - gestational age at PPROM, latency period and degree of oligohydramnios for the presence of hypoplasia ${ }^{4}$. The gestational age at which PPROM occurred was a significantly better predictor than the latency period and degree of oligohydramnios for the occurrence of pulmonary hypoplasia. The accuracy in the prediction of the lethal variant of pulmonary hypoplasia was similar.

Biometric parameters assessed by ultrasound (two- or threedimensional, Doppler) or MRI have also been proposed as instruments to predict pulmonary hypoplasia following PPROM. To our knowledge, the predictive capacity of these parameters for the presence of hypoplasia after midtrimester PPROM specifically has not been assessed systematically. We therefore performed this meta-analysis to assess the capacity of biometric parameters assessed with ultrasound or MRI to predict pulmonary hypoplasia following mid-trimester PPROM.

\section{Materials and methods}

We searched the literature for studies that reported on neonatal outcome after midtrimester PPROM, using combinations of the following search terms: pregnancy, oligohydramnios, fetal membranes - premature rupture, diagnostic imaging, fetal diseases, respiratory system,

fetal mortality, fetal death, infant mortality, pulmonary hypoplasia, lung hypoplasia, lung diseases and respiratory system. We performed an electronic search of MEDLINE (inception to 05-3-2011) and EMBASE (inception to 05-03-2011) and checked reference lists of known reviews and primary articles to identify cited articles not captured by electronic searches. Language restrictions were not applied.

The selection process was performed by one of the authors (A.S.P.v.T.). To be selected for inclusion, a study had to report on the outcome of pregnancies complicated by PPROM between 14 and 27 completed weeks of gestational age, in which any 
ultrasound or MRI parameter was used with the goal of predicting pulmonary hypoplasia. The diagnosis of pulmonary hypoplasia could be based either on clinical and radiological findings or on findings at autopsy. For the purposes of analysis we distinguished two types of hypoplasia: lethal hypoplasia and any form of hypoplasia. Lethal hypoplasia was defined as hypoplasia resulting in the death of the fetus or neonate due to hypoplasia. Fetuses with lung hypoplasia proven on autopsy after early pregnancy termination were also included in the lethal group. Any form of hypoplasia was defined as the sum of all cases of hypoplasia, both lethal and non-lethal. We chose not to include cases of oligohydramnios caused by conditions other than mid-trimester PPROM, since these are other entities, with their own specific pathophysiology which might have influenced the outcome of our review. Moreover, the biometric indices studied in this review might have been influenced by these conditions, for example measurements in foetuses with polycystic kidneys or obstructive uropathy might be influenced by subsequent abdominal enlargement ${ }^{5}$.

Studies had to report on any ultrasound or MRI parameter that was used with the goal of predicting pulmonary hypoplasia. The following characteristics of each study were noted: (1) sampling (consecutive or other), (2) data collection (prospective or retrospective) (3) study design (cohort study or case-control study), (4) blinding (present or absent), (5) verification bias (present or absent) and (6) selection bias (present or absent) ${ }^{6}$.

\section{Analysis}

\section{Data analysis}

For each published study, its characteristics were scored by two of the authors (A.S.P.v.T. and J.v.d.H.), who each constructed independently a $2 \times 2$ table crossclassifying one or more of the imaging parameters with the presence of pulmonary hypoplasia. In case of disagreement, the judgement of a third author (B.W.J.M.) was decisive. It appeared that all but two studies found were aimed at diagnosing lethal rather than any form of pulmonary hypoplasia. Therefore, we limited the outcome in this review to lethal hypoplasia.

To visualize the data, for each model we combined sensitivity and specificity in the form of a receiver-operating characteristics (ROC) curve. A bivariate meta-regression model was used to calculate summary estimates of sensitivity and specificity for predictive values and to fit summary ROC (sROC) curves. The bivariate method has been described extensively elsewhere ${ }^{7-10}$. Briefly, rather than using a single outcome measure per study, such as the diagnostic odds ratio, the bivariate model preserves the twodimensional nature of diagnostic data in a single model. This model incorporates the correlation that may exist between sensitivity and specificity within studies due to possible differences in threshold between studies. The bivariate model uses a random 
effects approach for both sensitivity and specificity, allowing for heterogeneity beyond chance due to clinical or methodological differences between studies. In addition, the model acknowledges the difference in precision by which sensitivity and specificity have been measured in each study. This means that studies with a larger number of pregnancies resulting in lethal pulmonary hypoplasia receive more weight in the calculation of the pooled estimate of sensitivity, while studies with more patients without hypoplasia are more influential in the pooling of specificity.

When individual study sensitivity-specificity points were grouped close to an imaginary underlying ROC curve (i.e. studies with high sensitivity had relatively low specificity and vice versa), an sROC-curve was drawn using parameter estimates from the bivariate model $^{11}$.

Differences in the capacity of all parameters to predict lethal pulmonary hypoplasia were tested for statistical significance by entering the tests as covariates in the bivariate regression model. $\mathrm{P}<0.05$ was taken to indicate a significant difference of one parameter as compared with the other.

\section{Results}

Figure 6.1 summarizes the identification and selection process of the thirteen published studies included in this meta-analysis ${ }^{12-24}$. All studies reported on ultrasound parameters, and one also evaluated (two-dimensional) MRI parameters. Study characteristics of the 13 included studies are listed in Table 6.1. In two of the studies, sampling of data was consecutive. Data collection was prospective in all studies, and all studies were designed as cohort studies.

\begin{tabular}{|c|c|c|}
\hline \multicolumn{2}{|c|}{$\begin{array}{l}\text { Total citations identified from electronic searches to capture primary articles on diagnostic } \\
\text { imaging and neonatal outcome after midtrimester rupture of fetal membranes: }\end{array}$} & $n=497$ \\
\hline & $\begin{array}{l}\text { Citations excluded after screening titles and/or } \\
\text { abstracts: }\end{array}$ & $\mathrm{n}=478$ \\
\hline \multicolumn{2}{|c|}{$\begin{array}{l}\text { Primary articles on diagnostic imaging and neonatal outcome after midtrimester rupture of fetal } \\
\text { membranes: } \\
\text { Cross references articles retrieved: } \\
\text { Total: }\end{array}$} & $\begin{array}{l}n=19 \\
n=17 \\
n=36\end{array}$ \\
\hline & $\begin{array}{l}\text { No data to construct } 2 \times 2 \text { table: } \\
\text { No original data (reviews, letters) } \\
\text { No report on pulmonary hypoplasia } \\
\text { Study population not right:: } \\
\text { Total excluded: }\end{array}$ & $\begin{array}{l}\mathrm{n}=3 \\
\mathrm{n}=3 \\
\mathrm{n}=3 \\
\mathrm{n}=14 \\
\mathrm{n}=23\end{array}$ \\
\hline Eligible for review & & $\mathrm{n}=13$ \\
\hline
\end{tabular}

Figure 6.1 Process of literature identification and selection. 


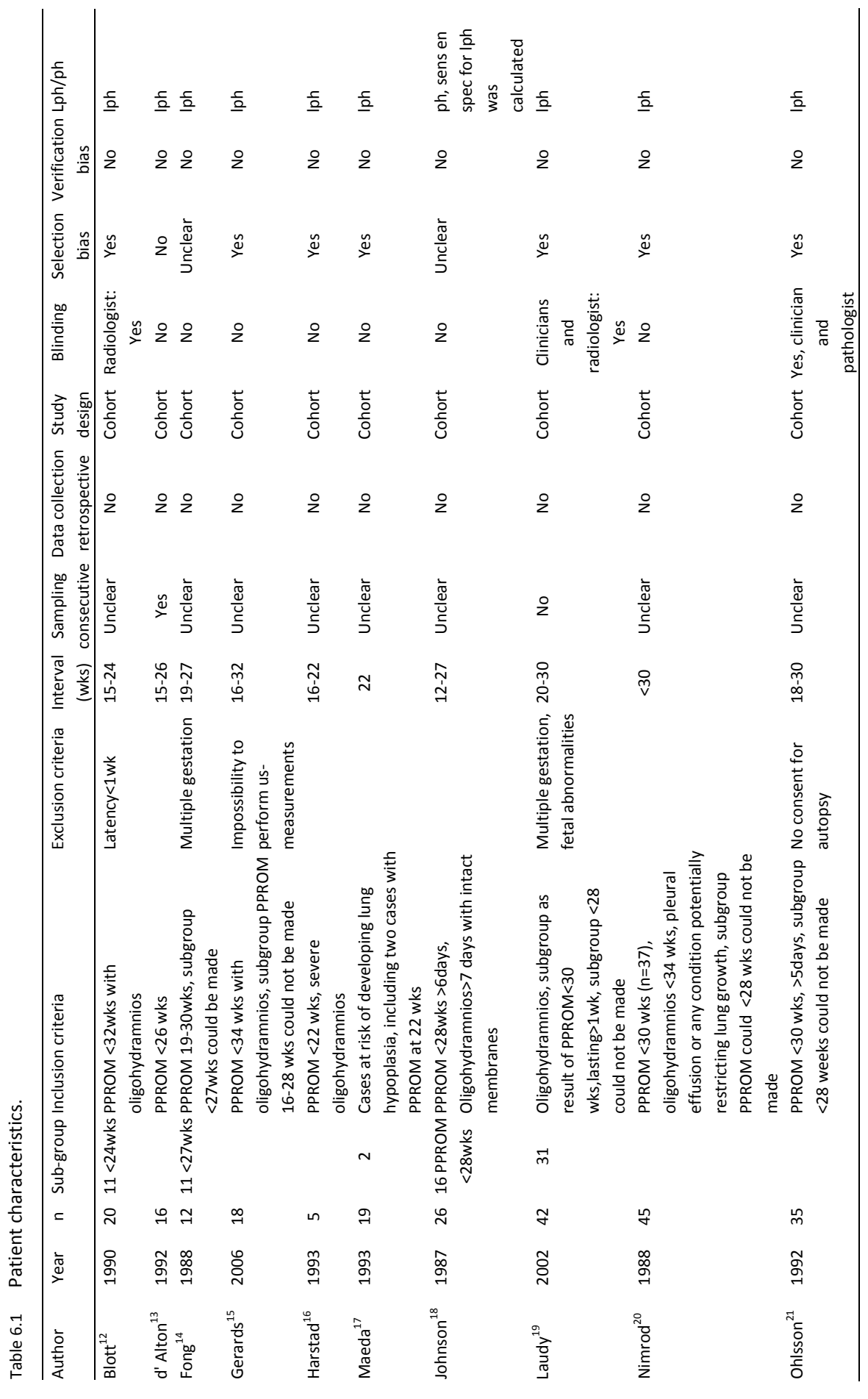


Imaging parameters in the prediction of lethal pulmonary hypoplasia

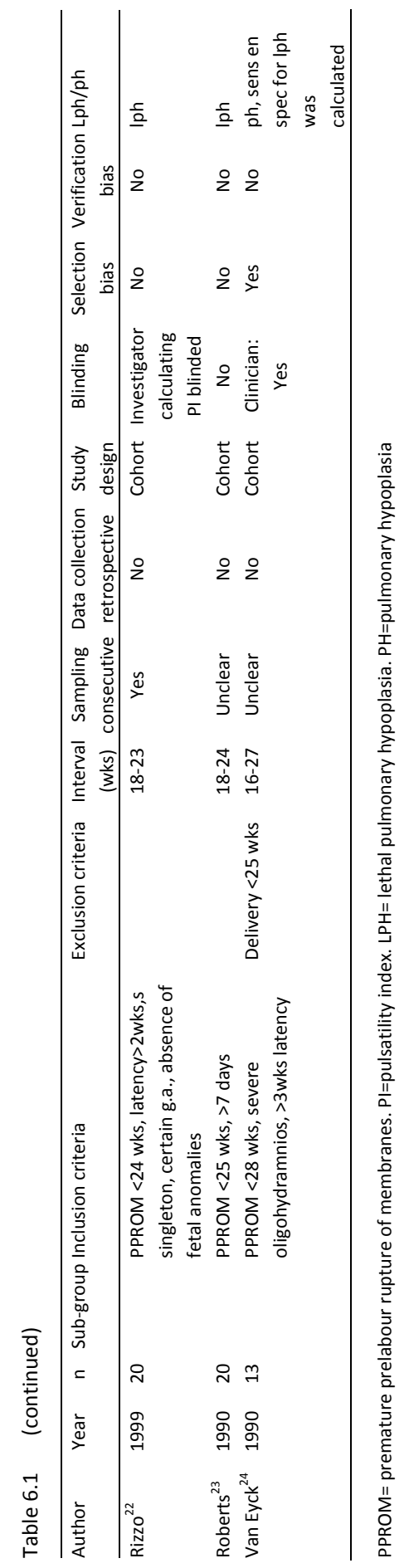




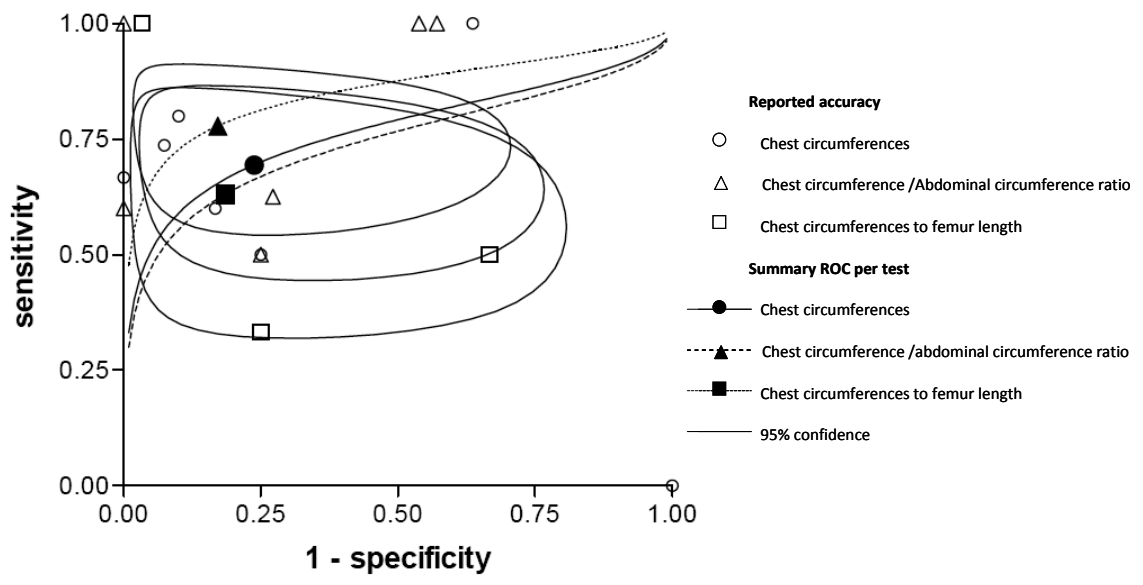

Figure 6.2 Sensitivity-specificity points and their reported accuracy for chest circumferences, the ratio of chest circumferences to abdominal circumferences, and for the ratio of chest circumferences to femur length for lethal pulmonary hypoplasia.

Five studies were adequately blinded. Selection bias was present in eight studies. Selection biases most frequently seen were limitation of studies to pregnancies with established oligohydramnios and inclusion of pregnancies in which PPROM occurred over 28 weeks. In one study of 45 pregnancies with oligohydramnios, in eight cases the oligohydramnios was not caused by PPROM ${ }^{20}$. Since in the majority of cases in this study the cause was PPROM, we included it in our review. One study excluded pregnancies in which measurements were unsuccessful or in which the results of reference tests were not obtained ${ }^{15}$. Verification bias was not present in any study. In six of the 13 studies, the diagnosis of lethal pulmonary hypoplasia was not always based on autopsy data; sometimes clinical and radiological data had to be used ${ }^{14}$. Table 6.2 gives characteristics of the biometric parameters that were used. The most commonly used ultrasound parameters were chest circumference (seven studies), chest circumference/abdominal circumference ratio (six studies) and chest circumference/femur length ratio (three studies). The MRI parameters used in the only study incorporating MRI were chest circumference and ratio of chest area minus cardiac area divided by cardiac area; volumes were not measured. The sensitivities and specificities for chest circumference, chest circumference/abdominal circumference ratio and chest circumference/femur length ratio, as well as some other parameters that were used less frequently in the diagnosis of lethal hypoplasia, are summarized in Tables 6.3 and 6.4, the former giving parameters derived from 2D ultrasound measurements, and the latter parameters derived from 3D ultrasound, 2D MRI or Doppler measurements. 
Imaging parameters in the prediction of lethal pulmonary hypoplasia

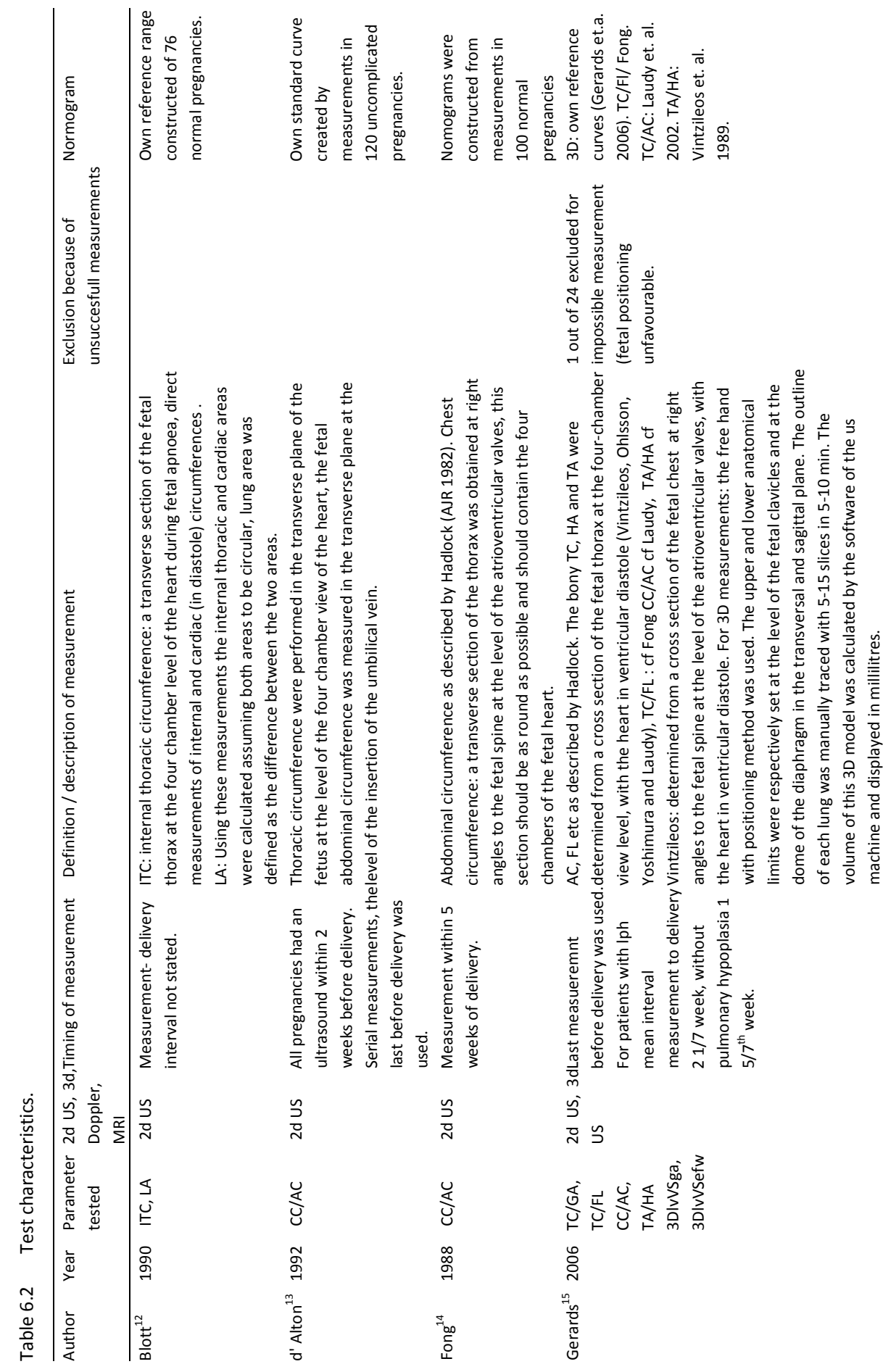




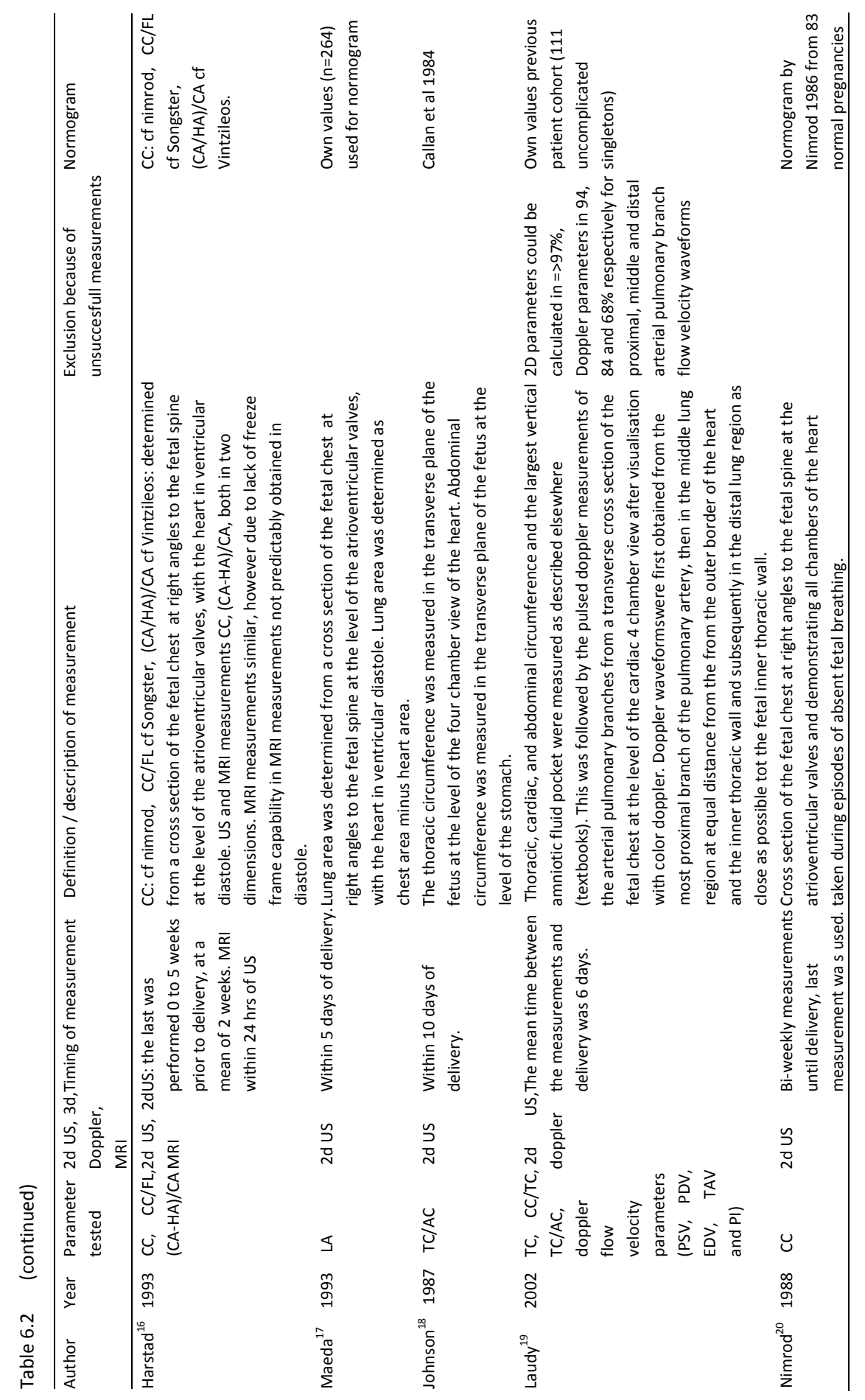


Imaging parameters in the prediction of lethal pulmonary hypoplasia

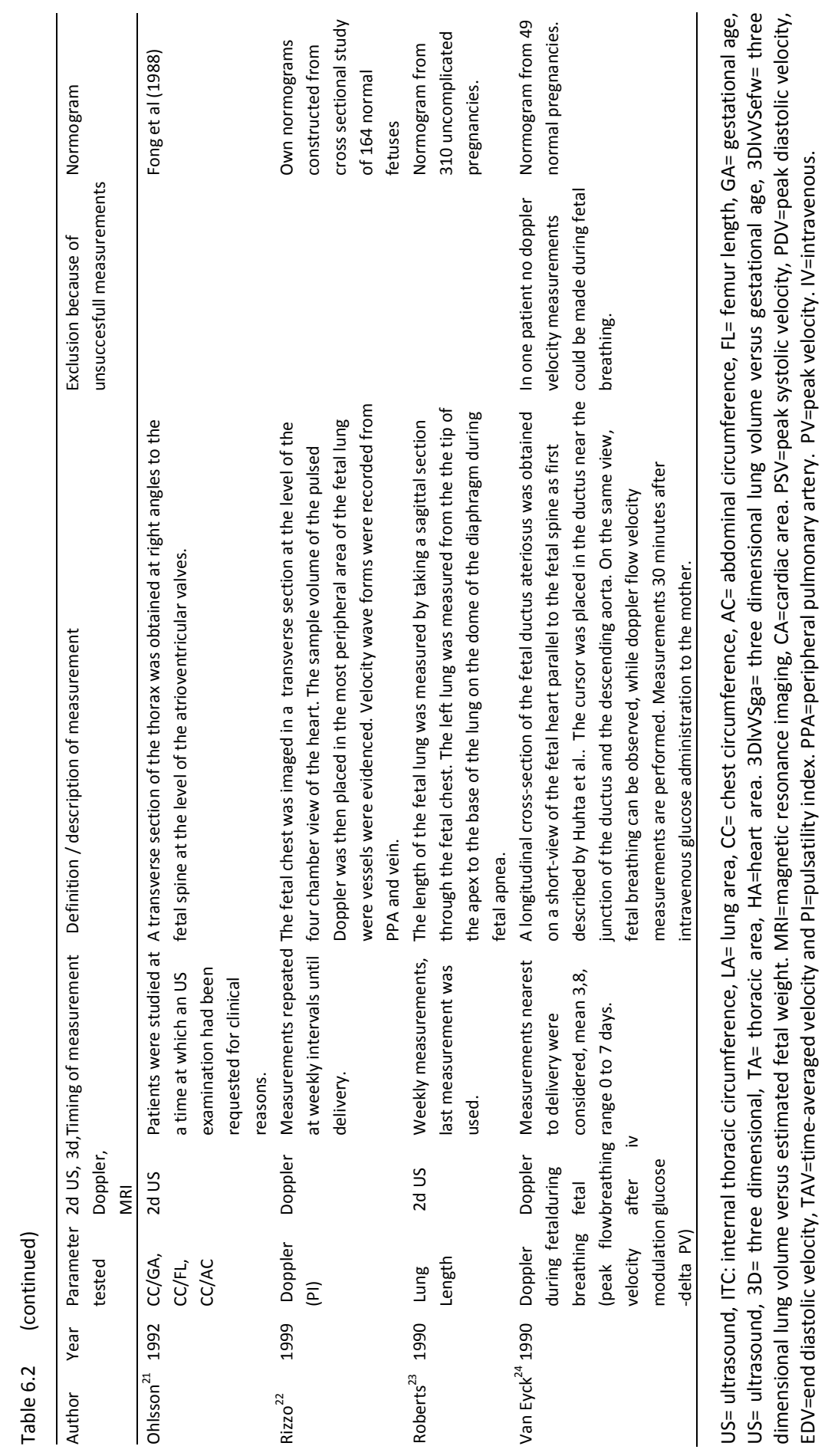


Chapter 6

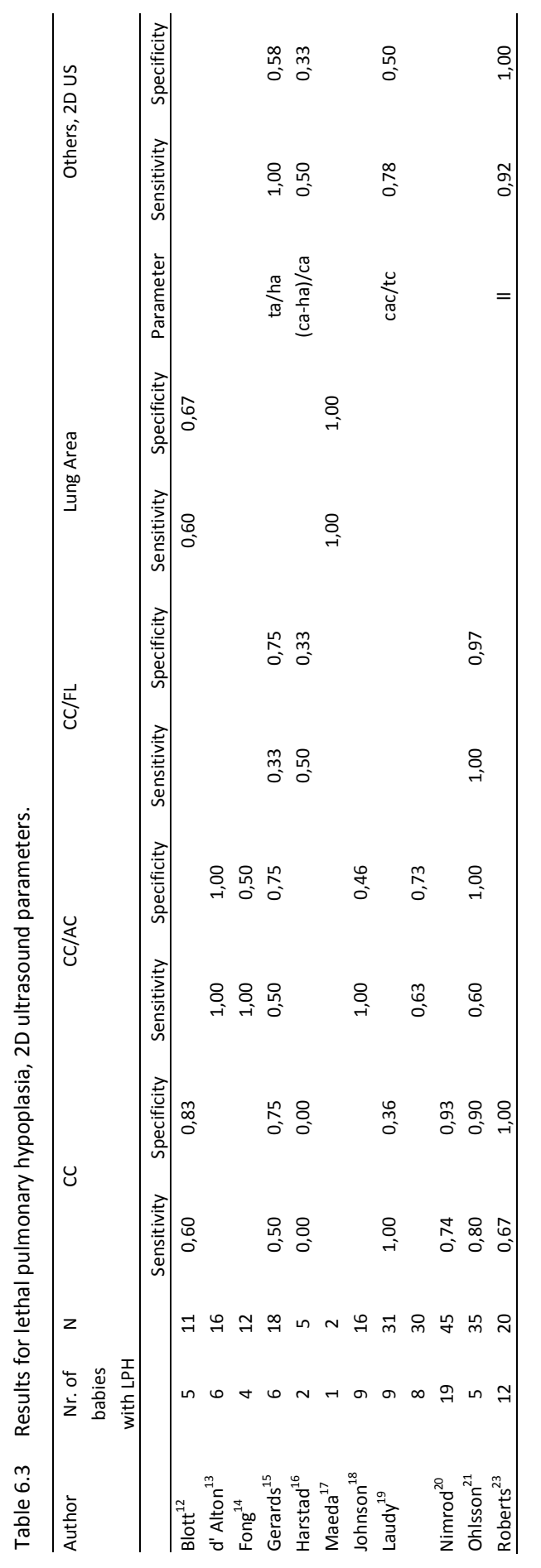


A plot of sensitivity-specificity points for chest circumference, chest circumference/abdominal circumference ratio and chest circumference/femur length ratio for lethal pulmonary hypoplasia is shown in Figure 6.2. The study of Laudy et al. ${ }^{19}$ was the only one to report an optimal sensitivity for chest circumference, but this was at the expense of low specificity; the other six studies combined a high specificity with a sensitivity varying between $50 \%$ and $80 \%$. The study of d'Alton et al. ${ }^{13}$ was the only one to demonstrate perfect sensitivity and specificity for chest circumference/abdominal circumference ratio; all other studies had either suboptimal sensitivity or suboptimal specificity. Figure 6.3 shows the performance of chest circumference/abdominal circumference ratio, as in Figure 6.2, as compared with the sROC of our previous metaanalysis ${ }^{4}$ which assessed the predictive capacity of gestational age at PPROM, latency time between PPROM and delivery and amount of amniotic fluid. The study of van Eyck et al. ${ }^{24}$ used Doppler measurements during (induced) periods of fetal breathing. All these studies were relatively small, and none indicated that any of the evaluated tests had a good accuracy. The study of Ohlsson et al. ${ }^{21}$ reported almost perfect accuracy for the chest circumference/femur length ratio, with a sensitivity of $100 \%$ and a specificity of $97 \%$, but again the sample size in this study was rather low, as there were only 35 pregnancies in the cohort. Neither the amount nor the timing of measurements performed throughout the latency period was uniform, as can be seen from Table 6.2.

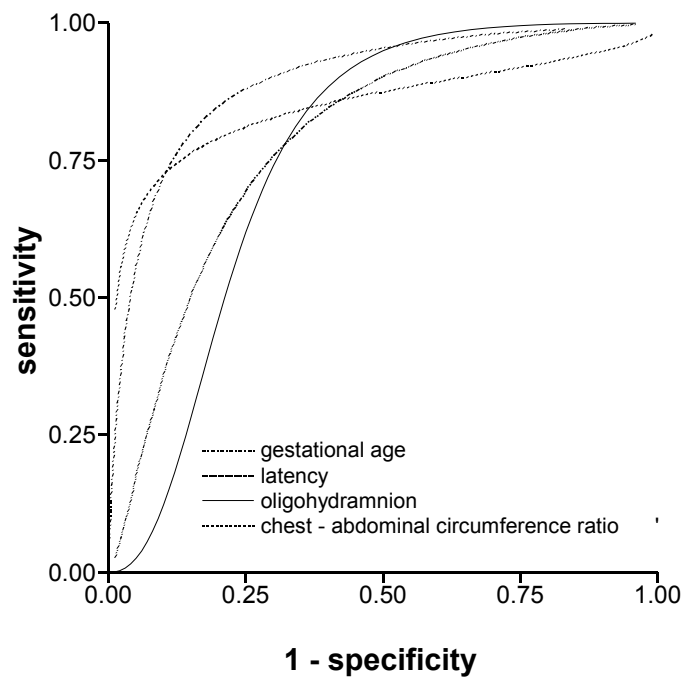

Figure 6.3 Performance of the ratio of chest circumferences to abdominal circumferences, as compared to the estimated summary ROC-curves for gestational age at PPROM, latency time and oligohydramnios for the prediction of lethal pulmonary hypoplasia. 
Table 6.4 Results for lethal pulmonary hypoplasia, 3D ultrasound, 2D MRI, Doppler parameters.

\begin{tabular}{|c|c|c|c|c|c|}
\hline \multirow[t]{2}{*}{ Author } & \multirow[t]{2}{*}{ Nr. of babies with LPH } & \multirow[t]{2}{*}{$\mathrm{n}$} & \multirow[t]{2}{*}{ Parameter } & \multicolumn{2}{|c|}{ Others } \\
\hline & & & & Sensitivity & Specificity \\
\hline \multirow[t]{2}{*}{ Gerards $^{15}$} & 6 & 18 & 3D US Iv/ga & 0,83 & 1,00 \\
\hline & & & 3D US Iv/efw & 0,67 & 1,00 \\
\hline \multirow[t]{2}{*}{ Harstad $^{16}$} & 2 & 3 & 2D MRI ca-ha/ca & 0,00 & 1,00 \\
\hline & & & 2D MRI cC & 0,00 & 0,00 \\
\hline \multirow[t]{10}{*}{ Laudy $^{19}$} & 6 & 29 & Doppler PPB tav & 0,63 & 0,76 \\
\hline & & & Doppler PPB psv & 0,63 & 0,9 \\
\hline & & & Doppler PPB pdv & 0,25 & 0,9 \\
\hline & & & Doppler PPB edv & 0,38 & 0,86 \\
\hline & & & Doppler PPB pi & 0,38 & 0,76 \\
\hline & 6 & 26 & Doppler MPB tav & 0,71 & 0,84 \\
\hline & & & Doppler MPB psv & 0,43 & 0,84 \\
\hline & & & Doppler MPB pdv & 0,14 & 0,68 \\
\hline & & & Doppler MPB edv & 0,57 & 0,95 \\
\hline & & & Doppler MPB pi & 0,29 & 0,79 \\
\hline $\operatorname{Rizzo}^{22}$ & 6 & 20 & Doppler pi/ppa & 0,63 & 0,95 \\
\hline Van Eyck ${ }^{24}$ & 4 & 12 & $\begin{array}{c}\text { Doppler during fetal breathing } \\
\text { (peak flow velocity modulation - } \\
\text { delta PV) }\end{array}$ & 1,00 & 0,88 \\
\hline
\end{tabular}

US=ultrasound, $3 D=$ three dimensional, $2 D=$ two dimensional, $L A=l$ ung area, $C C=$ chest circumference, $\mathrm{AC}=$ abdominal circumference, $\mathrm{FL}=$ femur length, $\mathrm{GA}=$ gestational age, $3 \mathrm{D}=$ three dimensional, $\mathrm{TA}=$ thoracic area, $H A=$ heart area. $L L=$ lung length, $C A C=$ cardiac circumference, $T C=$ thoracic circumference lv=lung volume, efw=estimated fetal weight. MRI=magnetic resonance imaging, $C A=c a r d i a c$ area. PSV=peak systolic velocity, $\mathrm{PDV}=$ peak diastolic velocity, $\mathrm{EDV}=$ end diastolic velocity, $\mathrm{TAV}=$ time-averaged velocity and $\mathrm{PI}=$ pulsatility index. $P P A=$ peripheral pulmonary artery. $\mathrm{PV}=$ peak velocity

\section{Discussion}

In this meta-analysis, we included 13 studies that reported on the prediction of lethal pulmonary hypoplasia. The estimates for sensitivity and specificity showed the capacity of imaging techniques to predict hypoplasia to be very limited. Our review identified several weaknesses in the literature. First, the methodological quality of the studies was limited. Many suffered from verification bias, as a result of the test being used in the management of the patients or because the observers were not blinded. All studies were single-center, which is worrisome, since second-trimester PPROM is a rare condition $(0.7 \%$ of pregnancies), making it unlikely that a single-center study would reach sufficient power. Indeed, the sample size of each of the studies was rather small, especially with respect to the number of cases of hypoplasia. Most of the studies that we identified focussed on lethal pulmonary hypoplasia. This is important, as accurate prediction of lethal pulmonary hypoplasia before 24 weeks gives parents the chance to opt for termination of pregnancy. Moreover, this information could be of clinical relevance in women for whom discussions on intervention have to be made at 
gestational ages around that of viability of the child. In women relatively early on in pregnancy who are at high risk of fetal lethal pulmonary hypoplasia, the decision for an unnecessary cesarean section could be delayed. As we included studies performed between 1988 and 2006, there will have been differences between them in terms of treatments. Differences in antenatal management (tocolysis, corticosteroids, antibiotics) and advances in neonatal intensive care could have resulted in lower mortality figures in the more recent studies, with a subsequent lower incidence of lethal pulmonary hypoplasia. The reference test used in the various articles showed strong variation, which is also a source of heterogeneity. In seven of the 13 studies, all cases with lethal pulmonary hypoplasia were proven by autopsy, albeit with different pathological standards. The technique to diagnose pulmonary hypoplasia in autopsy varies widely. The three criteria used to define pulmonary hypoplasia are lung weight/body weight ratio, radial alveolar count and amount of DNA detected in lung tissue (lung DNA (in $\mathrm{mg}$ )/body weight (in g) ratio). Each of these three criteria has its own disadvantage. (Wet) lung weight/body weight ratio is decreased in pulmonary hypoplasia; however, tissue edema could increase the ratio, confusing the diagnosis. Radial alveolar counts are difficult to interpret in the preterm lung before the development of alveoli. The numbers in a fixed expanded lung differ from those in a fixed collapsed lung. The lung DNA/body weight ratio is confounded by the presence of increased pulmonary interstitial inflammatory cells ${ }^{25}$. In six studies, some of the affected cases were identified by (predefined) clinical and radiological characteristics. However, a clinical diagnosis of pulmonary hypoplasia is difficult to establish since congenital pneumonia or infant respiratory distress syndrome sometimes occur simultaneously and have overlapping symptoms. The diagnostic meta-analysis we performed allows for control for heterogeneity in sensitivity and specificity, since both report on the same underlying test. When the cut-off for abnormality increases, sensitivity increases and specificity decreases, while a decrease in the cut-off for abnormality has the opposite effect. The summary ROC curves we estimated are a means of addressing this heterogeneity. We previously assessed the predictive capacity of gestational age at PPROM, latency time between PPROM and delivery and the amount of amniotic fluid ${ }^{4}$. Gestational age at PPROM performed significantly better than did the two other parameters in the prediction of pulmonary hypoplasia. Future studies should focus on whether ultrasound parameters or other imaging techniques can further improve on the prediction of pulmonary hypoplasia that is possible using age at PPROM. In view of the current evidence, we feel that there is no indication to perform such tests in a clinical setting. 


\section{References}

1. Kilbride HW, Thibeault DW. Neonatal complications of preterm rupture of membranes. Clin Perinatol 2001;28:761-85.

2. Sherer DM, Davis JM, Woods JR Jr. Pulmonary hypoplasia: a review. Obstet Gynecol Surv 1990; 45: 792-803.

3. Laudy JA, Wladimiroff JW. The fetal lung. 2: Pulmonary hypoplasia. Ultrasound Obstet Gynecol 2000;16:482-94

4. van Teeffelen AS, van der Ham DP, Oei SG, Porath MM, Willekes C, Mol BW. The accuracy of clinical parameters in the prediction of perinatal pulmonary hypoplasia secondary to midtrimester prelabour rupture of fetal membranes: a meta-analysis. Eur J Obstet Gynecol Reprod Biol 2010;148:3-12.

5. Vintzileos AM, Campbell WA, Rodis JF, Nochimson DJ, Pinette MG, Petrikovsky BM. Comparison of six different ultrasonographic methods for predicting lethal fetal pulmonary hypoplasia. Am J Obstet Gynecol 1989;161:606-12.

6. Lijmer JG, Mol BW, Heisterkamp S, Bonsel GJ, Prins MH, van der Meulen JH, Bossuyt PM. Empirical evidence of design-related bias in studies of diagnostic tests. JAMA 1999;282:1061-6.

7. Van Houwelingen HC, Zwinderman KH, Stijnen T. A bivariate approach to meta-analysis. Stat Med 1993; 12:2273-84.

8. Van Houwelingen HC, Arends LR, Stijnen T. Advanced methods in meta-analysis: multivariate approach and meta-regression. Stat Med 2002 28;21:589-624.

9. Reitsma JB, Glas AS, Rutjes AW, Scholten RJ, Bossuyt PM, Zwinderman AH. Bivariate analysis of sensitivity and specificity produces informative summary measures in diagnostic reviews. J Clin Epidemiol 2005;58:982-90.

10. Arends LR, Hamza TH, Van Houwelingen HC, Heijenbrok KMH, Hunink MGM, Stijnen T. Multivariate random-effects meta-analysis of ROC-curves. Med Decis Making 2006.

11. Harbord RM, Deeks JJ, Egger M, Whiting P, Sterne JAC. A unification of models for meta-analysis of diagnostic accuracy studies. Biostatistics 2007;8:239-51.

12. Blott M, Greenough A, Nicolaides KH, Campbell S. The ultrasonographic assessment of the fetal thorax and fetal breathing movements in the prediction of pulmonary hypoplasia. Early Hum Dev 1990; 21:143-51.

13. D'Alton M, Mercer B, Riddick E, Dudley D. Serial thoracic versus abdominal circumference ratios for the prediction of pulmonary hypoplasia in premature rupture of the membranes remote from term. Am J Obstet Gynecol 1992;166:658-63.

14. Fong K, Ohlsson A, Zalev A. Fetal thoracic circumference: a prospective cross-sectional study with realtime ultrasound. Am J Obstet Gynecol. 1988; 158(5):1154-60. Erratum in: Am J Obstet Gynecol 1990; 163:1363.

15. Gerards FA, Twisk JW, Fetter WP, Wijnaendts LC, Van Vugt JM. Two- or three-dimensional ultrasonography to predict pulmonary hypoplasia in pregnancies complicated by preterm premature rupture of the membranes. Prenat Diagn 2007;27:216-21.

16. Harstad TW, Twickler DM, Leveno KJ, Brown CE. Antepartum prediction of pulmonary hypoplasia: an elusive goal? Am J Perinatol 1993;10:8-11.

17. Maeda H, Nagata H, Tsukimori K, Satoh S, Koyanagi T, Nakano H. Prenatal evaluation and obstetrical management of fetuses at risk of developing lung hypoplasia. J Perinat Med 1993;21:355-61.

18. Johnson A, Callan NA, Bhutani VK, Colmorgen GH, Weiner S, Bolognese RJ. Ultrasonic ratio of fetal thoracic to abdominal circumference: an association with fetal pulmonary hypoplasia. Am J Obstet Gynecol 1987;157:764-9.

19. Laudy JA, Tibboel D, Robben SG, de Krijger RR, de Ridder MA, Wladimiroff JW. Prenatal prediction of pulmonary hypoplasia: clinical, biometric, and Doppler velocity correlates. Pediatrics 2002;109:250-8.

20. Nimrod C, Nicholson S, Davies D, Harder J, Dodd G, Sauve R. Pulmonary hypoplasia testing in clinical obstetrics. Am J Obstet Gynecol 1988;158:277-80.

21. Ohlsson A, Fong K, Rose T, Hannah M, Black D, Heyman Z, Gonen R. Prenatal ultrasonic prediction of autopsy-proven pulmonary hypoplasia. Am J Perinatol 1992;9:334-7. 
22. Rizzo G, Capponi A, Angelini E, Mazzoleni A, Romanini C. Blood flow velocity waveforms from fetal peripheral pulmonary arteries in pregnancies with preterm premature rupture of the membranes: relationship with pulmonary hypoplasia. Ultrasound Obstet Gynecol 2000;15:98-103.

23. Roberts $A B$, Mitchell JM. Direct ultrasonographic measurement of fetal lung length in normal pregnancies and pregnancies complicated by prolonged rupture of membranes. Am J Obstet Gynecol 1990;163:1560-6.

24. van Eyck J, van der Mooren K, Wladimiroff JW. Ductus arteriosus flow velocity modulation by fetal breathing movements as a measure of fetal lung development. Am J Obstet Gynecol 1990;163:558-66.

25. Kilbride HW, Yeast J, Thibeault DW. Defining limits of survival: lethal pulmonary hypoplasia after midtrimester premature rupture of membranes. Am J Obstet Gynecol 1996;175:675-81. 



\section{Chapter}

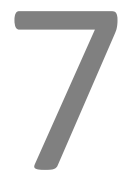

Transabdominal amnioinfusion for improving fetal

outcomes after oligohydramnios secondary to preterm prelabour rupture of membranes before 26 weeks (Review)

van Teeffelen ASP, Pajkrt E, Willekes C, Van Kuijk SMJ, Mol BW Cochrane Database Syst Rev 2013;8:CD009952 


\section{Abstract}

\section{Background}

Preterm prelabour rupture of membranes (PPROM) before 26 weeks can delay lung development and can cause pulmonary hypoplasia, as a result of oligohydramnios. Restoring the amniotic fluid volume by transabdominal amnioinfusion might prevent abnormal lung development and might have a protective effect for neurological complications, fetal deformities and neonatal sepsis.

\section{Objectives}

To assess the effectiveness of transabdominal amnioinfusion in improving perinatal outcome in women with oligohydramnios secondary to rupture of fetal membranes before 26 weeks.

\section{Search methods}

We searched the Cochrane Pregnancy and Childbirth Group's Trials Register (30 April 2013).

\section{Selection criteria}

All randomised controlled trials comparing transabdominal amnioinfusion with no transabdominal amnioinfusion. Cluster- or quasi-randomised trials were not eligible for inclusion. In cases where only an abstract was available, we attempted to find the full articles.

\section{Data collection and analysis}

Two review authors assessed trials for inclusion. No eligible trials were identified.

\section{Main results}

There are no included studies.

\section{Authors' conclusions}

There is currently no evidence to evaluate the use of transabdominal amnioinfusion in women with oligohydramnios secondary to rupture of fetal membranes before 26 weeks for improving perinatal outcome. Further research examining the effects of this intervention is needed. Two randomised controlled trials are ongoing but final data have not yet been published. 


\section{Summary}

Babies born after preterm prelabour rupture of membranes (PPROM) between 16 and 26 weeks of pregnancy are prone to underdevelopment of the lungs. When the membranes containing the fluid that surrounds the baby (amniotic fluid) rupture, a shortage of this fluid can occur, a condition that is called oligohydramnios. Oligohydramnios is thought to interfere with normal lung development so that it is delayed, resulting in a condition that is called pulmonary hypoplasia.

Pulmonary hypoplasia can present as severe breathing problems or as milder and even transient breathing problems. It can be accompanied by bleeding in the lung and can also result in chronic breathing problems due to scarring of lung tissue. There may also be neurological complications, fetal deformities and neonatal sepsis with oligohydramnios.

Replacement of fluid via a needle passed through the abdominal wall in the uterine cavity and into a pocket of amniotic fluid, (transabdominal amnioinfusion) under ultrasound guidance has been proposed to improve pregnancy outcome. Most clinical experience suggests that amnioinfusion is safe for both the mother and the baby, however, we did not identify any randomised trials of transabdominal amnioinfusion following PPROM before 26 weeks for inclusion in this review. Currently, there is no evidence to evaluate the use of transabdominal amnioinfusion in women with oligohydramnios following rupture of fetal membranes before 26 weeks for improving birth outcomes. 


\section{Background}

\section{Description of the condition}

It is thought that the formation of lung tissue is dependent on an adequate amount of amniotic fluid, especially during the interval between 16 and 26 weeks (the midtrimester). A reduced amount of amniotic fluid (oligohydramnios) after preterm prelabour rupture of membranes (PPROM) in this interval might cause pulmonary hypoplasia ${ }^{1}$. Oligohydramnios is commonly defined as a single deepest pocket of amniotic fluid of less than $2 \mathrm{~cm}$ or an amniotic fluid index of less than $5 \mathrm{~cm}$ as measured by ultrasound.

Pulmonary hypoplasia is a term used to describe pulmonary underdevelopment. It is characterised by an inadequate formation of the respiratory tree resulting in a reduced amount of functional lung tissue, with reduced capacity for gas exchange.

Pulmonary hypoplasia poses a serious threat to the neonate and is associated with high mortality and morbidity rates. It can present as severe breathing problems resulting in early neonatal death or, as milder and even transient breathing problems. It may be accompanied by bleeding in the lungs. It can also result in chronic breathing problems due to scarring of lung tissue ${ }^{2}$. Perinatal mortality approximates $70 \%$ in most series (55 to $100 \%)^{3}$.

An internationally recognised definition of pulmonary hypoplasia does not exist, rather a diagnosis is made by eliminating other possible causes of symptoms. Congenital pneumonia, infant respiratory distress syndrome and pulmonary hypoplasia sometimes occur simultaneously, and have overlapping symptoms. Post mortem diagnosis is not uniform throughout the literature, however, post mortem criteria are more objective than those for infants who survive.

Apart from PPROM, numerous other conditions are associated with pulmonary hypoplasia. These include renal and urinary tract abnormalities leading to decreased amniotic fluid, decreased amniotic fluid unrelated to disorders of the urinary system, diaphragmatic hernia, fetal oedema, skeletal and muscular pathologies, central nervous system abnormalities, and other conditions causing compression of the fetal thorax ${ }^{4}$.

\section{Description of the intervention}

Transabdominal amnioinfusion has been attempted for diagnostic and therapeutic purposes in women with second trimester oligohydramnios ${ }^{5}$. The aim of the procedure is to restore the amount of amniotic fluid, by infusing fluid through a needle passed through the abdominal wall into the womb. After sterile preparation of the abdomen, a pocket of amniotic fluid is identified by ultrasound guidance, after which a needle is advanced into this pocket. After insuring proper placement by withdrawing a small amount of fluid, the desired volume of fluid is infused, by manual push or infusion 
pump. The procedure can be repeated if oligohydramnios recurs or persists (it is then called serial amnioinfusion).

\section{How the intervention might work}

The mechanism by which oligohydramnios impairs lung development is not fully understood. Several mechanisms have been proposed (mechanical effects, effects on fetal breathing movements, effects on the transcription of growth factors, and effects of inflammation and infection. ${ }^{6}$. Restitution of amniotic fluid volume in cases of artificially induced oligohydramnios in experimental animals has prevented pulmonary hypoplasia $^{2,7}$.

Persistent oligohydramnios appears to be a poor prognostic sign in terms of pulmonary hypoplasia or other morbidity as described in a review by Laudy and Wladimiroff ${ }^{3}$. Restoring the amniotic fluid volume might prevent abnormal lung growth and development. Furthermore, it has been hypothesised that amnioinfusion might also have a protective effect for other neurological complications and fetal deformities ${ }^{5}$. Dilution, and the antibacterial effect of the infused fluid might have a protective effect for neonatal sepsis ${ }^{8}$. There is no consensus on the definition of successful amnioinfusion. Leakage of the infused fluid has been described. In two observational studies, in only $24 \%$ to $30 \%$ of cases was infused fluid retained 48 hours after the intervention $^{9,10}$.

\section{Why it is important to do this review}

In another Cochrane review Hofmeyr et al reviewed amnioinfusion for PPROM before 37 weeks with the aim to assess the effects of amnioinfusion for PPROM on perinatal and maternal morbidity and mortality ${ }^{11}$. Hofmeyr's review reports on transabdominal as well as transcervical amnioinfusion. It was concluded that transcervical amnioinfusion reduced variable decelerations during labour and improved fetal umbilical artery $\mathrm{pH}$ at delivery. Transabdominal amnioinfusion was associated with a reduction in neonatal death, neonatal sepsis, pulmonary hypoplasia and puerperal sepsis. Furthermore, the interval between PPROM and birth seemed to be longer in the amnioinfused group. It was stressed that the results should be interpreted with caution, since the positive findings were mainly due to one trial with unclear allocation concealment.

The present review, in contrast, specifically considers women with rupture of membranes before 26 weeks and subsequent oligohydramnios who are treated with transabdominal amnioinfusion.

PPROM before 26 weeks with oligohydramnios is a distinct condition within PPROM in general, with a distinct pathophysiology leading to abnormal lung development and a very poor prognosis. To date, no effective management has been recognised, although several therapies have been investigated. Some of these therapies aim to normalise the 
amniotic fluid volume, either by preventing further leakage of amniotic fluid (occlusion by fibrin, platelets, cryoprecipitate), or to add fluid to the amniotic cavity by transabdominal amnioinfusion.

Antepartum amnioinfusion for the management of oligohydramnios is a difficult procedure. Technical difficulty lies in the fact that the needle has to be inserted in a pocket of amniotic fluid where, in severe oligohydramnios, such a pocket may be difficult to identify.

Some researchers have claimed that the procedure, if successful, has been shown to decrease the risk of pulmonary hypoplasia and significantly improves perinatal outcome ${ }^{12}$.

Recently Porat et al. $^{13}$ reviewed transabdominal amnioinfusion for PPROM with associated oligohydramnios. Just as in Hofmeyr's review, studies on PPROM before 37 weeks were included. Porat 2012 meta-analysed available randomised controlled trials (RCTs) as well as observational studies. Two RCTs and one quasi-randomised RCT were included in the review as well as four observational studies. The two RCTs were carried out on women with PPROM between 24 and 34 completed weeks; the two RCTs were also included in the review by Hofmeyr ${ }^{11}$. The quasi-randomised study included only women with PPROM before 26 weeks of gestation ${ }^{14}$. Of the four observational studies, two were on very early PPROM. Porat et al. concluded that serial transabdominal amnioinfusion might improve early PPROM associated morbidity and mortality, however, a large randomised trial is needed.

A meta-analysis of all randomised controlled trials on women with PPROM before 26 weeks and associated oligohydramnios could indicate if serial transabdominal amnioinfusion is a safe and effective intervention for this specific obstetric problem.

\section{Objectives}

To assess the effectiveness of transabdominal amnioinfusion in improving perinatal outcome in women with oligohydramnios secondary to rupture of fetal membranes before 26 weeks. 


\section{Methods}

\section{Criteria for considering studies for this review}

\section{Types of studies}

Randomised controlled trials. Cluster- or quasi-randomised trials were not eligible for inclusion. In cases where only an abstract was available, we attempted to find the full articles.

\section{Types of participants}

Women with a pregnancy complicated by premature prelabour rupture of membranes (PPROM) before 26 weeks and subsequent oligohydramnios.

\section{Types of interventions}

Transabdominal amnioinfusion versus standard management.

\section{Types of outcome measures}

\section{Primary outcomes}

- Perinatal mortality, defined as intrauterine death, intrapartum death or neonatal death in the first 28 days of life.

\section{Secondary outcomes}

- Pulmonary hypoplasia as defined by the individual trials.

- Retention of infused fluid as defined by a single deepest pocket of amniotic fluid of more than $2 \mathrm{~cm}$ or an amniotic fluid index of more than five, for at least 48 hours.

- Gestational age at birth.

- Latency (interval between PPROM and birth).

- Neonatal mortality, defined as neonatal death in the first 28 days of life.

- Stillbirth (intrauterine death).

\section{Neonatal morbidity}

- Sepsis as defined by the individual trials.

- Respiratory distress syndrome as defined by the individual trials.

- Necrotising enterocolitis as defined by the individual trials.

- Chronic lung disease as defined by the individual trials.

- Periventricular leucomalacia as defined by the individual trials.

- Severe intraventricular haemorrhage as defined by the individual trials.

- Postural deformities as defined by the individual trials. 


\section{Adverse events}

- Placental abruption.

- Cord prolapse.

- Chorioamnionitis as defined by the individual trials.

- Fetal trauma due to puncture.

- Premature labour and birth.

- Maternal sepsis as defined by the individual trials.

- Maternal death.

\section{Search methods for identification of studies}

\section{Electronic searches}

We contacted the Trials Search Co-ordinator to search the Cochrane Pregnancy and Childbirth Group's Trials Register (30 April 2013).

The Cochrane Pregnancy and Childbirth Group's Trials Register is maintained by the Trials Search Co-ordinator and contains trials identified from:

1. monthly searches of the Cochrane Central Register of Controlled Trials (CENTRAL);

2. weekly searches of MEDLINE;

3. weekly search of EMBASE;

4. handsearches of 30 journals and the proceedings of major conferences;

5. weekly current awareness alerts for a further 44 journals plus monthly BioMed Central email alerts.

Details of the search strategies for CENTRAL, MEDLINE and EMBASE, the list of handsearched journals and conference proceedings, and the list of journals reviewed via the current awareness service can be found in the 'Specialized Register' section within the editorial information about the Cochrane Pregnancy and Childbirth Group. Trials identified through the searching activities described above are each assigned to a review topic (or topics). The Trials Search Co-ordinator searches the register for each review using the topic list rather than keywords.

We did not apply any language restrictions.

\section{Data collection and analysis}

\section{Selection of studies}

Two review authors (Stijn Van Teeffelen and Eva Pajkrt) independently assessed for inclusion all the potential studies that were identified as a result of the search strategy. We resolved any disagreement through discussion or, if required, we consulted Ben Willem Mol (BWM). 
There are no included studies. Data collection and analysis methods to be used in future updates of this review are provided in Appendix 1.

\section{Results}

\section{Description of studies}

\section{Results of the search}

The search of the Cochrane Pregnancy and Childbirth Group's Trials Register retrieved 11 reports. There are no included studies. We excluded nine studies, ${ }^{8,14-21}$ and two studies are ongoing ${ }^{22,23}$.

\section{Included studies}

There are no included studies.

\section{Excluded studies}

We excluded nine studies from the review because they did not meet our study eligibility criteria (see Characteristics of excluded studies).

De Santis 2003 used a quasi-randomisation process in which women with PPROM before 26 weeks were allocated to amnioinfusion or expectant management, participants were admitted by chance into one of two departments, amnioinfusion was given in only one of these departments.

Gowri 2004 studied a group of 17 participants of which only three had premature rupture of membranes, data on their outcomes could not be extracted. Leake 1983 studied 35 participants with preterm labour and or ruptured membranes who received ritodrine or a placebo to study its effect on neonatal glucose homeostasis. Singla 2010 and Tranquilli 2005 were excluded since the inclusion criteria did not fit the criteria for this review (they studied participants with PPROM after 24 weeks) and Puertas 2007 and Nageotte 1985 studied intrapartum amnioinfusion in women with PPROM between 26 and 35 weeks. We excluded Gonzalez 2001 since we could not find the final data published (preliminary results). The Vergani 2007 report is a study proposal.

\section{Risk of bias in included studies}

There are no included studies.

\section{Effects of interventions}

There are no included studies. 


\section{Discussion}

No randomised controlled trials of transabdominal amnioinfusion to improve perinatal outcome in women with oligohydramnios secondary to rupture of fetal membranes before 26 weeks were identified for inclusion in this review. Two randomised controlled trials have started ${ }^{22,23}$ but final data have not yet been published.

At this point, transabdominal amnioinfusion cannot be recommended for women with oligohydramnios secondary to rupture of fetal membranes before 26 weeks. Women requesting a trial of therapy should be informed of the lack of any well-designed studies assessing effectiveness, and the risk of adverse events.

\section{Authors' conclusions}

\section{Implications for practice}

There is currently no evidence to evaluate the use of transabdominal amnioinfusion for improving perinatal outcome in women with oligohydramnios secondary to rupture of fetal membranes before 26 weeks.

\section{Implications for research}

Randomised controlled studies to determine the effectiveness of transabdominal amnioinfusion in women with oligohydramnios secondary to rupture of fetal membranes before 26 weeks are needed. 


\section{References}

1. van Teeffelen AS, van der Ham DP, Oei SG, Porath MM, Willekes C, Mol BW. The accuracy of clinical parameters in the prediction of perinatal pulmonary hypoplasia secondary to midtrimester prelabour rupture of fetal membranes: a meta-analysis. Eur J Obstet Gynecol Reprod Biol 2010;148:3-12.

2. Sherer DM, Davis JM, Woods JR Jr. Pulmonary hypoplasia: a review. Obstet Gynecol Surv, 1990;45:792803.

3. Laudy JA, Wladimiroff JW. The fetal lung. 2: Pulmonary hypoplasia. Ultrasound Obstet Gynecol 2000; 16:482-94.

4. Lauria MR, Gonik B, Romero R. Pulmonary hypoplasia: pathogenesis, diagnosis, and antenatal prediction. Obstet Gynecol 1995;86:466-75.

5. Gramellini D, Fieni S, Kaihura C, Piantelli G, Verrotti C. Antepartum amnioinfusion: a review. J Matern Fetal Neonatal Med 2003;14:291-6.

6. Williams O, Hutchings G, Hubinont C, Debauche C, Greenough A. Pulmonary effects of prolonged oligohydramnios following mid-trimester rupture of the membranes--antenatal and postnatal management. Neonatology 2012;101:83-90.

7. Nakayama DK, Glick PL, Harrison MR, Villa RL, Noall R. Experimental pulmonary hypoplasia due to oligohydramnios and its reversal by relieving thoracic compression. J Pediatr Surg 1983;18:347-53.

8. Singla A, Yadav P, Vaid NB, Suneja A, Faridi MM. Transabdominal amnioinfusion in preterm premature rupture of membranes. Int J Gynaecol Obstet 2010;108:199-202.

9. Tan LK, Kumar S, Jolly M, Gleeson C, Johnson P, Fisk NM. Test amnioinfusion to determine suitability for serial therapeutic amnioinfusion in midtrimester premature rupture of membranes. Fetal Diagn Ther 2003;18:183-9.

10. Vergani P, Locatelli A, Verderio M, Assi F. Premature rupture of the membranes at $<26$ weeks' gestation: role of amnioinfusion in the management of oligohydramnios. Acta Biomed 2004;75:62-6.

11. Hofmeyr GJ, Essilfie-Appiah G, Lawrie TA. Amnioinfusion for preterm premature rupture of membranes. Cochrane Database Syst Rev 2011:CD000942.

12. Chin TW, N.G., Abdulhamid I. Pediatric pulmonary hypoplasia treatment and management. Medscape Reference 2009 [cited 2012; Available from: http: //emedicine.medscape.com/article/1005696treatment.

13. Porat S, Amsalem H, Shah PS, Murphy KE. Transabdominal amnioinfusion for preterm premature rupture of membranes: a systematic review and metaanalysis of randomised and observational studies. Am J Obstet Gynecol, 2012;207:393 e1-11.

14. De Santis M, Scavo M, Noia G, Masini L, Piersigilli F, Romagnoli C, Caruso A. Transabdominal amnioinfusion treatment of severe oligohydramnios in preterm premature rupture of membranes at less than 26 gestational weeks. Fetal Diagn Ther 2003;18:412-7.

15. Tranquilli AL, Giannubilo SR, Bezzeccheri V, Scagnoli C. Transabdominal amnioinfusion in preterm premature rupture of membranes: a randomised controlled trial. BJOG 2005;112:759-63.

16. Puertas A, Tirado P, Pérez I, López MS, Montoya F, Cañizares JM, Miranda JA. Transcervical intrapartum amnioinfusion for preterm premature rupture of the membranes. Eur J Obstet Gynecol Reprod Biol 2007;131:40-4.

17. Nageotte MP, Freeman RK, Garite TJ, Dorchester W. Prophylactic intrapartum amnioinfusion in patients with preterm premature rupture of membranes. Am J Obstet Gynecol 1985;153:557-62.

18. Leake RD, Hobel CJ, Okada DM, Ross MG, Williams PR. Neonatal metabolic effects of oral ritodrine hydrochloride administration. Pediatr Pharmacol (New York) 1983;3:101-6.

19. Gowri R, S.S., Evaluation of transabdominal amnioinfusion in the antepartum management of oligohydramnios complicating preterm pregnancies. Journal of Obstetrics and Gynecology of India 2004;54:460-3.

20. Gonzalez R, M.J., Carrillo MP, Sancho-Minano J, Garrote A, Munoz A, et al., The use of amnioinfusion in preterm deliveries. Preliminary results [abstract]. Journal of Perinatal Medicine 2001;29 Suppl 1:629.

21. Vergani, P., et al., OP24.09: Proposal for open randomised trial comparing perinatal outcome following expectant management versus amnioinfusion in PPROM $<25$ weeks with persistent oligohydramnios (amnioinfusion initiative). Ultrasound in Obstetrics \& Gynecology 2007;30:541. 
22. A., L. Open randomised trial comparing perinatal outcome following expectant management versus amnioinfusion in PPROM <25 wks with persistent oligohydramnios. 20086 July 2012]; Available from: http://clinicaltrials.gov/show/NCT00787163.

23. Roberts, D., et al., OP08.06: AMIPROM: a pilot RCT on serial transabdominal amnioinfusion versus expectant management in very early PROM. Ultrasound in Obstetrics \& Gynecology 2012;40(S1):80. 


\section{Chapter 8}

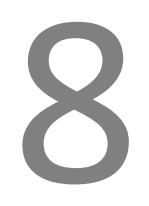

Midtrimester preterm prelabour rupture of

membranes (PPROM). Expectant management or

Amnioinfusion for improving perinatal outcomes

(PPROMEXIL - III trial)

van Teeffelen ASP, van der Ham DP, Willekes C, AI Nasiry S, Nijhuis JG, van Kuijk SMJ, Schuyt E, Mulder ALM, Franssen MTM, Oepkes D, Jansen FAR, Woiski MD, Bekker MN, Bax CJ, Porath MM, de Laat MWM, Mol BW, Pajkrt E Accepted subject to revision 


\section{Abstract}

\section{Background}

Babies born after midtrimester preterm prelabour rupture of membranes (PPROM) are at risk to develop neonatal pulmonary hypoplasia. Perinatal mortality and morbidity after this complication is high. Oligohydramnios in the midtrimester following PPROM is considered to cause a delay in lung development. Repeated transabdominal amnioinfusion with the objective to alleviate oligohydramnios might prevent this complication and might improve neonatal outcome.

\section{Methods/Design}

Women with PPROM and persisting oligohydramnios between 16 and 24 weeks gestational age will be asked to participate in a multi-centre randomised controlled trial. Intervention: random allocation to (repeated) abdominal amnioinfusion (intervention) or expectant management (control). The primary outcome is perinatal mortality. Secondary outcomes are lethal pulmonary hypoplasia, non-lethal pulmonary hypoplasia, survival till discharge from NICU, neonatal mortality, chronic lung disease (CLD), number of days ventilatory support, necrotizing enterocolitis (NEC), periventricular leucomalacia (PVL) more than grade I, severe intraventricular hemorrhage (IVH) more than grade II, proven neonatal sepsis, gestational age at delivery, time to delivery, indication for delivery, successful amnioinfusion, placental abruption, cord prolapse, chorioamnionitis, fetal trauma due to puncture. The study will be evaluated according to intention to treat. To show a decrease in perinatal mortality from $70 \%$ to $35 \%$, we need to randomise two groups of 28 women (two sided test, $\beta$-error 0.2 and $\alpha$-error 0.05 ).

\section{Discussion}

This study will answer the question if (repeated) abdominal amnioinfusion after midtrimester PPROM with associated oligohydramnios improves perinatal survival and prevents pulmonary hypoplasia and other neonatal morbidities. Moreover, it will assess the risks associated with this procedure. 


\section{Background}

Preterm prelabour rupture of membranes (PPROM) before or near the limit of viability is associated with high perinatal morbidity and mortality. Respiratory complications are frequent after periviable PPROM, as well as sepsis, intraventricular haemorrhage, retinopathy and necrotising enterocolitis (NEC). Among respiratory complications pulmonary hypoplasia is an important cause of death. Other respiratory complications consist of pneumonia, Infant respiratory distress syndrome (IRDS) and bronchopulmonary dysplasia (BPD).

PPROM before 26 weeks can delay lung development and can cause pulmonary hypoplasia ${ }^{1}$. Pulmonary hypoplasia is a term to describe an altered pulmonary development characterised by a reduction in the number of pulmonary alveoli or in bronchial branching. In fetal lung development a critical interval, the canalicular phase, exists between 16 and 28 weeks gestation. Gestational age at rupture of membranes has been shown to be inversely related to the risk of pulmonary hypoplasia.

Pulmonary hypoplasia results in severe respiratory failure leading to early neonatal death, respiratory insufficiency with pulmonary haemorrhage, bronchopulmonary dysplasia, or sub-acute lung disease, or sometimes in mild transient respiratory disease ${ }^{2}$. Perinatal mortality approximates $70 \%$ in most series $(55-100 \%)^{3}$.

In a review of 11 studies on midtrimester PPROM, the reported incidence of pulmonary hypoplasia secondary to midtrimester PPROM ranged widely from $1 \%$ to $48 \%{ }^{4}$. A review of 6 studies on PPROM before 24 weeks reported an incidence of pulmonary hypoplasia of $19 \%(n=120)^{5}$. These percentages do not represent the true natural history, given the limitations of these reviews, summarising only retrospective cohorts from tertiary care centres. The wide range in prevalence is partly explained by the absence of uniform pathological and clinical definitions. Histological findings form the basis of the diagnosis pulmonary hypoplasia, however complete autopsy data were often not available ${ }^{2}$. An international recognized definition of pulmonary hypoplasia is lacking, and it rather is a diagnosis by exclusion ${ }^{6}$. Congenital pneumonia, infant respiratory distress syndrome (IRDS) and pulmonary hypoplasia sometimes occur simultaneously, and have overlapping symptoms ${ }^{1}$. Moreover, there were methodological problems in the reviews, such as differences in follow-up and lack of blinded assessment of the endpoints.

Pregnancies complicated by midtrimester PPROM are associated with high immediate and long-term costs. These are caused by extended maternal hospital admissions, increased incidence of premature delivery, and frequent neonatal complications hereafter requiring NICU-admission.

Amnioinfusion might improve fetal outcome by preventing pulmonary hypoplasia, by preventing neurological complications, increasing time to delivery interval, and improving fetal biophysical profile through prevention of umbilical cord compression. It also might prevent fetal deformity ${ }^{7}$. Porat et al. ${ }^{8}$ reviewed serial transabdominal 
amnioinfusion and meta-analysed observational as wel as randomised studies. The only two included randomised studies however were on women with PPROM between 24 and 34 weeks whereas the critical interval for development of pulmonary hypoplasia, the canalicular phase, exists between 16 and 28 weeks gestation. One quasirandomised study included women with PPROM before 24 weeks. There were two observational studies on PPROM before 24 weeks. Recently, Roberts et al. ${ }^{9}$ published the only randomized trial on PPROM between 16 and 24 weeks. They found no difference in the primary outcome (perinatal mortality $19 / 28$ vs. $19 / 28$; RR $1.0 ; 95 \%$ Cl0.70-1.43), maternal or neonatal morbidity. The observed difference in long term outcome (4/28 morbidity free survival at 2 years in the treatment group vs. $0 / 28$ in the group with expectant management) justifies further study.

Adverse events after antepartum transabdominal amnioinfusion have been reported. It is not clear which adverse effects are to be attributed to the procedure rather than to the condition of PPROM and oligohydramnios, since conservatively managed PPROM carries high risks inherent to the condition itself ${ }^{7}$. Waters and Mercer recently reviewed perinatal mortality after conservatively managed PPROM $<26$ weeks ${ }^{5}$. Meta-analysis of 6 studies $(n=275)$ shows a perinatal mortality of $54 \%$, (if restricted to $<24$ weeks this incidence is $57 \%$ ). These data are biased by the fact that patients not amenable to continued expectant management were often excluded (i.e. stillbirths, pregnancy terminations), and therefore survival is likely to be overestimated.

A retrospective analysis by Van der Heijden et al. on outcome after PPROM in three tertiary centres in The Netherlands was recently published ${ }^{10}$. Their study included 14 multiple pregnancies. When these were excluded, in 164 singleton pregnancies with PROM before 24 weeks there was a perinatal mortality of $71 \%$. Of all mortality $38 \%$ occurred in the neonatal period (data not published). It can be questioned whether all pregnancies with PROM $<24$ weeks have been referred. Lethal pulmonary hypoplasia was documented in only 16 cases $(10 \%)$, which is probably an underestimation as discussed before (personal communication by Van der Heijden).

In summary, midtrimester PPROM is associated with a high incidence of perinatal mortality, pulmonary hypoplasia and other neonatal complications. Exact incidences are difficult to obtain because of selection biases, probably leading to substantial underreporting. Diagnosis of pulmonary hypoplasia is difficult due to overlapping symptoms and absence of uniform definitions. Amnioinfusion might be beneficial, however there is no solid evidence to incorporate this seemingly safe procedure in daily practice. Therefore we believe there is the need to assess the role of amnioinfusion after midtrimester PPROM. We are currently conducting a multicentre randomised controlled clinical trial. This study is conducted within the Dutch Obstetric Consortium, a collaborative effort of obstetric clinics in The Netherlands to perform clinical trials. Seven Dutch perinatal centres with NICU facilities participate in this trial. 


\section{Methods and design}

\section{Aims}

The primary aim of this study is to evaluate the effectiveness of amnioinfusion compared to expectant management for relieving oligohydramnios in women with midtrimester PPROM occurring before 24 weeks gestational age in reducing perinatal mortality and neonatal morbidities.

\section{Participants/eligibility criteria}

All women with a singleton pregnancy who are first diagnosed between 16 and 24 weeks gestational age with oligohydramnios secondary to PPROM, at least 72 hours after PPROM was diagnosed, but no longer than 21 days after the diagnosis of oligohydramnios, are eligible for the trial. Women with oligohydramnios secondary to iatrogenic PPROM are also eligible.

We will exclude women with signs of uterine contractions, $(8$ uterine contractions per hour) intrauterine infection (temperature $>38^{\circ} \mathrm{C}$ plus fetal tachycardia or uterine tenderness or foul/purulent amniotic fluid), a pregnancy complication (hypertension, HELLP syndrome, preeclampsia or other) in which there is a need for termination of pregnancy, placental or major structural fetal anomalies, signs of cervical incompetence (visible cervical dilatation or a cervical length of $<25 \mathrm{~mm}$ ), and women whose child has signs of fetal distress (abnormal biophysical profile).

\section{Procedures, recruitment, randomisation and collection of data}

The research nurse and/or the staff of participating hospitals will identify eligible women. Prior to randomisation, in all patients amniotic fluid loss will be objectified by sterile speculum examination for visible fluid loss from the cervical os, by a nitrazineand/or ferning test. Speculum examination will be performed to exclude signs of cervical incompetence (visible dilatation). Hereafter patients will undergo an ultrasound examination to determine the single deepest pocket (SDP) of amniotic fluid and to exclude placental and or fetal structural anomalies. At this time ultrasound measurements used in the prediction of pulmonary hypoplasia - TC/AC (thoracic circumference/ abdominal circumference), TC/FL (thoracic circumference/ femur length), Doppler measurement of pulmonary artery proximal branch peak systolic velocity, 3D lung volume measurement -, will be performed by specialized personnel. If oligohydramnios is present $(S D P<2 \mathrm{~cm})$ patients will be counselled for the study. Randomisation, will take place immediately after informed consent has been obtained, at least 72 hours after diagnosis of PPROM. See also Figure 8.1. 


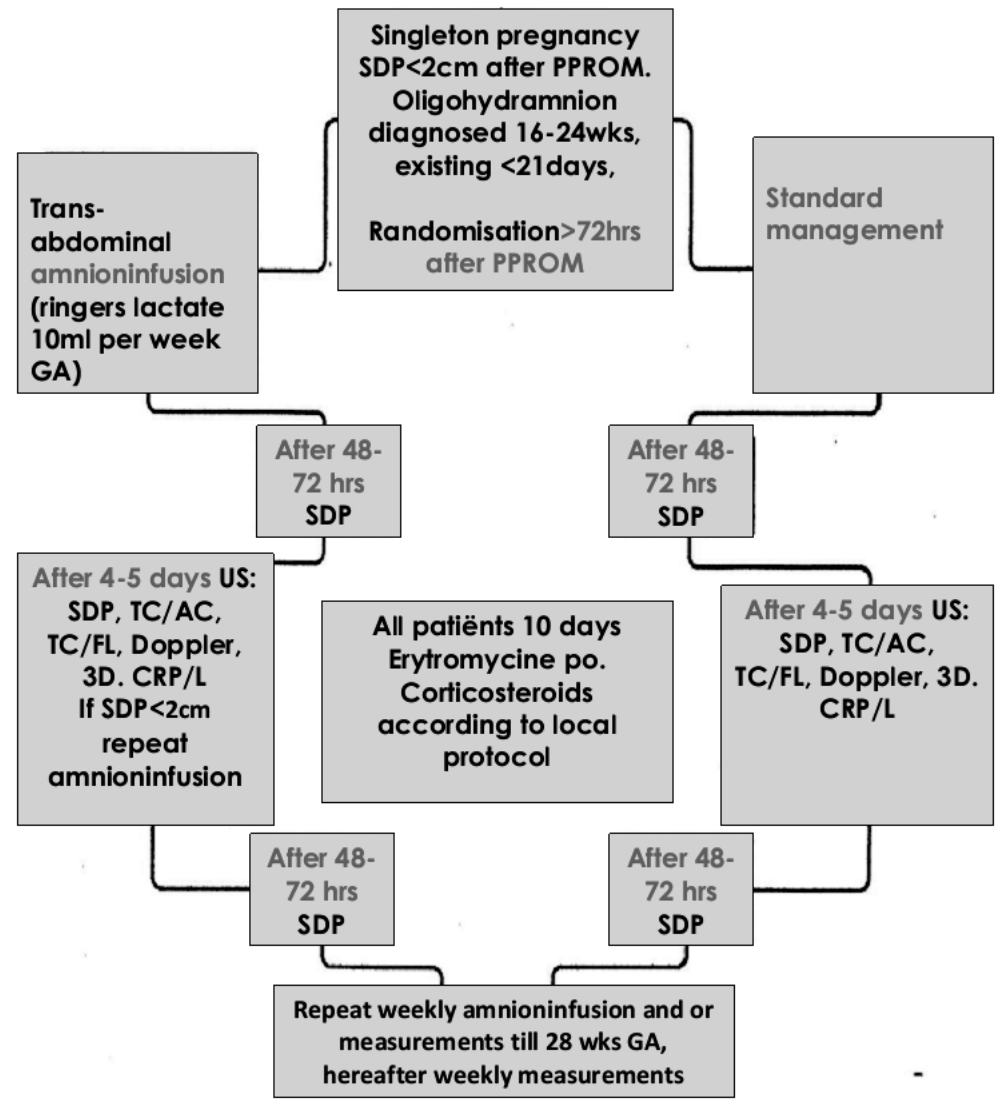

Figure 8.1 Flowchart PPROMEXIL-III trial.

Randomisation will be performed, using an internet-based procedure, with the use of a permuted-block design, after informed consent and baseline data have been entered in a web-based database system.

Treatment allocation will obviously have to be unblinded for patients and clinicians and sonographers, and the personnel performing the ultrasound investigations, however, allocation will remain blinded for paediatricians, pathologists and/or radiologists who are assessing outcomes.

All data are collected, coded and processed with adequate precautions to ensure patient confidentiality. The investigators will publish the results of the study in a peer reviewed medical journal as soon as appropriate. 


\section{Interventions}

The intervention being evaluated is trans-abdominal amnioinfusion. After sterile preparation of the abdomen, a pocket of fluid is identified by ultrasound guidance after which a needle is advanced into this pocket. After insuring proper placement by withdrawing a small amount of fluid, the desired volume of fluid (Ringers lactate), defined by the number of weeks of gestational age times 10 millilitres, is infused manually. This procedure is repeated on a weekly basis if oligohydramnios re-occurs or persists.

If, after initial amnioinfusion, uterine contractions and signs of infection have been excluded, discharge is optional. Fluid retention will be assessed by measurement of SDP 48-72 hours after first amnioinfusion. Five to seven days after initial amnioinfusion, SDP is reassessed, as well as infection parameters (white cell count and CRP). Measurement of TC/AC, TC/FL, Doppler measurement, 3D lung volume measurement, will be performed by specialised personnel. If persisting or re-occurring oligohydramnios is diagnosed, amnioinfusion will be repeated. The same procedure will be repeated on a weekly basis until 28 weeks' gestation.

Patients randomised to expectant management will undergo the same clinical and ultrasound examination bi-weekly (once a week measurement of SDP, TC/AC, TC/FL, Doppler, 3D lung volume, infection parameters, and on the second weekly visit assessment of fetal well-being and measurement of SDP). These patients can, if signs of premature labour or infection have been excluded, at the discretion of the local physician, be discharged as well (Figure 8.1). All discharged patients will be instructed to take their temperature twice daily and contact the hospital in case of fever (temperature $>37,8^{\circ} \mathrm{C}$, rectally measured) or suspected infection. Patients with midtrimester PPROM are usually hospitalised after 24 weeks in a tertiary centre.

\section{Use of co-intervention}

Corticosteroids are given according to local protocol, usage will be recorded in the case report form. All patients will receive treatment with antibiotics (Erythromycin orally $250 \mathrm{mg} 4$ times per day for ten days)

Patients may stop participating in the study at any time for any reason if they wish to do so without any consequences. The investigator can decide to withdraw a subject from the study for urgent medical reasons.

\section{Study parameters / endpoints}

We will compare two groups:

1) Amnioinfusion for midtrimester PPROM with oligohydramnios, and

2) Expectant management for midtrimester PPROM with oligohydramnios. 
The primary outcome measure will be perinatal mortality, defined as intrauterine death, intrapartum death or neonatal death in the first 28 days of life.

Secondary outcomes are:

- Gestational age at delivery.

- Time from membrane rupture to delivery.

- Indication for delivery.

- Successful amnioinfusion (defined as retention of infused fluid as defined by a single deepest pocket of amniotic fluid of more than $2 \mathrm{~cm}$ for at least 48 hours).

- Placental abruption.

- Cord prolapse.

- Chorioamnionitis, (defined as fever before or during labour as a temperature greater than $37.5^{\circ} \mathrm{C}$ on two occasion more than one hour apart or a temperature > $38.0^{\circ} \mathrm{C}$ with either uterine tenderness (or contractions), leucocytosis, maternal or fetal tachycardia, or a foul-smelling vaginal discharge in absence of any other cause of hyperpyrexia).

- Fetal trauma due to puncture.

- Maternal length of stay in hospital

Occurrence of secondary outcomes placental abruption, cord prolapse, chorioamnionitis and fetal trauma will be related to the number of amnioinfusions that have been performed.

Neonatal endpoints:

- Lethal pulmonary hypoplasia diagnosed according to radiological, clinical and pathological criteria. Pathological criteria are based on radial alveolar counts and lung/body weight ratios according to Askenazi and Perlman ${ }^{9}$, when radial alveolar counts cannot be obtained, criteria by Wigglesworth et al will be used ${ }^{10}$. Clinical criteria used to diagnose lethal pulmonary hypoplasia are: immediate onset of severe respiratory insufficiency after birth, small lung capacity and requirement of high ventilatory pressures in the absence of obstruction or atelectasis. Radiological criteria according to Leonidas will be used ${ }^{11}$.

- Non-lethal pulmonary hypoplasia diagnosed using same clinical and radiological criteria in surviving neonates.

- Survival till discharge from NICU.

- Neonatal mortality, defined as neonatal death in the first 28 days of life.

- Chronic lung disease (CLD), CLD defined as oxygen dependency at 28 days of life ${ }^{12}$.

- Number of days on ventilatory support.

- Length of stay in hospital.

- Necrotising enterocolitis (NEC) more than stage I and defined according to the criteria of Bell et al. ${ }^{13}$. 
- Periventricular leukomalacia (PVL) more than grade I and defined according to the classification described by De Vries et al. ${ }^{14}$.

- Severe intraventricular hemorrhage (IVH) more than grade II and defined according to the criteria of Papile et al $^{15}$.

- Proven neonatal sepsis defined as (1) Positive blood culture taken at birth or (2) within 72 hours two or more symptoms of infection (apnea, temperature instability, lethargy, feeding, intolerance, respiratory distress, hemodynamic instability) plus one of three items: (a) positive blood culture (culture proven sepsis); (b) CRP>20 (suspicion sepsis); (c) positive surface cultures of a known virulent pathogen (suspicion sepsis).

The neonatal endpoints will be defined by two neonatologists. The status of these endpoints will be evaluated at six months corrected age. Additional application for long-term follow-up of children ( 2 and 5 years) and mothers will be performed.

\section{Safety reporting}

This study has been approved by the ethics committee (METC) of the Academic Medical Centre Amsterdam and by the boards of management of all participating hospitals.

In accordance with the National Medical Research Act (WMO, Section 10, subsection 1), the investigator will inform the subjects and the reviewing accredited METC in case it appears that the disadvantages of participation may be significantly greater than was foreseen in the research proposal. All observed or volunteered adverse events, regardless of suspected causal relationship to the intervention, will be recorded.

An adverse event (AE) is defined as an event after which the intervention has to be stopped. Reasons for discontinuation are placental abruption, cord prolapse, chorioamnionitis, fetal loss, fetal trauma due to puncture, premature labour and delivery.

A serious adverse event (SAE) is defined as fetal or maternal death or illness necessitating IC or CCU treatment. All SAEs will be reported to the accredited METC that approved the protocol, according to the requirements of that METC. In addition to the expedited reporting of SAE's, the principal investigator will submit, once a year throughout the clinical trial, a safety report to the accredited METC.

A Data Safety Monitoring Board (DSMB) will be established prior to start of the trial.

\section{Sample size calculation}

A sample size calculation was based on an expected rate of perinatal mortality of $70 \%$ with expectant management, to be reduced to $35 \%$ with amnioinfusion. Using a twosided test, with a $\beta$-error of 0.20 and an $\alpha$-error of 0.05 a sample size of 56 women (28 in each $\mathrm{arm}$ ) is needed. 
An interim analysis is planned after the follow up data of the first 28 women that have been included. The analysis will be performed using the O'Brien-Flemming alpha spending function meaning a nominal $P$ value of less than 0.005 will be considered to indicate statistical significance ${ }^{16}$. If there is a significant difference in the primary outcome the trial will be stopped.

\section{Statistical analysis}

The analysis of the randomised clinical trial will be performed on an intention-to-treat principle. The differences between the amnioinfusion and expectant management will be assessed by calculating the ratio of the outcome rates in the two groups. Hence, the measure of association is a relative risk (RR) with a $95 \%$ confidence interval $(\mathrm{Cl})$, calculated using a log-binomial model. Time to delivery will be evaluated by Cox proportional hazard analysis, Kaplan-Meier estimates and tested with a log rank test.

In case of equivalence between outcomes, the analysis will be repeated on an "astreated" basis. Subsequently, primary and secondary outcomes will be described in a subgroup of women with successful amnioinfusion (retention of infused fluid first 48 hours). All analyses will be adjusted for the fact that an interim analysis will be performed using the O'Brien-Flemming alpha spending function[16]. Consequently, a nominal $P$ value of less than 0.049 will be considered to indicate statistical significance.

\section{Discussion}

There are signs that pregnancies complicated by oligohydramnios after midtrimester PPROM might benefit from amnioinfusion. However, currently there is insufficient evidence to recommend this procedure. The benefits might be increased neonatal survival and decreased pulmonary complications, especially pulmonary hypoplasia. Potential harms include placental abruption, premature labour and delivery, cord prolapse, chorioamnionitis, fetal loss, fetal trauma due to puncture. Of these, only the last mentioned is not a known potential complication of the underlying condition itself as well (midtrimester PPROM). Expectant management indeed carries these same risks. At present, there is no evidence on which a rational choice between expectant management or therapeutic amnioifusion can be based. 


\section{References}

1 Kilbride H.W., Thibeault D.W. Neonatal complications of preterm rupture of membranes. Clin Perinatol. 2001; 28:761-85.

2 Sherer DM, Davis JM, Woods JR Jr. Pulmonary hypoplasia: a review. Obstetrical \& gynecological survey 1990;45:792-803.

3 Laudy JA, Wladimiroff JW. The fetal lung. 2: Pulmonary hypoplasia. Ultrasound Obstet Gynecol. 2000;16:482-94.

4 Grisaru-Granovsky S, Eitan R, Kaplan M, Samueloff A. Expectant management of midtrimester premature rupture of membranes: a plea for limits. J Perinatol. 2003; 23:235-9.

5 Waters TP, Mercer BM. The management of preterm premature rupture of the membranes near the limit of fetal viability. Am J Obstet Gynecol. 2009 Sep;201:230-40.

6 Geary C, Whitsett J. Inhaled nitric oxide for oligohydramnios-induced pulmonary hypoplasia: a report of two cases and review of the literature. J Perinatol. 2002; 22:82-5.

7 Gramellini D, Fieni S, Kaihura C, Piantelli G, Verrotti C. Antepartum amnioinfusion: a review. The journal of maternal-fetal \& neonatal medicine : the official journal of the European Association of Perinatal Medicine, the Federation of Asia and Oceania Perinatal Societies, the International Society of Perinatal Obstetricians. 2003;14:291-6.

8 Porat S, Amsalem H, Shah PS, Murphy KE. Transabdominal amnioinfusion for preterm premature rupture of membranes: a systematic review and metaanalysis of randomized and observational studies. American journal of obstetrics and gynecology. 2012;207:393 e1-11.

9 Roberts D, Vause S, Martin W, Green P, Walkinshaw S, Bricker L, et al. Amnioinfusion in very early preterm premature rupture of membranes - pregnancy, neonatal and maternal outcomes in the AMIPROM randomised controlled pilot study. Ultrasound in obstetrics \& gynecology : the official journal of the International Society of Ultrasound in Obstetrics and Gynecology. 2013 Nov 21. Epub $2013 / 11 / 23$.

10 van der Heyden JL, van der Ham DP, van Kuijk S, Notten KJ, Janssen T, Nijhuis JG, et al. Outcome of pregnancies with preterm prelabor rupture of membranes before 27 weeks' gestation: a retrospective cohort study. European journal of obstetrics, gynecology, and reproductive biology. 2013;170:125-30.

11 Askenazi SS, Perlman M. Pulmonary hypoplasia: lung weight and radial alveolar count as criteria of diagnosis. Arch Dis Child. 1979;54: 614-618.

12 Wigglesworth JS, Desai R. Use of DNA estimation for growth assessment in normal and hypoplastic fetal lungs. Arch Dis Child. 1981;56: 601-605.

13 Leonidas JC, Bhan I, Beatty EC. Radiographic chest contour and pulmonary air leaks in oligohydramniosrelated pulmonary hypoplasia (Potter's syndrome). Invest Radiol 1982;17: 6-10.

14. Shennan AT, Dunn MS, Ohlsson A, Lennox K, Hoskins EM. Abnormal pulmonary outcomes in premature infants: prediction from oxygen requirement in the neonatal period. Pediatrics 1988; 82:527-532.

15 Bell MJ, Ternberg JL, Feigin RD et al. Neonatal necrotizing enterocolitis. Therapeutic decisions based upon clinical staging. Ann Surg 1978; 187:1-7.

16 de Vries LS, Eken P, Dubowitz LM. The spectrum of leukomalacia using cranial ultrasound. Behav Brain Res 1992; 49:1-6.

17 Papile LA, Burstein J, Burstein R, Koffler $\mathrm{H}$. Incidence and evolution of subependymal and intraventricular hemorrhage: a study of infants with birth weights less than 1,500 gm. J Pediatr 1978; 92:529-534.

18 O'Brien PC, Fleming TR. A multiple testing procedure for clinical trials. Biometrics 1979;35:549-56. 



\section{Chapter}

Concluding remarks and future perspectives 
Chapter 9 


\section{Concluding remarks and future perspectives}

Midtrimester PPROM continues to be a challenging problem. High perinatal mortality and morbidity rates have been reported, and are mainly caused by prematurity, pulmonary hypoplasia and infection. Counseling parents is difficult since limited data are available. The data that are available are often from small retrospective studies, that are susceptible to selection bias and verification bias.

Counseling and clinical decision making is hindered by two unanswered questions. Firstly, it is not well known what the chance is of a short latency (and thus what are the chances of an extreme preterm birth), and secondly it is not known how longer latency affects outcome.

The mechanism that underlies the PPROM might give support in answering these questions, but is, at present usually unknown. It is proposed that there are four pathways causing preterm birth (see Figure 9.1, adapted from Lockwood), with or without PPROM. These are stress, inflammation, abruptio placentae, and pathologic uterine distension ${ }^{1}$. An intrinsic weakness of the membranes might also contribute to PPROM. Obviously there are mixed images.

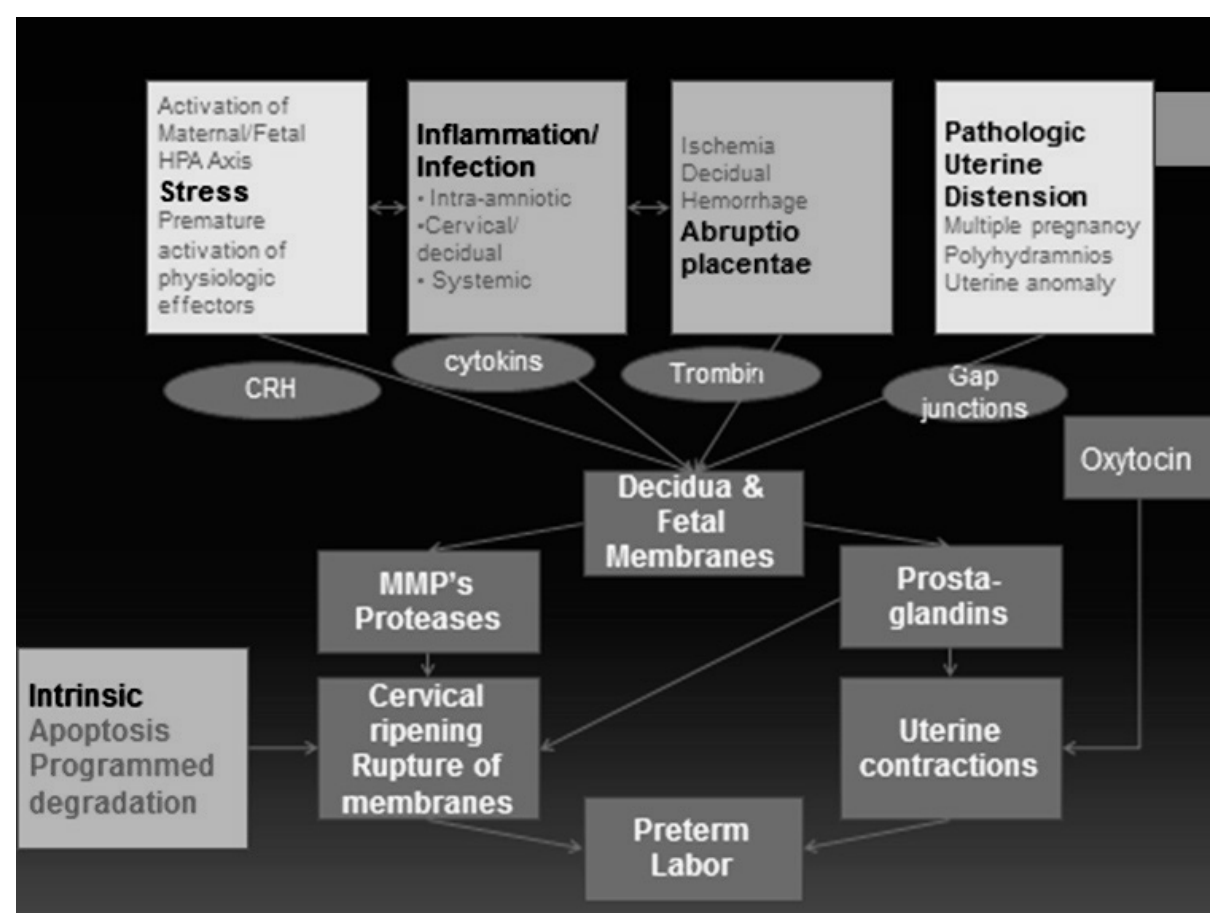

Figure 9.1 Pathways of preterm delivery adapted from Lockwood and Kuczynski ${ }^{1}$. 
Thus, for some pregnancies midtrimester PROM is a sign of antenatal exposure to intraamniotic inflammation, whilst in other pregnancies inflammation seems to play a smaller role. It seems that inflammation in itself has an impact on outcome even without the existence of infection ${ }^{2}$. Infection might lead to inflammation and FIRS, with long-term neurological and respiratory damage for the newborn ${ }^{3}$. Furthermore a prolonged epsiode with oligohydramnios after midtrimester PPROM can lead to pulmonary hypoplasia. To investigate the impact of extended stay in utero, stratification of outcomes for gestational age at delivery can provide insight into the impact of latency on these outcomes.

With this intention, analysis of the Dutch perinatal registry (PRN) data in Chapter 2 was done. This proved difficult as there is an important bias caused by the minimum gestational age at delivery of 22 weeks that is inherent to the PRN database. Yet there seems to be no obvious deterioration with longstanding PPROM if one compares groups with different gestational age at ROM who are born at the same gestational age. The data can be used when counseling women with PPROM who reach 22 weeks. Longer latency nor early gestational age should not be used as an argument to terminate the pregnancy. Before 22 weeks, expectant management is a reasonable course given the high percentage of morbidity free survival in the ones who do survive.

As illustrated in Chapter 3 identification of patients with PPROM remains a sometimes difficult task. By using conventional methods the diagnosis is not clear in about $10 \%$ of cases. The review shows that the majority of studies carried out were not designed to answer the question that matters, namely, does equivocal fluid loss prove to be amniotic fluid or not. Furthermore it should be pointed out that it is not clear what the entity 'equivocal ruptured membranes' means in case of a true positive test. In the group of women with PPROM near term, it may have little relevance since expectant management seems preferable either way. However in the group with midtrimester PROM it is more likely that subclinical inflammation is involved. In this case an accurate diagnosis is likely to be more significant. New tests should be evaluated in this group (equivocal early PPROM), using a gold- or silver standard.

The PRN data in chapter 2, as well as unpublished data by van der Heyden, as well as extrapolated results of research by Manuck ${ }^{4}$ provide indirect evidence that expectant management is generally associated with a better outcome for early cases of PROM. Considering the steep decrease in perinatal mortality after preterm birth between 24 and 28 weeks, this is not a surprise. If opting for expectant management, prediction of neonatal inflammation and infection and pulmonary hypoplasia is important.

In a retrospective cohort of patients with PPROM we assessed whether the C-reactive protein and Leucocytes were predictive of neonatal sepsis (Chapter 4). We found poor predictive capacity, and concluded that the decision to induce labour should not be based on these tests. This is in line with other reports. Indeed the role of monitoring CRP and leucocytes has not been established as useful in clinical practice ${ }^{5,6}$. Possibly there is a place for these tests in the context of a prediction model when multiple 
variables are added as was done by van der Ham (van der Ham, van Kuijk, unpublished data).

The other clinically relevant question is whether lethal pulmonary hypoplasia is likely. In case of a positive test with a $100 \%$ positive predictive value, termination of pregnancy is justified. The metanalyses in Chapters $\mathbf{5}$ and $\mathbf{6}$ in this paper show that there is only a very limited predictive value found from the available clinical data and currently used imaging techniques. As a single parameter, gestational age at rupture has the best predictive capacity at present, and scored better than the best ultrasound predictor. Therefore, as of yet, clinical practice and decision making should not be based on imaging parameters. A number of parameters combined offer possibilities as shown by Laudy and Tibboel et al. ${ }^{7}$ and deserve further investigation. This will be examined in the ongoing PPROMEXIL - III trial. Should a combination of parameters have a sufficient predictive value, diagnosis should preferably be early in order to allow for a timely termination of pregnancy.

Considering the supposed pathophysiological mechanisms of disturbed pulmonary development through a decreased amount of amniotic fluid and risk of preterm labour, respiratory and neurological damage through presence of subclinical infection, it seems logical to infuse fluid in the amniotic cavity. Uncontrolled studies show a possible benefit, however, adequate proof through randomised controlled studies is currently absent as was reviewed for the Cochrane database (Chapter 7). Roberts et al. have started a trial in the UK, from which the results recently have been published. Their study compared weekly serial amnioinfusion with expectant management in women with oligohydramnios due to PPROM between 16 and 24 weeks gestation, with a minimum latency of 10 days. There was no difference in the primary outcome (perinatal mortality $19 / 28$ vs. $19 / 28$; RR $1.0 ; 95 \%$ Cl0.70,1.43), maternal or neonatal morbidity. The observed difference in long term outcome $(4 / 28$ morbidity free survival at 2 years in the treatment group vs. 0/28) does not justify treatment, due to inadequate power, however it does justify further study ${ }^{8}$. In Italy there is a similar trial on-going ${ }^{9}$. In the Netherlands a randomised controlled trial - the PPROMEXIL-III study was started. Meta-analysis of these trials will be done in the scheduled update of the Cochrane review.

The PPROMEXIL-III trial is conducted by the Dutch consortium, which provides an excellent infrastructure to answer clinical questions like this in a multicenter setting. After the upcoming reorganisation of the consortium hopefully such studies can continue to take place. The protocol of the PPROMEXIL-III study is outlined in

\section{Chapter 8.}




\section{Recommendations for future research}

Diagnosis of PPROM: new tests should preferably be evaluated in patients with equivocal early PPROM using a gold- or silver standard. In the same studies the prognosis of equivocal PPROM should be clarified and compared to overt PPROM.

There is a substantial percentage group of women with midtrimester PROM who are still pregnant after several weeks. At present it is not possible to identify fetuses who are at increased risk for extreme preterm birth, lethal pulmonary hypoplasia, or who are being damaged by on-going inflammation or infection during expectant management after PPROM.

A number of parameters (clinical as well as imaging) combined might identify patients at risk of lethal pulmonary hypoplasia. A combination of tests with $100 \%$ positive predictive value, early in pregnancy could allow for a timely termination of pregnancy.

Development of prediction models incorporating CRP and leucocytes as well as multiple other variables might identify fetuses at high risk of FIRS. In the future, biomarkers or new microbiological techniques which can predict this risk might become available. Proteomics can identify biomarkers of use, and might gain insight in the pathway that has led to the PPROM.

Distinct therapies, new, or already in use, might show benefit in smaller trials for these specific subgroups and subsequently may improve long term outcome after midtrimester PROM. Trials on serial amnioinfusion are being performed. (Individual Participant Data) Meta-analysis might answer the clinical question of their safety and efficacy. Obviously, non -traditional treatments have to be evaluated in a randomised controlled setting before being implemented. 


\section{References}

1. Lockwood CJ, Kuczynski E., Risk stratification and pathological mechanisms in preterm delivery. Paediatr Perinat Epidemiol 2001;15 Suppl 2:78-89.

2. Yoon BH, Romero R, Moon JB, Shim SS, Kim M, Kim G, Jun JK. Clinical significance of intra-amniotic inflammation in patients with preterm labour and intact membranes. Am J Obstet Gynecol 2001;185:1130-6.

3. Galinsky R, Polglase GR, Hooper SB, Black MJ, Moss TJ. The consequences of chorioamnionitis: preterm birth and effects on development. J Pregnancy 2013;2013:412831.

4. Manuck TA, Maclean CC, Silver RM, Varner MW. Preterm premature rupture of membranes: does the duration of latency influence perinatal outcomes? Am J Obstet Gynecol 2009;201:414 e1-6.

5. Tita AT, Andrews WW. Diagnosis and management of clinical chorioamnionitis. Clin Perinatol 2010;37: 339-54.

6. Genc MR, Ford CE. The clinical use of inflammatory markers during pregnancy. Curr Opin Obstet Gynecol 2010;22:116-21.

7. Laudy JA, Tibboel D, Robben SG, de Krijger RR, de Ridder MA, Wladimiroff JW. Prenatal prediction of pulmonary hypoplasia: clinical, biometric, and doppler velocity correlates. Pediatrics 2002;109:250-8.

8. Roberts, D., et al., Amnioinfusion in very early preterm premature rupture of membranes - pregnancy, neonatal and maternal outcomes in the AMIPROM randomised controlled pilot study. Ultrasound Obstet Gynecol, 2013 Nov 21. [Epub ahead of print].

9. Locatelli, A. Open randomised trial comparing perinatal outcome following expectant management versus amnioinfusion in PPROM <25 wks with persistent oligohydramnios. 20086 July 2012]; Available from: http://clinicaltrials.gov/show/NCT00787163. 

Conclusies en toekomstperspectieven 


\section{Conclusies en toekomstperspectieven}

Midtrimester PPROM blijft een uitdagend probleem, gekenmerkt door hoge perinatale morbiditeit en mortaliteit. Deze worden vooral veroorzaakt door prematuriteit, longhypoplasie en infectie. Het counselen van ouders is moeilijk, omdat er onvoldoende gegevens beschikbaar zijn. De gegevens die beschikbaar zijn, komen vaak van kleine retrospectieve studies, die gevoelig zijn voor selectie- en verificatie bias.

Counseling en klinische besluitvorming wordt met name beperkt door twee onbeantwoorde vragen. Ten eerste is het niet bekend wat de kans is op een korte 'latency' - het interval tussen het breken van de vliezen en de partus - (en dus: wat zijn de kansen op een extreme vroeggeboorte), ten tweede is het niet bekend hoe een langere latency de uitkomst beïnvloedt.

Kennis van het mechanisme dat aan PPROM ten grondslag ligt zou kunnen helpen bij het beantwoorden van deze vragen, maar tot op heden is de oorzaak meestal onbekend. Verondersteld wordt dat er vier wegen zijn die leiden naar vroeggeboorte (zie afbeelding, gemodificeerd van Lockwood en Kuczynski), met of zonder PPROM. Deze zijn stress, inflammatie, abruptio placentae en uterine distensie ${ }^{1}$. Een intrinsieke zwakte van de vliezen kan ook bijdragen aan het ontstaan van PPROM. Uiteraard zijn er mengbeelden.

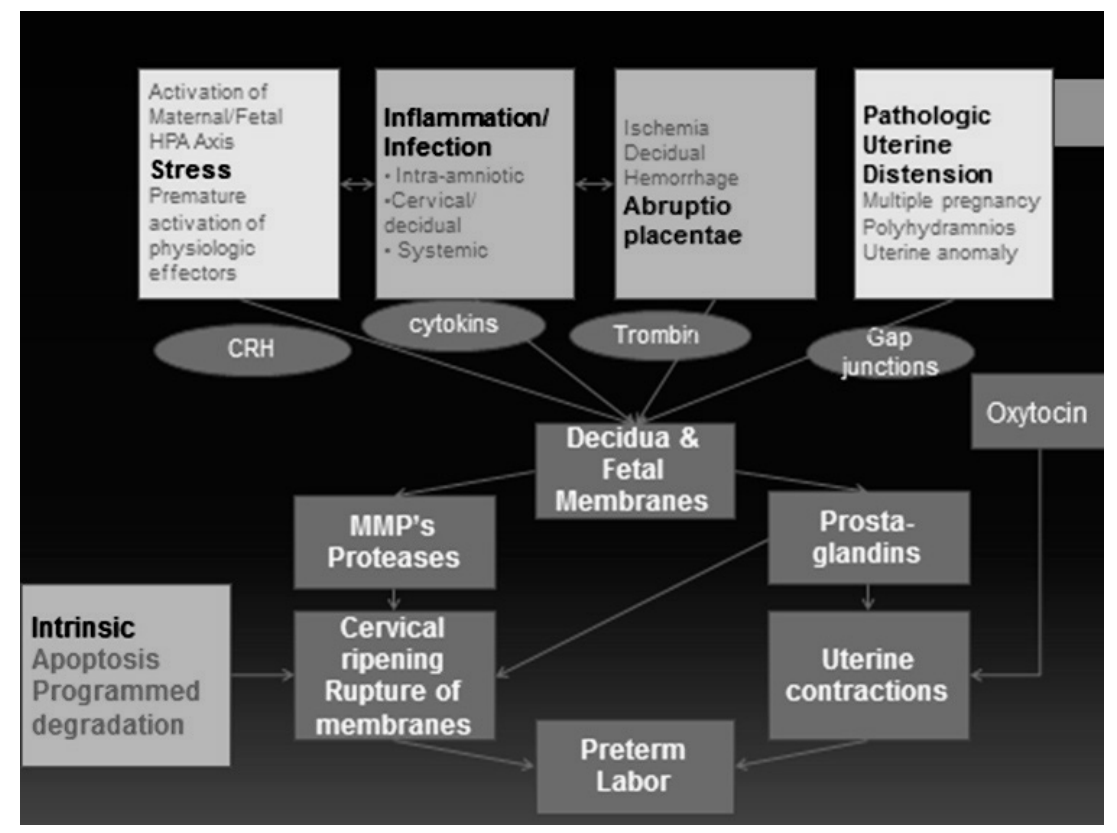

Pathways naar vroeggeboorte (gemodificeerd van Lockwood en Kuczynski ${ }^{1}$ ) 
Bij sommige zwangerschappen is midtrimester PROM dus een teken van prenatale blootstelling aan intra - amniotische inflammatie, terwijl in andere zwangerschappen inflammatie een kleinere rol lijkt te spelen. Het lijkt erop dat inflammatie op zich gevolgen heeft voor de uitkomst, zelfs zonder het bestaan van infectie ${ }^{2}$.

Infectie kan leiden tot inflammatie en FIRS (fetal inflammatory respons syndrome) met ook op lange termijn neurologische schade en beschadiging van de luchtwegen ${ }^{3}$. Daarnaast kan een langdurige episode met oligohydramnios als gevolg van midtrimester PPROM leiden tot longhypoplasie. Om de impact van een langdurig verblijf in de baarmoeder te onderzoeken, kan stratificatie van uitkomsten voor de factor 'zwangerschapsduur bij bevalling' inzicht geven in de impact van latency op deze uitkomsten.

Met dit voornemen, werden in hoofdstuk 2 gegevens van de Nederlandse perinatale registratie (PRN) geanalyseerd. Dit bleek moeilijk, aangezien de PRN database een zwangerschapsduur ten tijde van de geboorte van 22 weken als ondergrens kent. Dit levert een belangrijke bias op. Toch lijkt er geen duidelijke verslechtering met langdurige PPROM te zijn als men groepen vergelijkt met verschillende zwangerschapsduur ten tijde van ROM, geboren met dezelfde zwangerschapsduur. De gegevens kunnen worden gebruikt bij het counselen van vrouwen met PPROM die 22 weken hebben bereikt. Langere latency noch vroege zwangerschapsduur ten tijde van ROM zouden geen argument moeten zijn om de zwangerschap af te breken. Vóór 22 weken is er uiteraard een aanzienlijke mortaliteit, echter een afwachtend beleid is toch een redelijke optie gezien het hoge percentage van morbiditeit-vrije overleving binnen de groep van overlevenden.

Hoofdstuk 3 illustreert het gegeven dat het stellen van de diagnose PPROM soms een moeilijke taak blijft. Door gebruik te maken van de conventionele methode blijft de diagnose onduidelijk in ongeveer $10 \%$ van de gevallen. Het review toont dat de meerderheid van de uitgevoerde studies niet werd ontworpen om de vraag te beantwoorden die er werkelijk toe doet, namelijk, is twijfelachtig vochtverlies vruchtwaterverlies of niet. Verder moet worden opgemerkt dat het niet duidelijk is wat de entiteit dubieus gebroken vliezen betekent in het geval van een juist positieve test. In de groep vrouwen met PPROM nabij de uitgerekende datum, zal het weinig relevantie hebben aangezien een afwachtend beleid hoe dan ook de voorkeur heeft. Maar in de groep met midtrimester PROM is het waarschijnlijker dat er een relatie met subklinische ontsteking is. In dit geval is een nauwkeurige diagnose mogelijk wel relevant. Nieuwe tests moeten worden geëvalueerd in deze groep (vroegtijdig dubieus gebroken vliezen), met een gouden of zilveren standaard.

De PRN gegevens in hoofdstuk 2, ongepubliceerde gegevens door van der Heyden, alsmede geëxtrapoleerde resultaten van onderzoek door Manuck et al. ${ }^{4}$ leveren 
indirect bewijs dat afwachtend beleid in het algemeen geassocieerd is met betere uitkomsten in geval van vroege PROM. Gezien de sterke daling van de perinatale mortaliteit na vroeggeboorte tussen 24 en 28 weken, is dit geen verrassing. Als de keuze voor een afwachtend beleid gemaakt is, wordt vervolgens de voorspelling van neonatale inflammatie en infectie en pulmonale hypoplasie belangrijk.

In een retrospectief cohort van patiënten met PPROM onderzochten we of het C-reactief proteïne (CRP) en leukocyten voorspellend waren voor neonatale sepsis (hoofdstuk 4). We vonden een zwak voorspellend vermogen, en concludeerden dat de beslissing om weeën op te wekken niet gebaseerd moet zijn op deze tests. Dit is in overeenkomst met reeds gepubliceerde bevindingen. De bruikbaarheid van CRP en leukocyten-controle is niet aangetoond in de klinische praktijk ${ }^{5,6}$. Mogelijk is er wel een plaats voor deze tests in het kader van een predictiemodel waarin meerdere variabele toegevoegd worden, zoals werd gedaan door van der Ham (Van der Ham, van Kuijk, ongepubliceerde data).

De andere klinisch relevante vraag is of er lethale longhypoplasie aanwezig is of gaat zijn. Bij een positieve test met een $100 \%$ positief voorspellende waarde is zwangerschapsafbreking gerechtvaardigd. Uit de metanalyses in de hoofdstukken 5 en 6 in dit document blijkt dat de beschikbare klinische gegevens en de momenteel gebruikte beeldvormende technieken slechts een zeer beperkte voorspellende waarde hebben. Op dit moment heeft de parameter 'zwangerschap ten tijde van het breken van de vliezen' de beste voorspellende waarde, deze scoorde beter dan de best voorspellende echo parameter. Daarom kunnen, op dit moment, klinische beslissingen niet genomen worden op basis van beeldvormende parameters. Een aantal parameters (klinische en beeldvormende) gecombineerd bieden wellicht mogelijkheden zoals werd beschreven door Laudy en Tibboel et al. ${ }^{7}$ dit verdient nader onderzoek. Hier zal naar worden gekeken in de lopende PPROMEXIL - III trial. Indien een combinatie van parameters voldoende voorspellende waarde biedt, dient het diagnosticeren bij voorkeur vroeg in de zwangerschap plaats te vinden zodat een tijdige beëindiging van zwangerschap mogelijk is.

Gezien de veronderstelde pathofysiologische mechanismen van verstoorde pulmonale ontwikkeling als gevolg van een verminderde hoeveelheid vruchtwater en het risico van vroegtijdige partus, respiratoire en neurologische schade ten gevolge van de aanwezigheid van subklinische infectie, lijkt het logisch om vocht in de amnionholte te infunderen. Ongecontroleerde studies tonen een mogelijke voordeel, voldoende bewijs door gerandomiseerde gecontroleerde studies is momenteel echter afwezig. Dit werd beschreven in het Cochrane -review (hoofdstuk 7). Roberts et al. deden een trial in het Verenigd Koninkrijk, waarvan de resultaten onlangs zijn gepubliceerd. Hun studie vergeleek wekelijkse amnioinfusie met afwachtend beleid bij vrouwen met een oligohydramnion als gevolg van PPROM tussen de $16 \mathrm{e}$ en $24 \mathrm{e}$ week in de zwangerschap, met een minimale latency van 10 dagen. Er was geen verschil in de 
primaire uitkomst (perinatale sterfte 19/28 versus 19/28; RR 1.0, $95 \%$ Cl0.70, 1.43), maternale of neonatale morbiditeit. Het waargenomen verschil in de lange termijn uitkomst (4/28 overleving zonder morbiditeit na 2 jaar in de behandelde groep versus $0 / 28$ ) is vanwege onvoldoende power nog geen reden om amnioninfusie als behandeling in te voeren, maar het rechtvaardigt verder onderzoek ${ }^{8}$. In Italië is er een vergelijkbare trial aan de gang ${ }^{9}$. In Nederland werd een gerandomiseerde gecontroleerde trial - de PPROMEXIL - III studie - gestart. Meta - analyse van deze onderzoeken zal worden gedaan in de geplande update van het eerder genoemde Cochrane review.

De PPROMEXIL - III trial wordt uitgevoerd binnen het Nederlandse consortium, dat een uitstekende infrastructuur biedt om klinische vragen als deze te beantwoorden in een multicenter setting. Na de op handen zijnde reorganisatie van het consortium kunnen dergelijke studies hopelijk blijven plaatsvinden. Het protocol van de PPROMEXIL - IIIstudie wordt beschreven in hoofdstuk 8 .

Aanbevelingen voor toekomstig onderzoek :

Diagnose van PPROM : nieuwe tests moeten bij voorkeur worden onderzocht bij patiënten met dubieus vroege PPROM, verificatie moet plaatsvinden met een gouden of zilveren standaard. In hetzelfde onderzoek moet de prognose van dubieus PPROM worden verduidelijkt en vergeleken worden met zekere PPROM.

Een aanzienlijke percentage van de vrouwen met midtrimester PROM is nog zwanger na enkele weken. Op dit moment is het niet mogelijk om foetussen te identificeren die een verhoogd risico lopen op extreme vroeggeboorte of lethale longhypoplasie, of die worden beschadigd door voortdurende ontsteking of infectie tijdens een afwachtend beleid na PPROM.

Een aantal parameters (zowel klinische als beeldvormende) gecombineerd zou patiënten met een risico op lethale longhypoplasie kunnen identificeren. Een combinatie van testen met een $100 \%$ positief voorspellende waarde, vroeg in de zwangerschap zou een tijdige beëindiging van de zwangerschap mogelijk maken.

Ontwikkeling van predictiemodellen met CRP, leukocytengetal samen met andere variabelen zou foetussen kunnen identificeren met een hoog risico op FIRS. In de toekomst kunnen biomarkers of nieuwe microbiologische technieken die dit risico kan voorspellen beschikbaar. Technieken in de proteomica kunnen bruikbare biomarkers identificeren en wellicht inzicht bieden in de weg die heeft geleid tot PPROM.

Van specifieke therapieën, nieuwe, of reeds in gebruik zijnde, kan mogelijk voordeel worden aangetoond in kleinere studies voor deze specifieke subgroepen, en kunnen op lange termijn de uitkomst na midtrimester PROM verbeteren. Onderzoek naar seriële amnioinfusie wordt uitgevoerd. (Individual Patient Data-) Meta-analyse kan de klinische vraag met betrekking tot veiligheid en doeltreffendheid beantwoorden. Uiteraard moeten niet-traditionele behandelingen eerst worden geëvalueerd in een gerandomiseerd gecontroleerde setting alvorens zij kunnen worden toegepast. 


\section{Referenties}

1. Lockwood CJ, Kuczynski E., Risk stratification and pathological mechanisms in preterm delivery. Paediatr Perinat Epidemiol 2001;15 Suppl 2:78-89.

2. Yoon BH, Romero R, Moon JB, Shim SS, Kim M, Kim G, Jun JK. Clinical significance of intra-amniotic inflammation in patients with preterm labour and intact membranes. Am J Obstet Gynecol 2001;185:1130-6.

3. Galinsky R, Polglase GR, Hooper SB, Black MJ, Moss TJ. The consequences of chorioamnionitis: preterm birth and effects on development. J Pregnancy 2013;2013:412831.

4. Manuck TA, Maclean CC, Silver RM, Varner MW. Preterm premature rupture of membranes: does the duration of latency influence perinatal outcomes? Am J Obstet Gynecol 2009;201:414 e1-6.

5. Tita AT, Andrews WW. Diagnosis and management of clinical chorioamnionitis. Clin Perinatol 2010;37: 339-54.

6. Genc MR, Ford CE. The clinical use of inflammatory markers during pregnancy. Curr Opin Obstet Gynecol 2010;22:116-21.

7. Laudy JA, Tibboel D, Robben SG, de Krijger RR, de Ridder MA, Wladimiroff JW. Prenatal prediction of pulmonary hypoplasia: clinical, biometric, and doppler velocity correlates. Pediatrics 2002;109:250-8.

8. Roberts, D., et al. Amnioinfusion in very early preterm premature rupture of membranes - pregnancy, neonatal and maternal outcomes in the AMIPROM randomised controlled pilot study. Ultrasound Obstet Gynecol, 2013 Nov 21. [Epub ahead of print].

9. Locatelli, A. Open randomised trial comparing perinatal outcome following expectant management versus amnioinfusion in PPROM <25 wks with persistent oligohydramnios. 20086 July 2012]; Available from: http://clinicaltrials.gov/show/NCT00787163. 

Dankwoord 


\section{Dankwoord}

Velen ben ik dankbaar voor het tot stand komen van dit proefschrift. Hoewel de prospectieve data van de PPROMEXIL-III studie grotendeels nog moeten volgen is er een begin gemaakt en hoop ik met onderstaanden verder te mogen gaan in goede samenwerking.

Beste Prof. J.G. Nijhuis, een betere promotor en opleider zou ik mij niet kunnen wensen. Je kwam na een wetenschappelijk ogenschijnlijk wat latente fase - waarin de twee meta-analyses in Veldhoven werden geschreven - in beeld toen ik in Maastricht begon in 2010. Je betrokkenheid, blijkend uit de snelle reacties en soms juist meer behoedzame aanpak, je raad en steun, je humor, is mij veel waard geweest. De reis naar China was onvergetelijk. Ha!

Prof. B.W.Mol, Ben Willem, er is al veel over je gezegd bij je afscheid eind vorig jaar, en je staat weer prominent in de Volkskrant ('de ratio achter onze zorg!'). Het is zeer bijzonder om een van jouw promovendi te zijn en daardoor te werken op dat grote schip met al die containers. Na onze kennismaking in Veldhoven in 2005 heb ik na enige tijd ondervonden dat de meeste geruchten over jou op waarheid berustten. Om 04:30 in een van mijn eerste diensten in het MMC mailde ik je bijvoorbeeld het woord 'ping' (ik had net een film over duikboten gezien), nog geen 10 minuten later belde je wat dit in !\#@!! te betekenen had. Ik ben er trots op dat ik met jou dit proefschrift heb geschreven en ik ben je dankbaar voor je oneindige geduld en vertrouwen.

Eva en Christine, bedankt voor jullie inzet. Jullie hebben een belangrijke voorbeeldfunctie voor mij als fellow, in het voor mij relatief nieuwe terrein van de prenatale diagnostiek. De telefonische vergaderingen op de dinsdagavonden waren altijd weer een zeer positieve noot in het geheel. David, jij hebt me laten zien hoe het moet, bedankt voor al je adviezen en snelle revisies. Wat jammer dat je helemaal daar in het barre Noorden bent gaan zitten, laten we jaarlijks tenminste blijven bijpraten in de exit row. Jantien respect voor jou met zoveel ballen in de lucht. Wij maken er een mooie dag van. Jij ook van harte gefeliciteerd.

Professor zur Hausen, dr. Oude Lashof, Professor Savelkoul, dank voor het beoordelen van dit werk. Professor Kramer, beste Boris, bedank voor je beoordeling, ik verheug me op een verdere samenwerking met jou, Marc en Sizzel. Professor Oei, beste Guid, dank en jammer dat je niet aanwezig kunt zijn. Professor Gyselaers, Professor Evers, dr. Van der Hoeven dank voor het opponeren. Len Cuppens, ik weet niet of je vaak in dankwoorden verschijnt, maar nu lijkt me dat wel op zijn plaats. 
Opleiders en opleidenden (gynaecologen maar ook alle verloskundigen en verpleegkundigen), het assistenten clubje van 2005 (Sjors, Nicol, Minouche, Juut, Tamara, Rafli, Josje, Josien, Femke en Ruben) in het Maxima Medisch Centrum Veldhoven, bedankt voor jullie aanstekelijke enthousiasme en de goede jaren bij jullie.

Collega's in Maastricht, inclusief alle assistenten, bedankt voor de opleiding en fijne samenwerking. Collega obstetrici, Audrey, Christine, Liesbeth, Mijntje, Ingrid, Salwan, Marc, Jan jullie zijn een geweldig team om mee te mogen werken. Bedankt voor de ruimte die ik van jullie krijg. Het wordt steeds leuker. Salwan, kameraad, ik waardeer je enorm. Marlies en Ruby, bedankt voor jullie mentorschap.

Secretaresses Monique, Manon en Carolien, dank voor al jullie hulp, ook aan jullie collega's voor de gezelligheid en ondersteuning in onze nieuwe gang. Gaby petje af voor hoe jij alles draaiend houdt.

Alle andere mede-auteurs, met name Twan Mulder, Ewout Schuyt, Jelle Schaaf, Anita Ravelli, Sander van Kuijk, Martina Porath en Dick Oepkes bedankt voor jullie bijdragen.

Tiny Wouters bedankt voor je vakwerk.

Maya, in het begin nog samen met Zelda, dank voor al je inspanningen. Met het consortium bureau krakend in zijn voegen bleef jij toch tijd houden om te helpen met het opzetten van de trial. Nathalie Teeuwen, ook jij dank voor je hulp bij het bewaken van de structuur. Perinatologen, echografisten en research nurses in de 7 deelnemende centra van de Ppromexil-III studie (Corine Verhoeven, Clara Kolster, Gerard Zijderveld, Lyda Ulkeman Jannet Bakker en Angelique de Vos), bedankt voor jullie inzet bij deze ongefinancierde studie, zo vlak voor het consortium 2.0. Patiënten die deelnemen aan de studie dank ik voor hun bereidheid hiertoe.

Verloskundigen, echografisten, verpleging, secretaresses en alle medewerkers op afdeling D2, PND en poli, wat is het leuk om met jullie te werken. Jullie houden de machine draaiend, altijd met oog voor de patiënt, en de benen stevig op de grond in dit soms onstuimige vak. Ik ben jullie veel dank verschuldigd.

Familie van Horn, jullie zijn een bijzondere familie. Jim, wat jammer dat je er niet bij bent. Je hebt me, of het nou in Suriname, Ghana, Utrecht of Maastricht was, veel waardevolle adviezen gegeven. Lieve Sylvia jouw boekje komt er ook. We zullen vaker skypen. Reta en Simon Vriend dank voor jullie advies. Gert Vriend, die orca was ook mooi. De varens zijn beter. 
Broertje, hoewel ik dat natuurlijk zo min mogelijk laat merken ben ik toch erg trots op je. We zien jou, Marthel en Morris veel te weinig. Goed dat je naast me staat. Ton en Laura, ouders, ik bewonder de manier waarop jullie samen in het leven staan, ik ben me altijd bewust van jullie liefde en betrokkenheid, nu meer vanaf de achtergrond. Bedankt voor alles.

Boris en Ella, lief stelletje holbewoners. Ik ben zo trots op jullie. Ik begin te grijnzen als ik aan jullie denk. We gaan avonturen beleven en krabbetjes vangen. Yvette, mijn liefste, dappere, eigenwijze 'moksi meti'. Wat zou ik zonder jou moeten. Het is eindelijk af. Eys. 

Curriculum vitae 


\section{Curriculum vitae}

Stijn van Teeffelen werd op 5 april 1973 geboren in Utrecht. Hij behaalde zijn VWO diploma in 1991 op de Katholieke Scholengemeenschap de Breul te Zeist en startte de studie Geneeskunde aan de Universiteit van Utrecht. Het co-schap gynaecologie en obstetrie werd gevolgd in Bulawayo bij dr. D.A.A. Verkuyl, een onderzoeksstage bij de interne geneeskunde (dr. J.D. Banga), en een clerkship heelkunde in Stockholm. Na het behalen van het artsexamen startte hij, samen met Yvette van Horn, de opleiding tot tropenarts in 1999. In het kader hiervan werkte hij, als tropenarts in opleiding, als assistent gynaecologie en verloskunde in het st. Antoniusziekenhuis in Nieuwegein (opleider dr. J.H. Schagen van Leeuwen) en als assistent chirurgie in ziekenhuis Gooi Noord te Blaricum (opleider dr. H.P.N.W. Hoedemaker).

$\mathrm{Na}$ het behalen van het diploma in 2001 trouwde hij met Yvette van Horn en werd hij samen met haar door Voluntary Services Overseas (VSO) uitgezonden naar Ghana als tropenarts. Zij werkten daar in twee ziekenhuizen (St John of God ziekenhuis te Sefwi Asafo en St. Martins Hospital te Agroyesum). In 2003 keerden zij voor enkele maanden terug naar Groningen alwaar hun zoon Boris werd geboren.

In 2005 repatrieerden zij naar Utrecht, en kreeg hij een aanstelling als arts-assistent gynaecologie niet in opleiding in het Maxima Medisch Centrum te Veldhoven, Yvette kon beginnen aan de opleiding tot revalidatiearts. In 2006 werd hij aangenomen voor de opleiding Obstetrie en Gynaecologie in het cluster Maastricht (opleiders prof. G.G. Essed, prof. R.F. Kruitwagen). In dat zelfde jaar werd dochter Ella geboren. De eerste 4 jaar van de opleiding werd gevolgd in het Maxima (opleiders prof. S.G. Oei en dr. M.Y. Bongers), aldaar werd de basis voor dit proefschrift gelegd onder bezielende leiding van prof. B.W. Mol. In 2010 verhuisde het gezin naar Maastricht, voor de laatste 2 jaar van de opleiding. Na het afronden hiervan in 2012 kreeg hij een aanstelling als fellow perinatologie in Maastricht (opleider prof. J.G. Nijhuis), alwaar hij momenteel werkzaam is. 

List of publications 


\section{List of publications}

Effect of timing of blood pressure measurement in the assessment of arterial stiffness: the SMART Study. Simons PC, Bots ML, Algra A, van Teeffelen AS, van der Graaf Y. Ultrasound Med Biol. 1998 Nov;24(9):1285-9.

The relation between duration of ruptured membranes and perinatal outcome in patients with midtrimester prelabour rupture of membranes. van Teeffelen ASP, van der Heyden JL, van der Ham DP, Schaaf JM, Ravelli A, Pajkrt E, Willekes C, Nijhuis JG, Mol BW. Submitted

Prelabour rupture of membranes: overview of diagnostic methods. van der Ham DP, van Teeffelen ASP, Mol BW. Curr Opin Obstet Gynecol 2012;24:408-412

Is it useful to measure C-reactive protein and leukocytes in patients with prelabour rupture of membranes? van der Heyden JL, van Teeffelen ASP, Coolen ACG, Halbertsma FJ, Aardenburg R, Mertens HJMM, Mol BW. Am J Perinatol 2010;27:543-547

The accuracy of clinical parameters in the prediction of perinatal pulmonary hypoplasia secondary to midtrimester prelabour rupture of fetal membranes: A meta-analysis. van Teeffelen AS, van der Ham DP, Oei SG, Porath MM, Willekes C, Mol BW. van Teeffelen ASP, van der Ham DP, Oei SG, Porath MM, Willekes C, Mol BW. Eur J Obstet Gynecol Reprod Biol 2010;148:3-12

Accuracy of imaging parameters in the prediction of lethal pulmonary hypoplasia secondary to mid-trimester prelabour rupture of fetal membranes: a systematic review and meta-analysis. van Teeffelen ASP, van der Heyden JL, Oei SG, Porath MM, Willekes C, Opmeer B, Mol BW. Ultrasound Obstet Gynecol 2012;39:495-499

Transabdominal amnioinfusion for improving fetal outcomes after oligohydramnios secondary to preterm prelabour rupture of membranes before 26 weeks (Review). van Teeffelen ASP, Pajkrt E, Willekes C, Van Kuijk SMJ, Mol BW. Cochrane Database Syst Rev 2013;8:CD009952

Midtrimester prelabour rupture of membranes (PROM). Expectant management or Amnioinfusion for improving perinatal outcomes (PPROMEXIL - III trial). van Teeffelen ASP, van der Ham DP, Willekes C, Al Nasiry S, Nijhuis J G, van Kuijk SMJ, E Schuyt E, Mulder ALM, Franssen MTM, Oepkes D, Jansen FAR, Woiski MD, Bekker MN, Bax CJ, Porath MM, de Laat MWM, Mol BW, Pajkrt E. Accepted subject to revision 
The relation between duration of rupture of membranes and perinatal outcome in pa tients with preterm prelabor rupture of membranes between 26 and 34 weeks' gestation. Van der Heyden JL, Ravelli ACJ, van Teeffelen ASP, van der Ham DP, Schaaf JM, ,Willekes C, Pajkrt E, J.G. Nijhuis, B.W.J. Mol. Submitted 